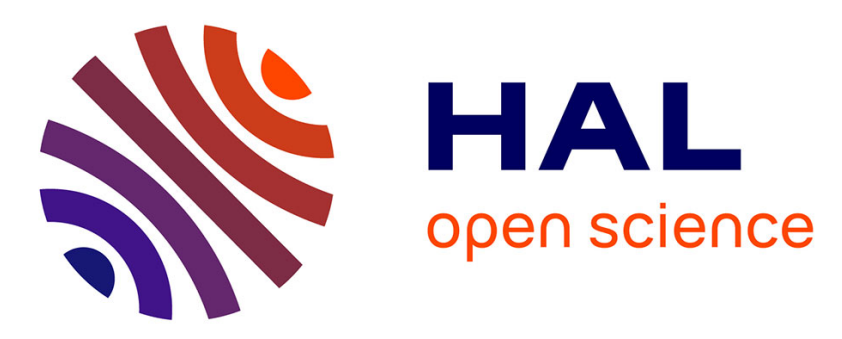

\title{
A trip in the nonlinear optical properties of iridium complexes
}

\author{
Alessia Colombo, Claudia Dragonetti, Véronique Guerchais, Claus Hierlinger, \\ Eli Zysman-Colman, Dominique Roberto
}

\section{- To cite this version:}

Alessia Colombo, Claudia Dragonetti, Véronique Guerchais, Claus Hierlinger, Eli Zysman-Colman, et al. A trip in the nonlinear optical properties of iridium complexes. Coordination Chemistry Reviews, 2020, 414, pp.213293. 10.1016/j.ccr.2020.213293 . hal-02562364

HAL Id: hal-02562364 https://hal-univ-rennes1.archives-ouvertes.fr/hal-02562364

Submitted on 19 May 2020

HAL is a multi-disciplinary open access archive for the deposit and dissemination of scientific research documents, whether they are published or not. The documents may come from teaching and research institutions in France or abroad, or from public or private research centers.
L'archive ouverte pluridisciplinaire HAL, est destinée au dépôt et à la diffusion de documents scientifiques de niveau recherche, publiés ou non, émanant des établissements d'enseignement et de recherche français ou étrangers, des laboratoires publics ou privés. 


\title{
A trip in the nonlinear optical properties of iridium complexes
}

Alessia Colombo, ${ }^{a}$ Claudia Dragonetti, ${ }^{\mathrm{a}, *}$ Véronique Guerchais, ${ }^{\mathrm{b}, *}$ Claus Hierlinger, ${ }^{\mathrm{b}, \mathrm{c}}$ Eli ZysmanColman, ${ }^{{ }^{*} *}$ and Dominique Roberto ${ }^{\mathrm{a}}$

${ }^{a}$ Department of Chemistry, Università degli Studi di Milano and Unità di Ricerca INSTM, via C. Golgi 19, Milan, Italy; claudia.dragonetti@unimi.it.

bUniv Rennes, CNRS UMR6226, F-35000 Rennes, France; veronique.guerchais@univ-rennes1.fr

'Organic Semiconductor Centre, EaStCHEM School of Chemistry, University of St Andrews, St Andrews, Fife, KY16 9ST, UK; eli.zysman-colman@st-andrews.ac.uk.

This review is dedicated to Prof. Renato Ugo, on the occasion of his $82^{\text {nd }}$ birthday, for his essential contribution to the field of iridium complexes with second-order nonlinear optical properties.

\begin{abstract}
Molecules with second-order nonlinear optical (NLO) properties have received a lot of attention in the last twenty years due to their potential use in photonic devices. In order to have a large second-order NLO response, a compound should not be centrosymmetric, it should have low energy charge-transfer transitions and there should be a large difference between the excited state and ground state dipole moments. Organic compounds with an electron-donor group and an electron-acceptor group connected via a $\pi$-conjugated polarizable spacer can reach a good NLO response. Metal complexes have also shown promise due to their accessible low-energy and high intensity ligand-to-metal due to their accessible low-energy and high-intensity ligand-to-metal, metal-to-ligand, ligand-to-ligand, and intraligand charge transfer (LMCT, MLCT, LLCT, and ILCT) excited states. The energy of these charge transfer states can be readily tuned as a function of the nature and the oxidation state of the metal centre and by the ligands that surround it. Among
\end{abstract}


them, iridium complexes are particularly fascinating, not only for their attractive second-order NLO properties but also for their remarkable two-photon absorption (TPA) properties, a third-order NLO process which is of interest for a number of photonic and optoelectronic applications.

The goal of this review is to show the potential of iridium compounds as molecular materials with NLO-activity. First, the principles of second-order nonlinear optics will be briefly introduced, then the review will illustrate the main families of second-order NLO iridium complexes, producing examples of iridium(I) complexes with monodentate nitrogen donor ligands (substituted pyridines and stilbazoles, azaphenanthrene and azachrysene), iridium(III) complexes with terpyridines, biscyclometalated phenylpyridine iridium(III) compounds with $\beta$-diketonate ligands, triscyclometalated phenylpyridine iridium(III) compounds, bis-cyclometalated phenylpyridine iridium(III) complexes with diimines or aryl isocyanides. Through this survey of NLO-phores we show how it is possible to tune the second-order NLO response by a suitable choice of the substituents about the ligands. The emphasis is on second-order NLO properties determined in solution at the molecular level, but examples of nanoorganization of some NLO-active iridium complexes in polymeric matrices to give second-order NLO-active thin films are presented as well. Further, some iridium complexes have shown potential as versatile NLO redox-switching materials and these are described in this review. Finally, a few examples of iridium complexes with TPA properties are given in the last section of the review. The coverage is not comprehensive but provides a suitable introduction to NLO-active iridium complexes and a framework for understanding their potential.

Keywords: iridium complexes, nonlinear optics, second harmonic generation, two-photon absorption

\section{Highlights:}


- The versatile properties of iridium complexes make them appealing for nonlinear optics (NLO)

- Iridium complexes with suitable ligands have interesting second-order NLO properties

- Iridium complexes with suitable ligands have interesting two-photon absorption properties

\section{Contents}

1. Second-order nonlinear optics.

2. Iridium(I) complexes with monodentate nitrogen donor ligands...................7

3. Iridium(III) complexes with terpyridines..................................12

4. Neutral bis-cyclometalated phenylpyridine-containing iridium(III) complexes with $\beta$ diketonate ancillary ligands .15

5. Neutral tris-cyclometalated phenylpyridine iridium(III) complexes....

6. Cationic bis-cyclometalated phenylpyridine iridium(III) complexes with diimine or aryl isocyanide ancillary ligands 25

7. Bis-cyclometalated iridium(III) compounds with redox-switchable second-order NLO activity .37

8. Iridium complexes with two-photon absorption properties. .41

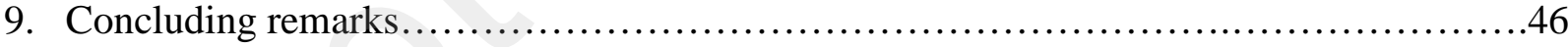

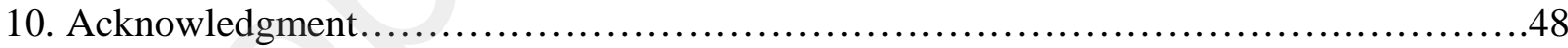

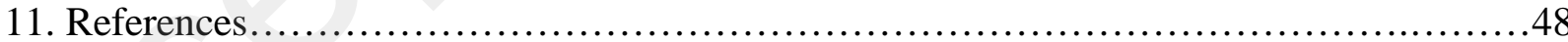

\section{Second-order nonlinear optics}

An introduction to second-order nonlinear optics (NLO) is briefly given. Greater details are presented in a number of books [1-3] and reviews [4-23].

In the presence of a strong electric field $\vec{E}$, there is a perturbation of the electrons of a bulk material and the induced polarization can be written according to equation (1): 


$$
\vec{P}=\overrightarrow{P_{0}}+\chi^{(1)} \vec{E}+\chi^{(2)} \overrightarrow{E^{2}}+\ldots \ldots \ldots \ldots+\chi^{(n)} \overrightarrow{E^{n}}
$$

where $\vec{P}_{0}$ is the intrinsic polarity, $\chi^{(1)}$ the electrical susceptibility or linear polarizability $\chi^{(2)}, \chi^{(3)}$ and $\chi^{(\mathrm{n})}$ tensors are, respectively, the second-, third- and n-order electrical susceptibilities, which correspond to nonlinear polarizabilities responses of the material.

At the molecular level, equation (1) becomes equation (2):

$$
\vec{P}=\mu_{0}+\alpha \vec{E}+\beta \vec{E}^{2}+\gamma \vec{E}^{3}+
$$

where $\mu_{0}$ is the ground state electric dipole moment, $\alpha$ the linear polarizability, $\beta$ the quadratic hyperpolarizability and $\gamma$ the cubic hyperpolarizability. $\beta \vec{E}^{2}$ corresponds to the generation of a second-order emission of light, with a frequency of the electromagnetic field corresponding to double of the incident one whereas $\overrightarrow{F E}^{3}$ is a third-order emission of light with a triple frequency with respect to the incident one. The emission decreases in intensity when the order increases, and both $\beta$ and $\chi^{(2)}$ fall off when the environment is centrosymmetric. An important NLO effect is the so-called Second Harmonic Generation (SHG). This occurs when two incident waves characterized by a frequency $\omega$ interact with a compound to give a new wave with frequency $2 \omega$.

In order to be characterized by a large second-order NLO response, a molecule must have high values of $\beta$. Supposing that in asymmetric linear-shaped organic molecules the second-order NLO response is mainly due to one charge-transfer process, $\beta$ can be calculated by means of equation (3):

$$
\beta_{z z z}=\frac{3}{2 h^{2} c^{2}} \frac{v_{e g}^{2} r_{e g}^{2} \Delta \mu_{e g}}{\left(v_{e g}^{2}-v_{L}^{2}\right)\left(v_{e g}^{2}-4 v_{L}^{2}\right)}
$$

In this equation, which is known as the "two level" model, $\mathrm{z}$ is the direction of the charge transfer, $\mathrm{r}_{\mathrm{eg}}$ is the transition dipole moment, $v_{\mathrm{eg}}$ is the frequency of the charge transfer transition, $v_{\mathrm{L}}$ is the frequency of the incident radiation and $\Delta \mu_{\mathrm{eg}}$ is the difference between the excited state and the ground state dipole moment [24-25]. Equation (3) shows that in order to have a high $\beta$ value, a 
compound must have charge-transfer transitions at low energy and huge $\Delta \mu_{\text {eg }}$ and $r_{\text {eg }}$ values. Clearly, in order to have a $\beta$ value, the molecule must not be centrosymmetric, otherwise $\Delta \mu_{\mathrm{eg}}$ is zero. As expected from the "two-level model", push-pull 1D dipolar organic molecules, in which an electron donor group (D) is separated from an electron acceptor (A) group by means of a $\pi$ conjugated polarizable spacer, are characterized by good quadratic hyperpolarizabilities. The prototypical example of a push-pull organic molecule is $p$-nitroaniline. As a general rule, the use of strong electron donors and acceptors and the incorporation of a bridge with a large conjugation length lead to a stronger second-order NLO response [26-30]. Compounds with $\mu \beta$ values superior to $500 \times 10^{-48}$ esu, the value reached by Disperse Red One [trans-4,4'$\left.\mathrm{O}_{2} \mathrm{NC}_{6} \mathrm{H}_{4} \mathrm{~N}=\mathrm{NC}_{6} \mathrm{H}_{4} \mathrm{NEt}\left(\mathrm{CH}_{2} \mathrm{CH}_{2} \mathrm{OH}\right)\right]$, which has been used in electrooptic polymeric poled films, [31] are of particular interest from an application point of view.

Coordination compounds have attracted growing interest, in the panorama of molecules for second-order nonlinear optics because they offer a more flexible molecular design when compared to organic chromophores due to the presence of a wider number of distinct charge-transfer transitions at relatively low energy and of high intensity that are tunable by virtue of the nature, oxidation state, and coordination sphere of the metal center. Many metal complexes, particularly 4d and 5d complexes, have low-energy metal-to-ligand charge-transfer (MLCT), ligand-to-metal charge-transfer (LMCT), ligand-to-ligand charge-transfer (LLCT) or intraligand charge-transfer (ILCT) excitations, the metal can effectively be the donor or the acceptor moiety or the polarizable bridge of a push-pull system that can act as a dipolar NLO chromophore [5-23]. The presence of the metal is also a desirable feature that has been exploited in efficient redox-switching of the NLO properties, which is of great interest for application in photonics [17].

Various methods exist to calculate $\beta$. The "Sum Over States" (SOS) approach, and Density Functional Theory (DFT) and Time-Dependent DFT (TD-DFT) calculations are all particularly useful [26, 32]. 
Experimentally, in order to determine $\beta$ in solution, one can use the Electric Field Induced Second Harmonic generation (EFISH) technique and the Hyper-Rayleigh Scattering (HRS) technique, also called Harmonic Light Scattering technique (HLS). The EFISH technique [33] can be used for dipolar molecules, providing information on the molecular NLO properties by means of equation (4):

$$
\gamma_{\mathrm{EFISH}}=\left(\mu \beta_{\lambda} / 5 \mathrm{kT}\right)+\gamma(-2 \omega ; \omega, \omega, 0)
$$

In this equation, $\mu \beta_{\lambda} / 5 \mathrm{kT}$ is the dipolar orientational contribution while $\gamma(-2 \omega ; \omega, \omega, 0)$ is the electronic cubic contribution, which is negligeable for dipolar molecules. $\beta_{\lambda}$ is the projection along the dipole moment axis of $\beta_{\mathrm{VEC}}$, which is the vectorial component of the tensor of the quadratic hyperpolarizability, working with an incident wavelength $\lambda$ of a pulsed laser. The EFISH technique gives the product $\mu \beta_{\lambda}$ where $\mu$ is the ground state dipole moment of the molecule, which can be calculated or determined experimentally with the Guggenheim method [34].

In the HLS technique [35-38], after irradiation of the molecule in solution with a laser of wavelength $\lambda$, the incoherently scattered second harmonic generated by the molecule is detected, leading to the mean value of the $\beta x \beta$ tensor product. By the analysis of the polarization dependence of the second harmonic signal, one can obtain the components of the quadratic hyperpolarizability tensor. Unlike EFISH, HLS can be used for the study of non dipolar molecules. In this review, we will call $\beta_{\lambda}(\mathrm{EFISH})$ and $\beta_{\lambda}$ (HLS), the $\beta$ values determined with an incident wavelength $\lambda$ by the EFISH and HLS techniques, respectively.

In the solid state, second-order susceptibility values, $\chi^{(2)}$, can be determined by means of the second harmonic generation (SHG) of noncentrosymmetric single crystals, thin films of poled polymers, or thin films of engineered acentric molecular assemblies [1-3].

As we previously mentioned, coordination complexes with second-order NLO properties have attracted increasing attention in the last two decades, often reaching an NLO response superior to that of the prototypal Disperse Red One, making them competitive materials with respect to organic 
chromophores [5-23]. Complexes using group 6 and groups 8-12 metals have been investigated with a variety of ligands. Particularly large quadratic hyperpolarizabilities have been reached with $\mathrm{Ru}$, Ir, and Zn complexes. Although reviews have appeared documenting the second-order NLO properties of ruthenium [39] and zinc [40] complexes, to the best of our knowledge no review has been dedicated to NLO-active iridium complexes. Although iridium is a more expensive metal than zinc, its complexes are more thermally stable and kinetically inert. Iridium complexes also can access a wide number of distinct CT excited states while zinc complexes are limited to LLCT and ILCT states. Moreover, iridium complexes have been shown to act as building blocks for the preparation of hybrid polymeric films with a significant second harmonic generation response [41]. Photoactive iridium(III) complexes have been exploited in a wide number of different applications, including in electroluminescent devices, as bioimaging reagents, in photodynamic therapy, in sensing, as dyes in solar cells, as photocatalysts and as photosensitizers in solar fuels [42]. These same complexes can also be used in the field of nonlinear optics. These observations prompted us to write an overview on iridium-containing second-order NLO active complexes which is reported in the following sections, with a focus on important aspects of each family of iridium complexes. This review therefore does not provide an exhaustive account of all NLO-active iridium complexes.

\section{Iridium(I) complexes with monodentate nitrogen donor ligands}

In 1994, Bruce and Thornton reported that the quadratic hyperpolarizability of a stilbazole, trans-4(S-(+)-2-methylbutoxy)-4'-stilbazole, increases upon coordination to a "cis- $\operatorname{Ir}(\mathrm{CO})_{2} \mathrm{Cl}$ " moiety [43]. Following this brief report, various iridium(I) metal complexes with pyridines (1) [44], stilbazole-related (2-4) [44-45], azaphenanthrene (5) [46] and azachrysene (6) [46] ligands (Fig. 1) were prepared, mainly by Ugo et al, in order to understand, using the EFISH technique, the effect that coordination to an iridium(I) metal center has on the second-order NLO activity of monodentate nitrogen donor ligands. In all cases there is an augmentation of the absolute value of 
$\mu \beta$ (EFISH) upon coordination caused by an augmentation of both $\mu$ and $\beta$. From these studies it appeared that iridium may have a donor or an acceptor role, controlled by the existence, in the nitrogen-based ligand, of an electron acceptor or donor group R.

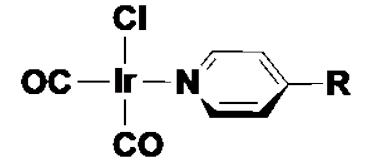

1

$R=N M e_{2}, f B u, C N$

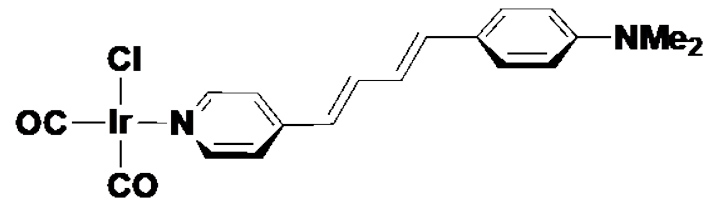

3

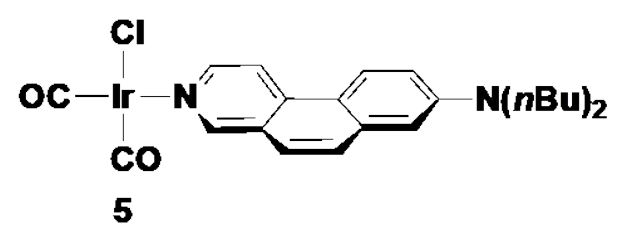

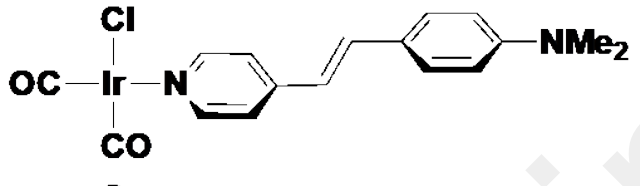

2
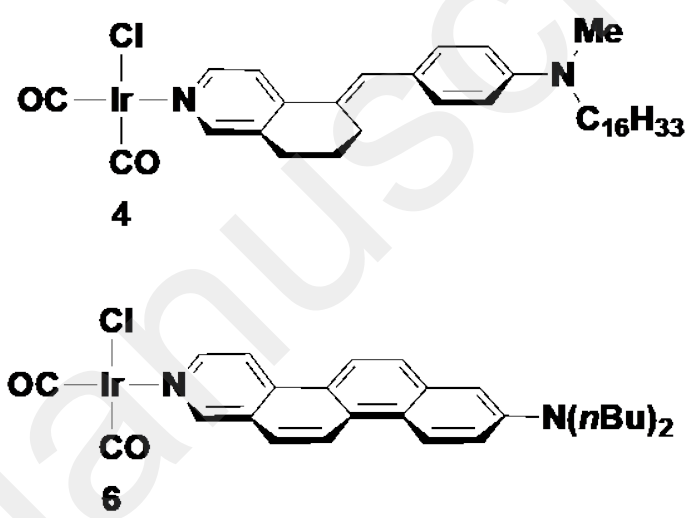

Fig. 1. Iridium(I) complexes with monodentate nitrogen donor ligands

Thus, the quadratic hyperpolarizability, measured by EFISH at $1.067 \mu \mathrm{m}$, of cis[Ir(CO) $\left.)_{2} \mathrm{Cl}(4-\mathrm{R}-\mathrm{Pyridine})\right]$ (1) $(\mathrm{R}=$ electron donor or acceptor group) depends on the identity of R: (i) $\beta>0$ when $\mathrm{R}$ is a strong electron-donor group such as $\mathrm{NMe}_{2}$; upon coordination, the quadratic hyperpolarizability goes from $0.07 \times 10^{-30}$ esu to $9 \times 10^{-30}$ esu due to the acceptor role of the metal; (ii) $\beta$ is very small when $\mathrm{R}$ is a weak electron-donor group such as $t$-butyl; upon coordination, the quadratic hyperpolarizability goes from $0.19 \times 10^{-30}$ esu to $0.1 \times 10^{-30}$ esu; (iii) $\beta<0$ when $\mathrm{R}$ is a strong electron-acceptor group like $\mathrm{CN}$; upon coordination, the quadratic hyperpolarizability goes from $0.33 \times 10^{-30}$ esu to $-9 \times 10^{-30}$ esu due to the donor role of the metal (Table 1) [44]. The negative sign of $\beta$ when $\mathrm{R}$ is a strong electron-acceptor group is due to a decrease of the dipole moment upon excitation since, according to the "two-level" model, equation (3) [24-25], $\beta$ is directly proportional to $\Delta \mu_{\mathrm{eg}}$. Similarly, for [W(CO) 5 (4-MeCO-Pyridine)], a negative $\Delta \mu_{\mathrm{eg}}$ leads to a 
negative value of $\beta$ [47]. The dipole moment is reduced upon excitation due to the donor behavior of the metal in the presence of $\pi$-accepting ligands with a metal-to-ligand charge transfer (MLCT) transition vectorially opposed to an LMCT transition [48]. By contrast, when R is a strong electrondonor group, $\beta$ remains positive and its augmentation is dominated by an intraligand charge transfer (ILCT) transition, with the metal behaving as an electron-acceptor, which intensifies the acceptor capacity of the pyridine and therefore produces a bathochromic shift of the ILCT transition. The mechanisms, proposed by Ratner and Marks to explain the acceptor or donor role of a metal moiety, can be rationalized as follows:
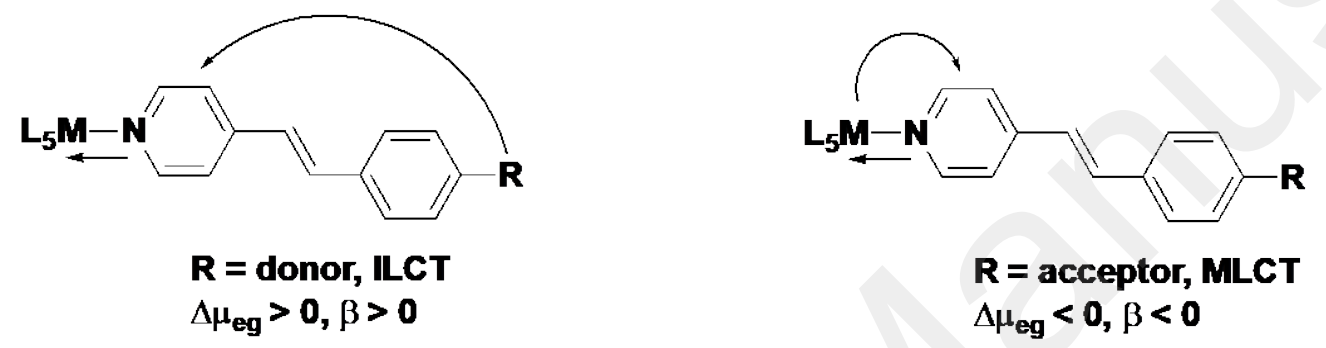

In a general manner, coordination leads to a very strong enhancement of the absolute value of $\beta_{1.06}$ (EFISH) of the pyridines, putting into evidence the important and positive role of the iridium(I) center.

The effect of coordination to iridium(I) of 4,4'-trans or trans,trans- $\mathrm{NMe}_{2}$ $\mathrm{C}_{6} \mathrm{H}_{4}(\mathrm{CHCH})_{n}$ pyridine $(\mathrm{n}=1,2) \quad(2,3)$ has been investigated [44]. In dipolar $\pi$-organic chromophores, it is known that an increase of the length of the $\pi$-delocalized bridge between the acceptor and the donor groups leads to a large augmentation of the quadratic hyperpolarizability [27-28]. Surprisingly, there is a much smaller increase in the case of coordination compounds. Thus, substitution of 4- $\mathrm{Me}_{2} \mathrm{~N}$-Pyridine (L1a) with 4,4'-trans- $\mathrm{Me}_{2} \mathrm{~N}-\mathrm{C}_{6} \mathrm{H}_{4}(\mathrm{CHCH})$ Pyridine (L2) leads to a 900 -fold enhancement of $\beta_{1.06}($ EFISH) (Table 1$)$ while substitution of cis-[ $\operatorname{Ir}(\mathrm{CO})_{2} \mathrm{Cl}(4-$ $\left.\left.\mathrm{Me}_{2} \mathrm{~N}-\mathrm{Pyridine}\right)\right]$ (1a) with cis-[ $\operatorname{Ir}(\mathrm{CO})_{2} \mathrm{Cl}\left(4,4^{\prime}\right.$-trans- $\mathrm{Me}_{2} \mathrm{~N}-\mathrm{C}_{6} \mathrm{H}_{4}(\mathrm{CHCH})$ Pyridine $\left.)\right]$ (2) leads to a 27-fold enhancement [44].

The effect due to coordination is less significant when the length of the $\pi$-delocalized bridge 
of the nitrogen donor ligand is increased. For example, coordination of 4,4'-trans-NMe ${ }_{2}$ $\mathrm{C}_{6} \mathrm{H}_{4}(\mathrm{CHCH})$ Pyridine to “cis- $\mathrm{Ir}(\mathrm{CO})_{2} \mathrm{Cl}$ ” causes a 4-fold enhancement of $\beta_{1.06}(\mathrm{EFISH})$ (Table 1 , $\mathbf{L} 2$ and 2), small if compared to the huge increase observed when 4-NMe 2 -Pyridine is coordinated ( $\beta_{1.06}$ enhancement factor of ca. 130, L1a and 1a) [44]. The increase upon coordination of 4,4'trans,trans- $\mathrm{NMe}_{2}-\mathrm{C}_{6} \mathrm{H}_{4}(\mathrm{CHCH})_{2}$ Pyridine is even lower, being only 2 ( $\mathbf{L 3}$ and 3). Interestingly, according to the poorer acceptor strength of the iridium center, the quadratic hyperpolarizability is reduced when the carbonyl ligands of cis- $\mathrm{Ir}(\mathrm{CO})_{2} \mathrm{Cl}$ ” are replaced by cyclooctene ligands (2 and 2') [44].

Table 1 Dipole moments and quadratic hyperpolarizability of 4-R-Pyridine, 4,4'-trans or trans, trans- $\mathrm{NMe}_{2}-\mathrm{C}_{6} \mathrm{H}_{4}(\mathrm{CHCH})_{n} \mathrm{Pyridine}(\mathrm{n}=1,2)$ and related iridium(I) compounds [44]

\begin{tabular}{|c|c|c|c|c|}
\hline & & $\begin{array}{l}\mu \beta_{1.06}{ }^{\mathrm{a}} \\
\left(\times 10^{-48} \mathrm{esu}\right)\end{array}$ & $\begin{array}{l}\mu^{\mathrm{b}} \\
\left(\times 10^{-18} \text { esu }\right)\end{array}$ & $\begin{array}{l}\beta_{1.06} \\
\left(\times 10^{-30} \mathrm{esu}\right)\end{array}$ \\
\hline L1a & 4-NMe $\mathrm{N}_{2}$-Pyridine & 0.25 & 3.5 & 0.07 \\
\hline 1a & cis $\left[\mathrm{Ir}(\mathrm{CO})_{2} \mathrm{Cl}\left(4-\mathrm{NMe}_{2}\right.\right.$-Pyridine $\left.)\right]$ & 58 & 6.4 & 9 \\
\hline L1b & 4-CMe $\mathrm{CM}_{3}$-Pyridine & $0.54^{\mathrm{C}}$ & $2.87^{\mathrm{C}}$ & $0.19^{\mathrm{c}}$ \\
\hline $1 \mathbf{b}$ & cis-[$\left[\mathrm{Ir}(\mathrm{CO})_{2} \mathrm{Cl}\left(4-\mathrm{CMe}_{3}\right.\right.$-Pyridine $\left.)\right]$ & 0.49 & 4.9 & 0.1 \\
\hline L1c & 4-CN-Pyridine & $0.54^{\mathrm{C}}$ & 1.63 & $0.33^{\mathrm{c}}$ \\
\hline 1c & cis-[ $\operatorname{Ir}(\mathrm{CO})_{2} \mathrm{Cl}(4-\mathrm{CN}$-Pyridine $\left.)\right]$ & -31 & 3.4 & -9 \\
\hline $\mathbf{L 2}$ & 4,4'-trans- $\mathrm{NMe}_{2}-\mathrm{C}_{6} \mathrm{H}_{4}(\mathrm{CHCH})$ Pyridine & 246 & 3.9 & 63 \\
\hline 2 & cis- $\left[\operatorname{Ir}(\mathrm{CO})_{2} \mathrm{Cl}\left(4,4^{\prime}\right.\right.$-trans- $\mathrm{NMe}_{2}-\mathrm{C}_{6} \mathrm{H}_{4}(\mathrm{CHCH})$ Pyridine $\left.)\right]$ & 1452 & 6 & 242 \\
\hline $\mathbf{2}^{\prime}$ & cis- $\left[\mathrm{Ir}(\mathrm{COT})_{2} \mathrm{Cl}\left(4,4^{\prime}\right.\right.$-trans- $\mathrm{NMe}_{2}-\mathrm{C}_{6} \mathrm{H}_{4}(\mathrm{CHCH})$ Pyridine $\left.)\right]$ & 1110 & 8.1 & 137 \\
\hline $\mathbf{L 3}$ & 4,4'-trans,trans- $\mathrm{NMe}_{2}-\mathrm{C}_{6} \mathrm{H}_{4}(\mathrm{CHCH})_{2}$ Pyridine & 558 & 4.5 & 124 \\
\hline 3 & cis- $\left[\mathrm{Ir}(\mathrm{CO})_{2} \mathrm{Cl}\left(4,4^{\prime}\right.\right.$-trans,trans- $\mathrm{NMe}_{2}-\mathrm{C}_{6} \mathrm{H}_{4}(\mathrm{CHCH})_{2}$ Pyridine $\left.)\right]$ & 2508 & 8.8 & 285 \\
\hline
\end{tabular}


${ }^{\mathrm{a}} \mathrm{EFISH}$ values determined in $\mathrm{CHCl}_{3}$ working with an incident wavelength of $1.06 \mu \mathrm{m}$. ${ }^{\mathrm{b}}$ Experimental values in $\mathrm{CHCl}_{3}$, measured by the Guggenheim method. ${ }^{\mathrm{c}}$ Computed values obtained with the MNDO-CPHF method.

Interestingly, complexes of “cis- $\mathrm{Ir}(\mathrm{CO})_{2} \mathrm{Cl}$ ” with 4,4'-trans- or trans,trans- $\mathrm{NMe}_{2}$ $\mathrm{C}_{6} \mathrm{H}_{4}(\mathrm{CHCH})_{\mathrm{n}}$ pyridine $(\mathrm{n}=1,2)$ show a $\mu \beta(\mathrm{EFISH})$ value greater than that of Disperse Red 1 $\left(\mu \beta(\right.$ EFISH $\left.)=c a 500 \times 10^{-48} \mathrm{esu}\right)$, which has found application in electrooptic polymers [31]. This can be explained by two factors: (i) an intensification of the ground state dipole moment upon coordination to the iridium center and (ii) an intensification of $\beta$ due to a large bathochromic shift of the ILCT transition [44].

In the early 1990s, it was thought that conjugation planarity was necessary to boost quadratic hyperpolarizabilities because a decrease of $\pi$-electron overlap due to a non-planar geometry should have reduced the communication between the donor and the acceptor groups, leading to a decrease of the quadratic hyperpolarizability [28]. Remarkably, fifteen years later, it was observed that the $\beta$ values of planar $N$-methyl- $N$-hexadecyl-aminostilbazole $\left(\beta_{1.907}(\mathrm{EFISH})=\right.$ $\left.55 \times 10^{-30} \mathrm{esu}^{-1}\right)$ and related “cis-Ir(CO) 2 Cl” complex $\left(\beta_{1.907}(\mathrm{EFISH})=101 \times 10^{-30} \mathrm{esu}^{-1}\right)$ are very close to that of twisted (E)-4-[(5,6,7,8-tetrahydro-5isoquinolylidene)methyl]- $N$-methyl- $N$ hexadecylaniline $\left(\beta_{1.907}(\mathrm{EFISH})=47 \times 10^{-30} \mathrm{esu}^{-1}\right)$ and related “cis- $\operatorname{Ir}(\mathrm{CO})_{2} \mathrm{Cl}$ ” complex (4, $\left(\beta_{1.907}(\right.$ EFISH $\left.)=81 \times 10^{-30} \mathrm{esu}^{-1}\right)$, respectively, putting in evidence that in traditional dipolar organic chromophores a planar structure is not necessary to reach a large quadratic hyperpolarizability [45]. In fact, density functional theory and time-dependent DFT calculations showed that the two aromatic rings of the stilbazole, linked by the double bond, are coplanar whereas the two rings of (E)-4-[(5,6,7,8-tetrahydro-5-isoquinolylidene)methyl]- $N$-methyl- $N$ hexadecylaniline form an angle of $-56.1^{\circ}$ [45]. It was suggested that the HOMO (highest occupied molecular orbital) and LUMO (lowest unoccupied molecular orbital) energies of the two ligands are 
not strongly affected by the twisting of the $\mathrm{C}=\mathrm{C}$ bond, due to the fact that the two orbitals are mostly localized on the donor and acceptor fragments, respectively [45].

The preparation of NLO-active molecules characterized not only by high quadratic hyperpolarizabilities but also by good chemical, thermal and photochemical stability is important from a technology point of view. Although stilbazole-based chromophores can present a high NLO response, they have two problems: (i) cis-trans photoisomerism around the $\mathrm{C}=\mathrm{C}$ bond and (ii) possible oxidation of the isolated double bond, which would disrupt the $\pi$-conjugation between the acceptor and the donor groups. A solution to these problems would be the inclusion of the double bond within a rigid polyaromatic moiety that would guarantee both stability and high electronic $\pi$ delocalization [46]. For this reason, 7-N,N-dibutylamino-2-azaphenanthrene and 8- $N, N$ dibutylamino-2-azachrysene were prepared, along with the related “cis- $\mathrm{Ir}(\mathrm{CO})_{2} \mathrm{Cl}$ ” complexes (5, 6, Fig. 1), and their NLO properties were studied by the EFISH method [46]. The $\beta_{1.907}(\mathrm{EFISH})$ value of 7-N,N-dibutylamino-2-azaphenanthrene $\left(123 \times 10^{-30} \mathrm{esu}^{-1}\right)$ was two-fold that of $N$-methyl- $N$ hexadecyl-aminostilbazole whereas that of the more $\pi$-delocalized $8-N, N$-di-n-butylamino-2azachrysene was even higher $\left(429 \times 10^{-30} \mathrm{esu}^{-1}\right)$ [46]. Upon coordination to the "cis- $\operatorname{Ir}(\mathrm{CO})_{2} \mathrm{Cl}$ " moiety (5, 6), a slight increase of $\mu \beta_{1.907}(\mathrm{EFISH})$ was observed (enhancement factor $=1.3$ ) [46]. The high NLO activity and good thermal stability of 8-N,N-di-n-butylamino-2-azachrysene make it particularly appealing as a material for downstream applications.

Interestingly, an attempt to coordinate $\left[\mathrm{W}(\mathrm{CO})_{3}(1,10\right.$-phenanthroline)(pyrazine)] to "cis$\operatorname{Ir}(\mathrm{CO})_{2} \mathrm{Cl}$ ” led to the loss of the pyrazine ligand with formation of $\left[(\mathrm{CO})_{3}(1,10\right.$-phenanthroline $) \mathrm{W}$ $\left.\operatorname{Ir}(\mathrm{CO})_{2} \mathrm{Cl}\right]$, characterized by a negative value of $\beta_{1.907}(\mathrm{EFISH})\left(-25.8 \times 10^{-30} \mathrm{esu}^{-1}\right)$ due to MLCT transitions (from $\mathrm{W}$ to $\pi^{*}$ of the phenanthroline, with a negative $\Delta \mu_{\mathrm{eg}}$ ) governing the second-order NLO response [49].

\section{Iridium(III) complexes with terpyridines}


The second-order NLO activity of iridium(III) compounds with $4^{\prime}-(\mathrm{Ph}-p-\mathrm{R}) 2,2^{\prime}: 6^{\prime}, 2^{\prime \prime}-$ terpyridine $\left(\mathrm{R}=\mathrm{NBu}_{2}, \mathrm{NO}_{2},-(E)-\mathrm{CH}=\mathrm{CHPh} p-\mathrm{NBu}_{2}\right)$ ligands (7, Fig. 2) have been investigated [5052].
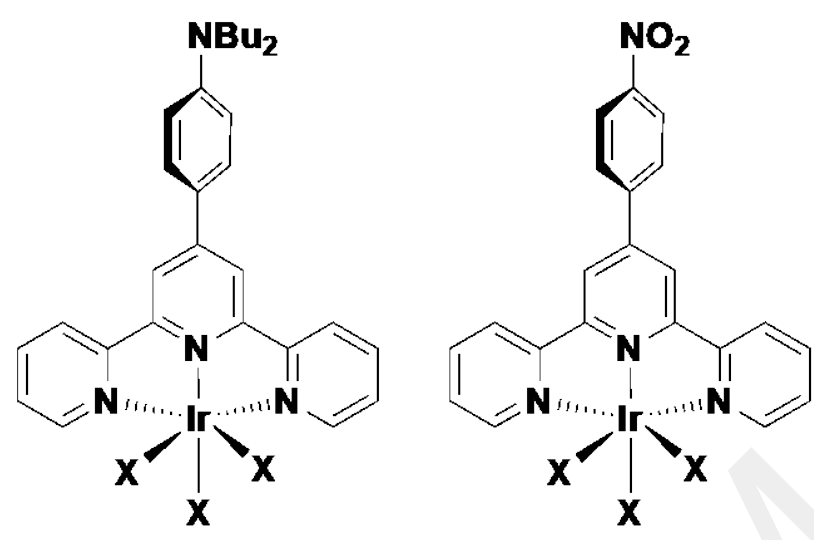

7

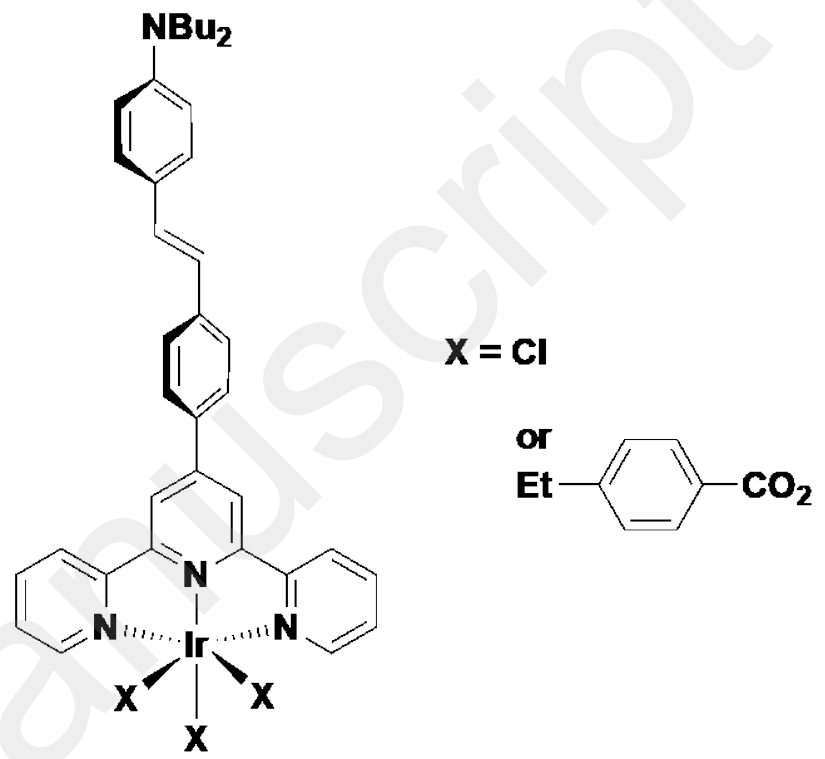

Fig. 2. Iridium(III) complexes with terpyridines

In a first study, 4'-(Ph-p-NBu 2$) 2,2^{\prime}: 6^{\prime}, 2^{\prime \prime}$-terpyridine was coordinated to " $\mathrm{IrCl}_{3}$ " and " $\mathrm{ZnCl}_{2}$ " moieties, demonstrating the important role of the identity of the metal ion on the value and sign of the quadratic hyperpolarizability. In both complexes the ILCT transition of the coordinated terpyridine is red-shifted because of an intensification of the $\pi$-acceptor capacity of its $\pi *$ orbitals, and there is a large increase (enhancement factor of ca 4, Table 2) of the permanent dipole moment [50]. The $\beta$ value of the terpyridine upon coordination to $3 \mathrm{~d}^{10} \mathrm{zinc}(\mathrm{II})$ increases $\left(\beta_{1.34}(\mathrm{EFISH})\right.$ goes from 22 to $67 \times 10^{-30}$ esu) and remains positive, similar to observations for various zinc(II) compounds with nitrogen donor ligands [53-56]. Remarkably, upon coordination to a $5 d^{6}$ iridium(III) metal center, there is a large increase of the absolute value of $\beta_{\text {EFISH }}$ but its sign is negative (Table 2, 7a and 7a') [50,51]. A solvatochromic study showed that whereas in zinc(II) 
complexes the increase is caused by the bathochromic shift of the ILCT transition of the terpyridine, in iridium(III) complexes, the second-order NLO response is governed by the negative contribution of a MLCT transition at lower energy [50]. This MLCT transition becomes more important when the terpyridine bears an electron-acceptor substituent $\left(\beta_{1.34}(\mathrm{EFISH})\right.$ value of -64 and $-230 \times 10^{-30}$ esu for $\mathrm{R}=\mathrm{NBu}_{2}$ and $\mathrm{NO}_{2}$, respectively; Table 2, 7a' and 7b'), affording a higher absolute value of $\beta[51]$.

It appeared that, for $\mathrm{NBu}_{2}$-substituted terpyridines, an increase of the length of the $\pi$ conjugated spacer between the $\mathrm{NBu}_{2}$ group and the terpyridine rings causes a large augmentation of $\beta_{1.34}$ (EFISH) (Table 2, L7a and L7c) [51], as previously observed for stilbazole ligands (Table 1). By contrast, for iridium(III) complexes there is a reduction of the absolute value of $\beta_{1.34}(\mathrm{EFISH})$ because of a decrease of the NLO importance of the MLCT transition with respect to the ILCT transition (7a and 7c).

Table 2 Dipole moments and quadratic hyperpolarizability of $4^{\prime}-(\mathrm{Ph}-\mathrm{p}-\mathrm{R}) 2,2^{\prime}: 6^{\prime}, 2^{\prime \prime}-$ terpyridine and related iridium(III) complexes [50,51]

\begin{tabular}{|c|c|c|c|c|}
\hline & 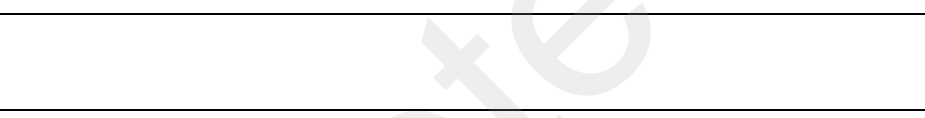 & $\begin{array}{l}\mu \beta_{1.34}{ }^{\mathrm{a}} \\
\left(\times 10^{-48} \text { esu }\right)\end{array}$ & $\begin{array}{l}\mu^{\mathrm{b}} \\
\left(\times 10^{-18} \text { esu }\right)\end{array}$ & $\begin{array}{l}\beta_{1.34} \\
\left(\times 10^{-30} \text { esu }\right) \\
\end{array}$ \\
\hline L7a & $4^{\prime}-\left(\mathrm{Ph}-p-\mathrm{NBu}_{2}\right) 2,2^{\prime}: 6^{\prime}, 2^{\prime \prime}$-terpy & 46 & 2.1 & 22 \\
\hline $7 a$ & {$\left[\mathrm{IrCl}_{3}\left(4^{\prime}-\left(\mathrm{Ph}-p-\mathrm{NBu}_{2}\right) 2,2^{\prime}: 6^{\prime}, 2^{\prime \prime}\right.\right.$-terpy) $]$} & -861 & 7.9 & -109 \\
\hline $7 a^{\prime}$ & {$\left[\operatorname{Ir}\left(4-\mathrm{EtPhCO}_{2}\right)_{3}\left(4^{\prime}-\left(\mathrm{Ph}-p-\mathrm{NBu}_{2}\right) 2,2^{\prime}: 6^{\prime}, 2^{\prime \prime}\right.\right.$-terpy)] } & -563 & 8.8 & -64 \\
\hline $\mathbf{L 7 b}$ & $4^{\prime}-\left(\mathrm{Ph}-p-\mathrm{NO}_{2}\right) 2,2^{\prime}: 6^{\prime}, 2^{\prime \prime}$-terpy & -20 & 1.7 & -12 \\
\hline 7b' & {$\left[\operatorname{Ir}\left(4-\mathrm{EtPhCO}_{2}\right)_{3}\left(4^{\prime}-\left(\mathrm{Ph}-p-\mathrm{NO}_{2}\right) 2,2^{\prime}: 6^{\prime}, 2^{\prime \prime}\right.\right.$-terpy $\left.)\right]$} & -2093 & 9.1 & -230 \\
\hline L7c & 4'-(Ph-p-(E)-CHCHPhp-NBu 2$) 2,2^{\prime}: 6^{\prime}, 2^{\prime \prime}$-terpy & 187 & 3.6 & 52 \\
\hline 7c & {$\left[\mathrm{IrCl}_{3}\left(4^{\prime}-\left(\mathrm{Ph}-p-(E)-\mathrm{CHCHPh} p-\mathrm{NBu}_{2}\right) 2,2^{\prime}: 6^{\prime}, 2^{\prime \prime}\right.\right.$-terpy)] } & -327 & 10.9 & -30 \\
\hline
\end{tabular}

${ }^{a}$ EFISH values measured in $\mathrm{CHCl}_{3}$ at $1.34 \mu \mathrm{m}$. ${ }^{\mathrm{b}}$ Experimental values in $\mathrm{CHCl}_{3}$, measured by the Guggenheim method. 
Interestingly, $\chi^{(2)}$ values of ca $5.2 \mathrm{pm} \mathrm{V}^{-1}$ were obtained for monolayer Langmuir-Blodgett films of an $\mathrm{IrCl}_{3}$ compound bearing a 4'-(1-Ph-p-NMe $\left(\mathrm{C}_{16} \mathrm{H}_{33}\right)-2,2$ ':6',2"-terpyridine when measuring their second harmonic generation at $1.064 \mu \mathrm{m}$ incident wavelength [52].

\section{Neutral bis-cyclometalated phenylpyridine-containing iridium(III) complexes with $\beta$ - diketonate ancillary ligands}

Coordination compounds characterized by luminescent and second-order NLO properties are fascinating as multifunctional molecular materials [20-22]. The impressive quadratic hyperpolarizability of iridium(III) complexes bearing terpyridines (see Section 3) acted as springboard to study the NLO activity of another family of iridium(III) complexes having two cyclometalated 2-phenylpyridine ligands (ppy) coupled with a chelated $\beta$-diketonate ligand (8, Fig. 3), known for its luminescence properties (Table 3) [57].

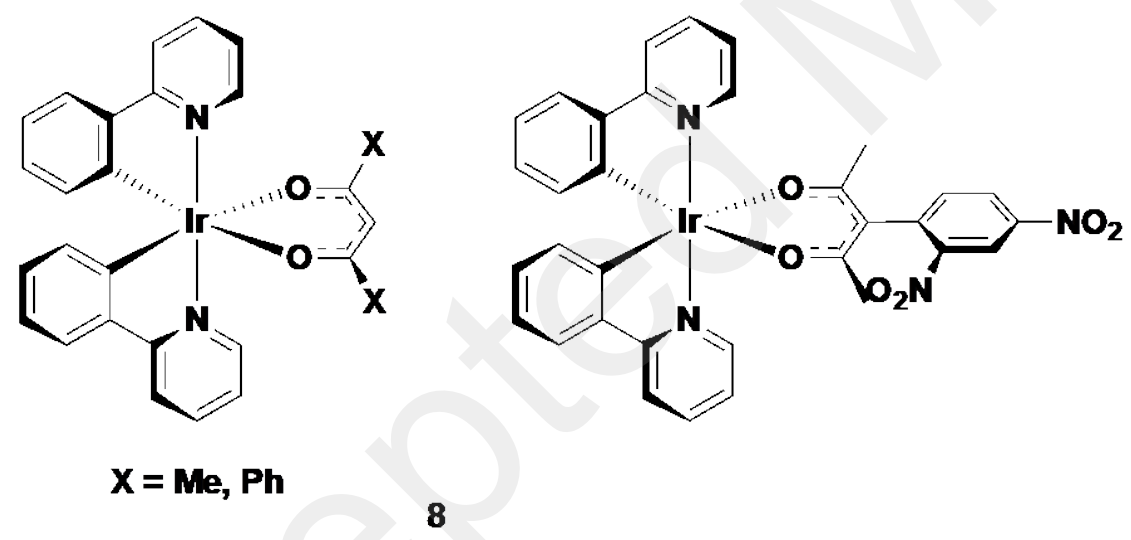

Fig. 3. Iridium(III) complexes with two cyclometalated phenylpyridines and $\beta$-diketonate as ancillary ligand.

The $\mu \beta_{1.907}(\mathrm{EFISH})$ values of these luminescent cyclometalated iridium(III) compounds are large and negative, ranging from -910 to $-1340 \times 10^{-48}$ esu (8a-8c, Table 3). Remarkably, their NLO response can be reached without a relevant cost in transparency, because these complexes do not have strong low energy absorption bands [57]. [ $\left.\operatorname{Ir}(\mathrm{ppy})_{2}(\mathrm{PhCOCHCOPh})\right]$ is characterized by the 
highest $\beta_{1.907}(\mathrm{EFISH})$ value $\left(-268 \times 10^{-30} \mathrm{esu}\right)$, in agreement with the higher polarizability of the phenyl compared to the methyl substituent; the lowest quadratic hyperpolarizxability is observed for the iridium(III) complex bearing a $\beta$-diketonate functionalized with the electron acceptor 2,4dinitrophenyl group (Table 3).

Table 3 Dipole moments and quadratic hyperpolarizability of $\left[\operatorname{Ir}(p p y)_{2}(R C O C R\right.$ 'COR $\left.)\right](R=$ Me, Ph; R' = H, 2,4-dinitrophenyl) [57] and [Ir(ppy-4-CHCHPhR $\left.)_{2}(\mathrm{MeCOCHCOMe})\right](\mathrm{R}=$ OMe, $\mathrm{NEt}_{2}, \mathrm{H}, \mathrm{NO}_{2}$ ) [41]

\begin{tabular}{|c|c|c|c|c|}
\hline & & $\begin{array}{l}\mu \beta_{1.907} \\
\left(\times 10^{-48} \text { esu }\right)\end{array}$ & $\begin{array}{l}\mu \\
\left(\times 10^{-18} \text { esu }\right)\end{array}$ & $\begin{array}{l}\beta_{1.907} \\
\left(\times 10^{-30} \text { esu) }\right.\end{array}$ \\
\hline 8a & {$\left[\operatorname{Ir}(\mathrm{ppy})_{2}(\mathrm{MeCOCHCOMe})\right]$} & $-910^{\mathrm{a}}$ & $4^{\mathrm{b}}$ & -228 \\
\hline $8 \mathbf{b}$ & {$\left[\operatorname{Ir}(\mathrm{ppy})_{2}(\mathrm{PhCOCHCOPh})\right]$} & $-1340^{\mathrm{a}}$ & $5^{\mathrm{b}}$ & -268 \\
\hline 8c & [Ir(ppy) $)_{2}(\mathrm{MeCOC}(2,4-$ dinitrophenyl)COMe)] & $-975^{\mathrm{a}}$ & $6^{\mathrm{b}}$ & -163 \\
\hline 9a & {$\left[\mathrm{Ir}(\mathrm{ppy}-4-\mathrm{CHCHPhNEt})_{2}(\mathrm{MeCOCHCOMe})\right]$} & $-550^{c}$ & $3.73^{d}$ & -147 \\
\hline $9 b$ & [Ir(ppy-4-CHCHPhOMe) $\left.)_{2}(\mathrm{MeCOCHCOMe})\right]$ & $-570^{\mathrm{C}}$ & $5.90^{\mathrm{d}}$ & -97 \\
\hline 9c & {$\left[\operatorname{Ir}(\mathrm{ppy}-4-\mathrm{CHCHPh})_{2}(\mathrm{MeCOCHCOMe})\right]$} & $-408^{\mathrm{C}}$ & $3.55^{\mathrm{d}}$ & -115 \\
\hline 9d & {$\left[\mathrm{Ir}(\mathrm{ppy}-4-\mathrm{CHCHPhNO})_{2}(\mathrm{MeCOCHCOMe})\right]$} & $-895^{\mathrm{C}}$ & $3.77^{\mathrm{d}}$ & -237 \\
\hline
\end{tabular}

${ }^{\mathrm{a}}$ EFISH values determined in $\mathrm{CHCl}_{3}$ with an incident wavelength of $1.907 \mu \mathrm{m} .{ }^{\mathrm{b}}$ Values measured in $\mathrm{CHCl}_{3}$ by the Guggenheim method. ${ }^{\mathrm{C}} \mathrm{EFISH}$ values determined in $\mathrm{CH}_{2} \mathrm{Cl}_{2}$ at $1.907 \mu \mathrm{m}$. ${ }^{\mathrm{d}} \mathrm{DFT}$ computed dipole moments.

A Sum-Over-States-TDDFT investigation was carried out to better understand the electronic factors dominating the NLO activity. This study showed that the large quadratic hyperpolarizability of these complexes is mainly due to ILCT transitions involving the cyclometalated ligands whereas transitions involving the acetylacetonate ligand do not contribute significantly [57]. The SOS contribution of each excited state to the quadratic hyperpolarizability of $\left[\operatorname{Ir}(\mathrm{ppy})_{2}(\mathrm{MeCOCHCOMe})\right]$ was calculated, putting in evidence counteracting positive and negative 
contributions, the latter being responsible for the negative sign of the quadratic hyperpolarizability [57].

For complexes with the acetylacetonate and the dinitrophenyl acetylacetonate ligand, the difference of the dipole moment (Table 3) is attributed to a component due to the nitro group at the 2-position of the aromatic ring that lies almost perpendicularly with respect to the acetylacetonatemetal axis. Because this component is not aligned with the transition vector of the excitations governing the overall $\beta_{1.907}$ (EFISH) value, a lower value of the quadratic hyperpolarizxability is observed for the complex with the dinitrophenyl acetylacetonate ligand [57].

It should be stated that the role of cyclometalation and thus of the iridium center is important to increase the quadratic hyperpolarizability; in fact, the absolute value of $\beta_{1.907}$ (EFISH) of the free 2-phenylpyridine is much lower $\left(35 \times 10^{-30}\right.$ esu) than that of $\left[\operatorname{Ir}(\mathrm{ppy})_{2}(\mathrm{MeCOCHCOMe})\right](-228 \times$ $\left.10^{-30} \mathrm{esu}\right)$ [57].

The fact that cyclometalated iridium(III) compounds with a $\beta$-diketonate ligand have an unexpectedly huge second-order NLO activity, dominated by $\pi-\pi^{*}$ ILCT transitions involving mainly the cyclometalated ligands, suggested that an appropriate functionalization of the phenylpyridine ligands could improve the quadratic hyperpolarizability. This observation was the springboard for an EFISH study on the second-order NLO activity of iridium(III) acetylacetonate compounds with a number of substituted cyclometalated 4-styryl-2-phenylpyridine (ppy-4CHCHPhR, with $\mathrm{R}=\mathrm{NEt}_{2}$, OMe, $\mathrm{H}, \mathrm{NO}_{2}$; 9, Fig. 4) [41]. 

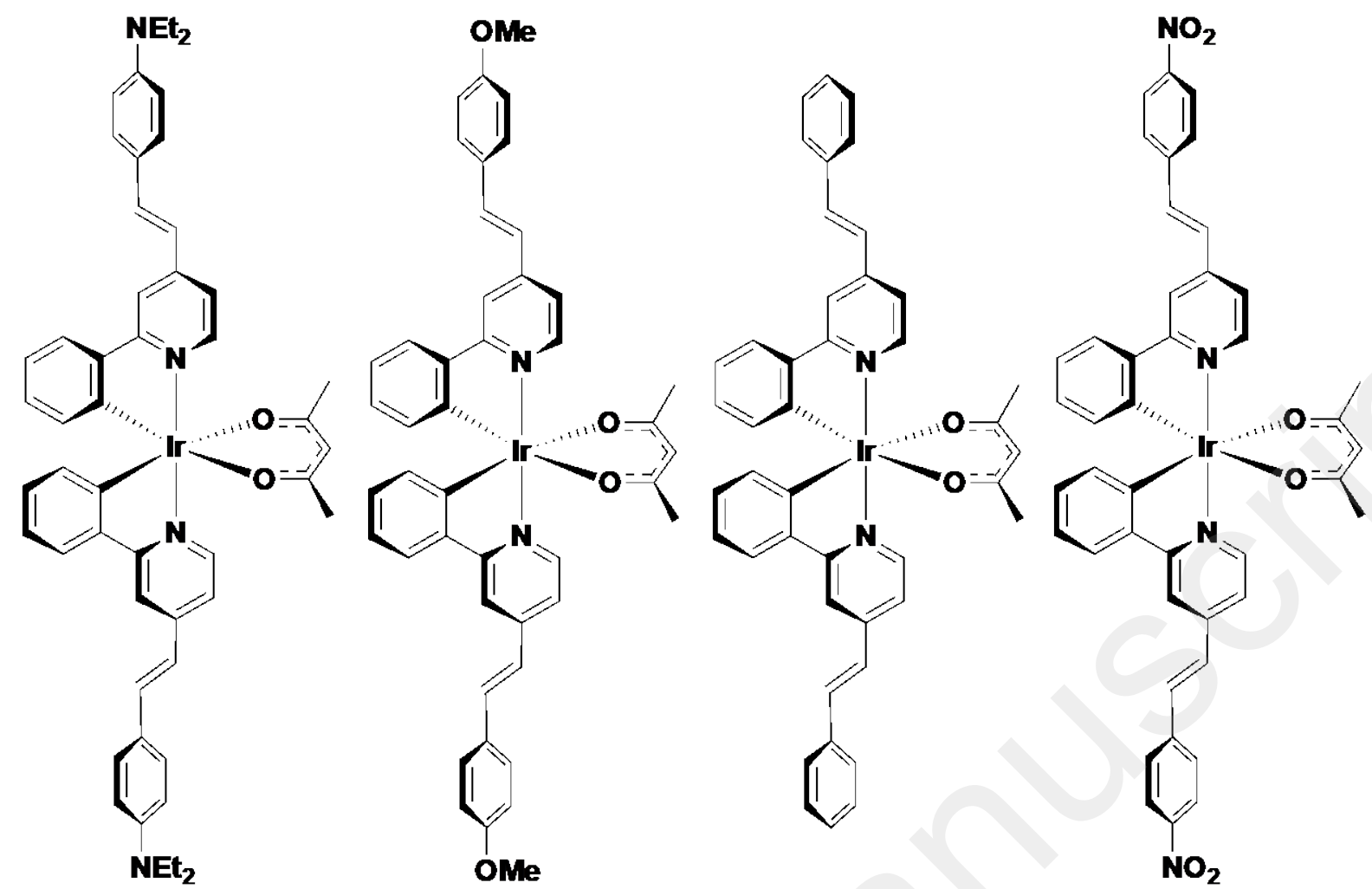

Fig. 4. Iridium(III) complexes with two cyclometalated substituted phenylpyridines and acetylacetonate as ancillary ligand.

The $\left.\mu \beta_{1.907}(\text { EFISH) values of complexes [Ir(ppy-4-(E)-CHCHPhR })_{2}(\mathrm{MeCOCHCOMe})\right](\mathrm{R}$ $\left.=\mathrm{NEt}_{2}, \mathrm{OMe}, \mathrm{H}\right)$ are comparable, whereas the absolute value obtained for the complex with $\mathrm{R}=$ $\mathrm{NO}_{2}$ is larger and comparable to that observed for [ $\left.\operatorname{Ir}(\mathrm{ppy})_{2}(\mathrm{MeCOCHCOMe})\right]$ (Table 3). The same tendency is found for the quadratic hyperpolarizability. In these iridium(III) complexes, the secondorder NLO activity is governed by various charge transfer transitions that contribute positively or negatively to the quadratic hyperpolarizxability, leading to the observed negative value of $\beta_{1.907}(\mathrm{EFISH})[41,57]$.

A study was conducted on the Second Harmonic Generation (SHG) of films containing $\left[\operatorname{Ir}(\mathrm{ppy})_{2}(\mathrm{MeCOCHCOMe})\right]$ and $\left[\operatorname{Ir}(\mathrm{ppy}-4-\mathrm{CHCHPhR})_{2}(\mathrm{MeCOCHCOMe})\right]\left(\mathrm{R}=\mathrm{NEt}_{2}, \mathrm{NO}_{2}\right)$ dispersed in a polymethylmethacrylate (PMMA) matrix [41] and oriented by corona poling [58]. 
The films based on both $\left[\operatorname{Ir}(\mathrm{ppy})_{2}(\mathrm{MeCOCHCOMe})\right]$ and $\quad[\operatorname{Ir}(\mathrm{ppy}-4-$ $\left.\left.\mathrm{CH}=\mathrm{CHC}_{6} \mathrm{H}_{4} \mathrm{NO}_{2}\right)_{2}(\mathrm{MeCOCHCOMe})\right]$ showed a low and unstable second harmonic signal that rapidly degraded upon turning off the electric field. Unexpectedly, the use of complex [Ir(ppy-4-

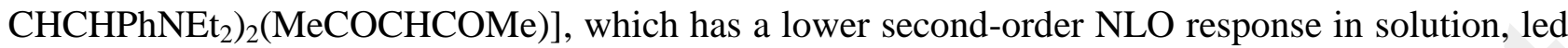
to a composite PMMA film with a stable and relatively high SHG response $\left(\chi^{(2)}\right.$ values of ca 3.04 pm $\mathrm{V}^{-1}$ ). Clearly this family of iridium(III) compounds can be used to prepare NLO active polymeric films [41].

\section{Neutral tris-cyclometalated phenylpyridine iridium(III) complexes}

We showed in section 4 that phosphorescent $\beta$-diketonate iridium(III)) compounds with a simple cyclometalated 2-phenylpyridine are characterized by a large second-order NLO activity due mostly to ILCT transitions involving the cyclometalated ligand, as shown by a SOS-TDDFT study [57]. Simple tris-cyclometalated iridium(III) compounds are also potentially good candidates as NLOactive chromophores. The $\mu \beta_{1.91}$ (EFISH) of a series of complexes containing substituted 2phenylpyridinato ligands were determined (see Table 4). A selection of compounds featuring a diversity of functional groups (Fig. 5), $\operatorname{Ir}[(\mathrm{Ph}-4-\mathrm{R}) \mathrm{py}-\mathrm{Me}]_{3}(\mathrm{R}=\mathrm{Br}, \mathrm{I}, \mathrm{CHO} ; \mathbf{1 0 - 1 2}), \operatorname{Ir}[(\mathrm{Ph}-4-$ $\left.\left.\mathrm{CH}=\mathrm{CH}-\mathrm{C}_{6} \mathrm{H}_{4}-\mathrm{CN}\right) \mathrm{py}\right]_{3}(\mathbf{1 3}), \operatorname{Ir}\left[\left(\text { th- } \mathrm{C}_{6} \mathrm{H}_{4}-\mathrm{CN}\right) \mathrm{py}\right]_{3}$ (th = 2-thienyl) (14), $\operatorname{Ir}[(\mathrm{ppy}-\mathrm{Me})]_{3}$ (15), $\operatorname{Ir}[(\mathrm{Ph}-$ 4-C=N-C $\left.\left.{ }_{6} \mathrm{H}_{4--N E t}\right) \mathrm{py}\right]_{3}$ (16), were chosen to evidence how substitution of the cyclometalated phenyl moiety can modulate the NLO activity of this class of complexes [59]. 

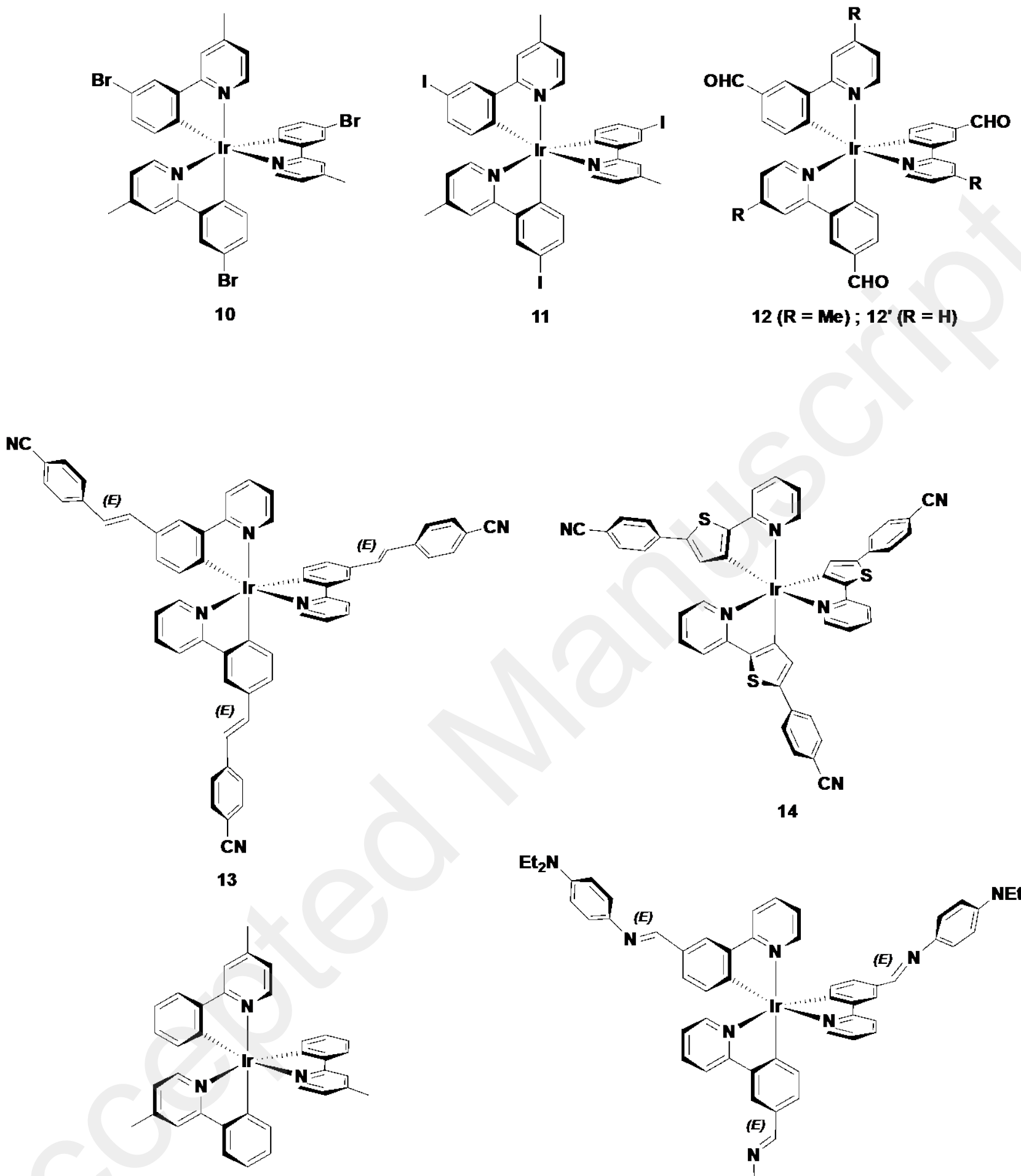

15

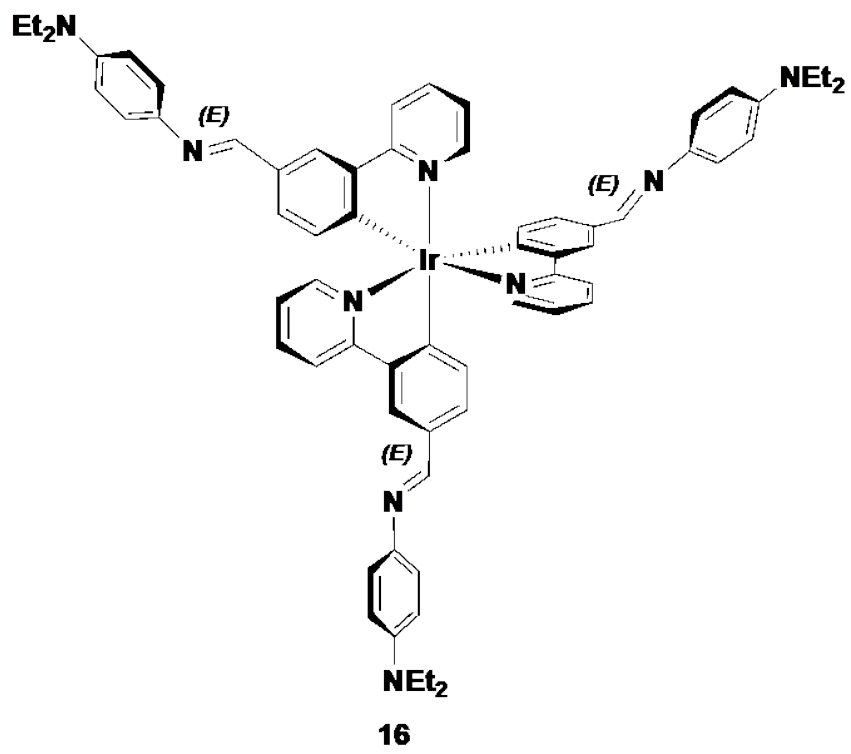

Fig. 5. Tris-cyclometalated iridium(III) complexes with three 2-phenylpyridines variously substituted on the phenyl group or with substituted 2-thienylpyridine 
The significant dipolar second-order nonlinear optical properties of these complexes are easily controlled by ligand modification, such as incorporation of appropriate electronaccepting substituents on the aryl ring (complexes 10-12, Table 4), the NLO activity being governed by MLCT transitions. These complexes display a negative value of $\mu \beta_{1.91}$ (EFISH), as a result of the negative value of $\Delta \mu_{\mathrm{eg}}$ resulting from the direction of the charge transfer from the Ir(III) center to the cyclometallated $\mathrm{C}^{\wedge} \mathrm{N}$ ligand that is in an opposite direction with respect to that of the ground state dipole moment [48].

Table $4 \mu \beta_{1.91}$ (EFISH) and $\mu$ values of tris-cyclometalated iridium(III) complexes 10-16 [59]

\begin{tabular}{|c|c|c|c|c|}
\hline & & $\begin{array}{c}\mu \beta_{1.91}^{\mathrm{a}, \mathrm{b}} \\
\left(\times 10^{-48}\right. \\
\text { esu })\end{array}$ & $\begin{array}{l}\mu_{\mathrm{tot}}{ }^{\mathrm{c}} \\
\quad\left(\times 10^{-18} \text { esu }\right)\end{array}$ & $\begin{array}{l}\beta_{1.91} \\
\quad\left(\times 10^{-30} \mathrm{esu}\right)\end{array}$ \\
\hline 10 & $\operatorname{Ir}[(\mathrm{Ph}-4-\mathrm{Br}) \mathrm{py}-\mathrm{Me}]_{3}$ & -487 & 16.9 & -29 \\
\hline 11 & $\operatorname{Ir}[(\mathrm{Ph}-4-\mathrm{I}) \mathrm{py}-\mathrm{Me}]_{3}$ & -465 & 16.3 & -29 \\
\hline 12 & $\operatorname{Ir}[(\mathrm{Ph}-4-\mathrm{CHO}) \mathrm{py}-\mathrm{Me}]_{3}$ & -240 & 22.8 & -10 \\
\hline 13 & $\operatorname{Ir}[(\mathrm{Ph}-4-\mathrm{CHCH}-\mathrm{Ph}-\mathrm{CN}) \mathrm{py}]_{3}$ & 430 & 23.4 & 18 \\
\hline 14 & $\operatorname{Ir}\left[(\text { th-Ph-CN)py }]_{3}\right.$ & 275 & 25.3 & 11 \\
\hline 15 & $\operatorname{Ir}[(\mathrm{ppy}-\mathrm{Me})]_{3}$ & 1047 & 11.8 & 89 \\
\hline 16 & $\operatorname{Ir}\left[\left(\mathrm{Ph}-4-\mathrm{C}=\mathrm{N}-\mathrm{Ph} \_\mathrm{NEt}_{2}\right) \mathrm{py}\right]_{3}$ & 1430 & 10.2 & 140 \\
\hline
\end{tabular}

${ }^{\mathrm{a}}$ In $\mathrm{CH}_{2} \mathrm{Cl}_{2}$. ${ }^{\mathrm{b}} \mathrm{By}$ using $10^{-3} \mathrm{M}$ solutions. ${ }^{\mathrm{c}}$ Calculated in solution.

It turned out that ILCT transitions, due to the presence of a $\pi$-delocalized donor group and vectorially opposed to MLCT transitions, play a dominant role in the control of the NLO response, giving rise to positive $\mu \beta_{1.91}(\mathrm{EFISH})(\mathbf{1 3}, \mathbf{1 4}, \mathbf{1 6}$, Table 4$)$. The greatest value of $\mu \beta_{1.91}$ (EFISH) is found for compound 16 (1430 × $10^{-48}$ esu) featuring an electron-donating group in position 4 of the phenyl ring. Notably, the methyl-substituted tris-cyclometalated $\operatorname{Ir}(\mathrm{III})$ complex $\operatorname{Ir}[(\mathrm{ppy}-\mathrm{Me})]_{3}\left(\mathbf{1 5}\right.$, Table 4) exhibits a good $\mu \beta_{1.91}(\mathrm{EFISH})$ value of $1047 \times$ $10^{-48}$ esu. 
Another family of Ir(III) complexes was investigated. In this family, the cyclometalated ppy derivatives possessed a donor-containing $\pi$-conjugated moiety at the 4-position of the pyridine [60]. The styryl complexes $\operatorname{Ir}\left[(\text { ppy-(CHCH)-(Ph-D) }]_{3}\left(\mathbf{1 7}, \mathbf{a}, \mathrm{D}=\mathrm{H} ; \mathbf{b}, \mathrm{D}=\mathrm{OMe}, \mathbf{c}, \mathrm{D}=\mathrm{NEt}_{2}\right)\right.$ and the related unsaturated complexes, in which (butadienyl)dianilino (17d), dimethylaminothienyl (17e), and ferrocenyl (17f) substituents were investigated (Fig. 6). All these complexes are readily accessible from fac-Ir[(ppy-Me) $]_{3}, \mathbf{1 5}$, used as the reference complex, and thus all have a facial configuration [61].

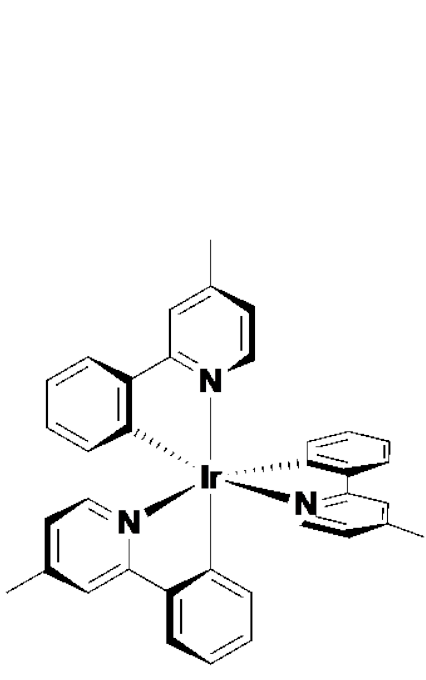

15
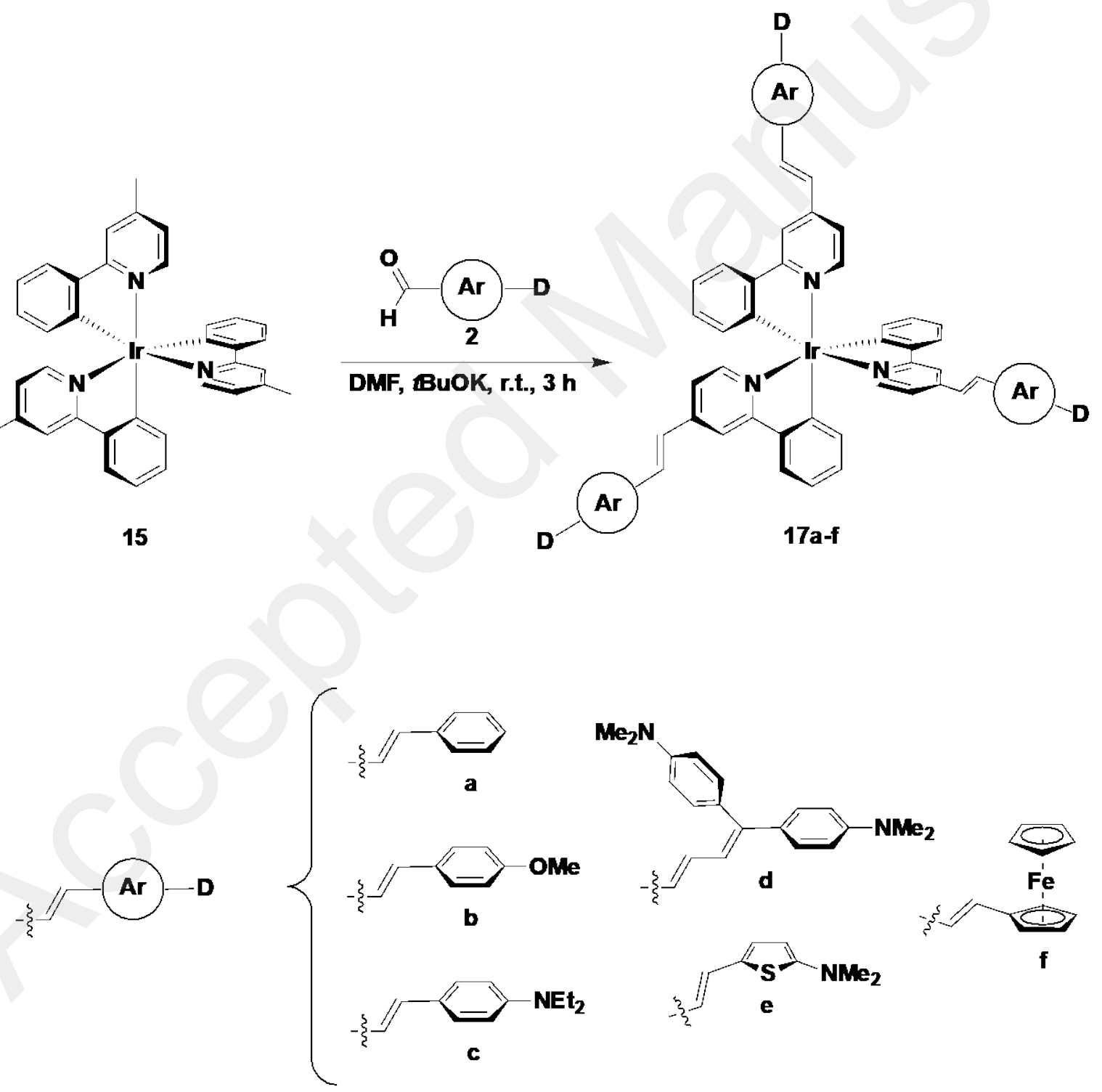

Fig. 6. Tris-cyclometalated iridium(III) compounds with three 2-phenylpyridines variously substituted on the pyridine ring 17a-f and the reference complex 15 
Their second-order NLO activity was studied by EFISH and HLS techniques. Their $\mu \beta_{1.907}$ (EFISH) values are reported in Table 5. To obtain $\beta_{1.907}(\mathrm{EFISH})$, the dipole moments $(\mu)$ were DFT-computed. The impact of terminal groups on the NLO response of the complexes was demonstrated by EFISH studies. The selected compounds 17a-f present a large absolute value of $\mu \beta_{1.907}$ (EFISH) (430-830 $\left.\times 10^{-48} \mathrm{esu}\right)$. ILCT transitions give rise to a positive sign of the NLO response (17c-e) while the sign is negative when MLCT transitions prevail (17a, $\mathbf{1 7 b}$ and $\mathbf{1 7 f})$. Replacing the methyl substituent in the 4-position of the pyridine (15) by a styryl moiety (17a, Table 5) inverts the sign of $\beta_{1.907}(\mathrm{EFISH})$ without affecting significantly the ground state dipole moment. The incorporation of a methoxy group in the 4-position of the styryl substituent (17b, Table 5) also gives a negative quadratic hyperpolarizability but with a lower absolute value, because ILCT transitions vectorially opposed to the MLCT transitions contribute to the NLO response [48]. The importance of ILCT transitions prevails over the MLCT ones and the $\beta_{1.907}$ (EFISH) becomes positive when the methoxy substituent is substituted by diethylamino, a stronger donor moiety (17c, Table 5). Complex 17e, having $\mathrm{NMe}_{2}$-thienyl group instead of a $\mathrm{NEt}_{2}$ phenyl group, displays a higher positive $\beta_{1.907}(\mathrm{EFISH})$ (Table 5), in agreement with the bathochromic shift of the ILCT on going from 17c to 17e. These studies demonstrate that, in these cyclometalated iridium(III) complexes, ferrocene donor ability is similar to that of the methoxyphenyl group (compare 17b vs 17f).

Table 5. $\mu \beta_{\text {EFISH, }} \mu, \beta_{\text {EFISH, }}$ and $\beta_{\text {HLS }}$ of the iridium(III) complexes 17a-f and the reference complex $15[60]$.

\begin{tabular}{|l|l|l|l|l|l|}
\hline & & $\begin{array}{l}\mu \beta_{\mathrm{EFISH}}^{\mathrm{a}} \\
\left(\times 10^{-48}\right. \\
\mathrm{esu})\end{array}$ & $\begin{array}{l}\mu^{\mathrm{b}} \\
\left(\times 10^{-18}\right. \\
\mathrm{esu})\end{array}$ & $\begin{array}{l}\beta_{\mathrm{EFISH}} \\
\left(\times 10^{-30}\right. \\
\mathrm{esu})\end{array}$ & $\begin{array}{l}\left\langle\beta_{\text {HLS }}\right\rangle^{\mathrm{a}} \\
\left(\times 10^{-30} \mathrm{esu}\right)\end{array}$ \\
\hline $\mathbf{1 5}$ & $\operatorname{Ir}[(\mathrm{ppy}-\mathrm{Me})]_{3}$ & 1050 & 7.5 & 140 & $-^{\mathrm{c}}$ \\
\hline $\mathbf{1 7 a}$ & $\operatorname{Ir}\left[(\mathrm{ppy}-(\mathrm{CHCH})-\mathrm{Ph}]_{3}\right.$ & -640 & 8 & -80 & 250 \\
\hline $\mathbf{1 7 b}$ & $\operatorname{Ir}\left[(\mathrm{ppy}-(\mathrm{CHCH})-(\mathrm{Ph}-\mathrm{OMe})]_{3}\right.$ & -700 & 12.8 & -54 & 290 \\
\hline
\end{tabular}




\begin{tabular}{|c|c|c|c|c|c|}
\hline 17c & $\operatorname{Ir}\left[\left(\mathrm{ppy}-(\mathrm{CHCH})-\left(\mathrm{Ph}^{2} \mathrm{NEt}_{2}\right)\right]_{3}\right.$ & 480 & 14.5 & 33 & 400 \\
\hline 17d & $\operatorname{Ir}\left[\left(\mathrm{ppy}-(\mathrm{CHCH})_{2}-\left(\mathrm{Ph} \mathrm{NEt}_{2}\right)_{2}\right]_{3}\right.$ & 620 & 17.11 & 36 & 460 \\
\hline 17e & $\operatorname{Ir}[(\text { ppy-(CHCH)-(thienyl-NMe } 2)]_{3}$ & 830 & 14.3 & 58 & 330 \\
\hline $17 f$ & $\operatorname{Ir}\left[(\text { ppy-(CHCH)-(ferrocenyl) }]_{3}\right.$ & -430 & 8.5 & -51 & 330 \\
\hline
\end{tabular}

${ }^{\mathrm{a}}$ Values measured in $\mathrm{CH}_{2} \mathrm{Cl}_{2}$, at $10^{-3} \mathrm{M}$. ${ }^{\mathrm{b}}$ Calculated dipole moment. ${ }^{\mathrm{c}}$ Could not be determined due to sparking.

Complexes 17a-17f are multipolar compounds with both dipolar $\left(\beta^{\mathrm{J}=1}\right)$ and octupolar $\left(\beta^{\mathrm{J}=3}\right)$ contributions to the second order NLO response, since they are $3 \mathrm{D}$ chromophores having $C_{3}$ symmetry. The EFISH method only provides the dipolar component and therefore complexes were also studied by the HLS method, which reflects both the dipolar and octupolar contributions [3538]. The identity of the end group and the $\pi$-conjugated moiety have a strong effect on the NLO activity. In all cases, a large value of $\left\langle\beta_{\mathrm{HLS}, 1.907}>\right.$ (see Table 5) is observed for complexes 17a-f. Comparative studies of the three complexes 17a-c show that $\beta_{\mathrm{HLS}}$ increases in the order 17a $(\mathrm{H})<$ 17b $(\mathrm{OMe})<$ 17c $\left(\mathrm{NEt}_{2}\right)$ (Table 5), due to the increasing electron-donating ability of the terminal group, in agreement with strong ILCT transitions. Similar NLO responses were obtained for complexes 17c and 17e (Table 5) featuring an amino-aryl and -thienyl group, respectively. This result contrasts with the general behaviour that is a higher NLO activity by replacing the phenyl ring with a thienyl one [62]. As expected, the addition of two strong electron-donor groups associated with a unsaturated spacer gives rise to the highest NLO activity, found for complex 17d having a (butadienyl)dianilino substituent (Table 5).

The $\beta_{\mathrm{HLS}}$ values are comparable to those measured for iridium(III) compounds bearing two cyclometalated 2-phenylpyridines and a 2,2'-bipyridine or 1,10 phenanthroline ancillary ligand (vide infra, section 6) where the the octupolar part controls the total quadratic hyperpolarizability. As for $C_{3}$ symmetry subphthalocyanine chromophores [63], all these tris-cyclometalated $\operatorname{Ir}(\mathrm{III})$ complexes bearing a $\pi$-conjugated substituent in the para position of the pyridyl ring of the ppy- 
type ligands have larger $\beta_{\mathrm{HLS}}$ vs $\beta_{\mathrm{EFISH}}$, because the octupolar contribution to the total quadratic hyperpolarizability is more important than the dipolar contribution.

These tris-cyclometalated iridium compounds represent an interesting class of complexes with a second-order NLO response easily controlled by rational ligand design. $\operatorname{Ir}(\text { ppy })_{3}$ compounds with $\pi$-extended vinyl-aryl appended moieties at the 4 position of the pyridine ring are multipolar molecules with a strong NLO activity. Higher $\beta_{\mathrm{HLS}}$ value were found for compounds having the strongest donor as terminal groups and the longest $\pi$ conjugated system: the (butadienyl)dianilino derivative (17d) displayed the largest value. The quadratic hyperpolarizability is governed by the octupolar part as evidenced by EFISH and HLS studies. Their known robustness makes these neutral $\operatorname{Ir}(\mathrm{III})$ complexes particularly appealing for NLO applications.

\section{Cationic bis-cyclometalated phenylpyridine iridium(III) complexes with diimine or aryl isocyanide ancillary ligands}

In 2006-2007, a large number of heteroleptic iridium(III) complexes bearing two cyclometalated phenylpyridines and an ancillary diimine ligand such as bipyridine [64-65] or phenanthroline [66-68] were reported to act as emitters in electroluminescent devices. DFT calculations on this family of phosphorescent iridium(III) compounds showed that the HOMO is mostly an antibonding combination of Ir $\left(\mathrm{t}_{2 \mathrm{~g}}\right)$ orbitals and $\pi$ orbitals of the cyclometalated ligand whereas the LUMO is localized on the $\pi^{*}$ antibonding orbitals of the ancillary ligand [64-68]. Therefore, transitions between HOMO and LUMO have a mixed MLCT and ligand-to-ligand charge tranfer (LLCT) character. The CT nature of the emissive excited state implies that these compounds could have an NLO activity with the cyclometalated moiety behaving as a donor moiety towards the $\pi$-accepting ancillary ligand. This observation was the inspiration for the study of the second-order NLO properties of this kind of complexes [69]. 
The quadratic hyperpolarizability of $\left[\operatorname{Ir}(\mathrm{ppy})_{2}(5-\mathrm{R}-1,10-\mathrm{phen})\right]\left[\mathrm{PF}_{6}\right]$ (ppyH = 2phenylpyridine; phen = phenanthroline; $\mathrm{R}=\mathrm{H}, \mathrm{Me}, \mathrm{NMe}_{2}, \mathrm{NO}_{2}$; 18, Fig.7) and $\left[\operatorname{Ir}(\mathrm{ppy})_{2}\left(4-\mathrm{R}^{\prime}, 7-\mathrm{R}^{\prime}-\right.\right.$ 1,10-phen) $]\left[\mathrm{PF}_{6}\right]\left(\mathrm{R}^{\prime}=\mathrm{Me}, \mathrm{Ph}, \mathbf{1 9}\right)$ was determined in $10^{-3} \mathrm{M} \mathrm{CH}_{2} \mathrm{Cl}_{2}$ solution by the EFISH method working at $1.907 \mu \mathrm{m}$ [69]. It is worth noting that the use of a low polarity solvent such as $\mathrm{CH}_{2} \mathrm{Cl}_{2}$ permits tighter ion-pairing and therefore the study of ionic compounds is possible [70].

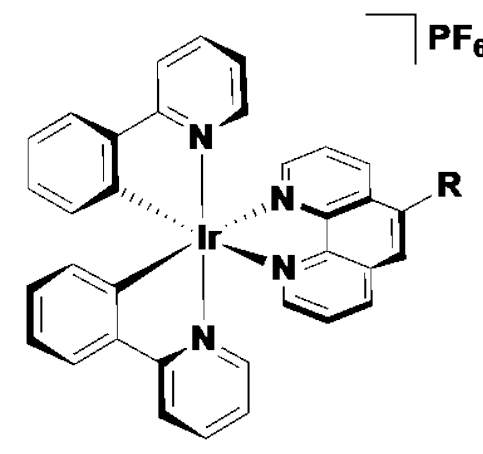

18

$\mathrm{R}=\mathrm{H}, \mathrm{Me}, \mathrm{NMe}_{2}, \mathrm{NO}_{2}$

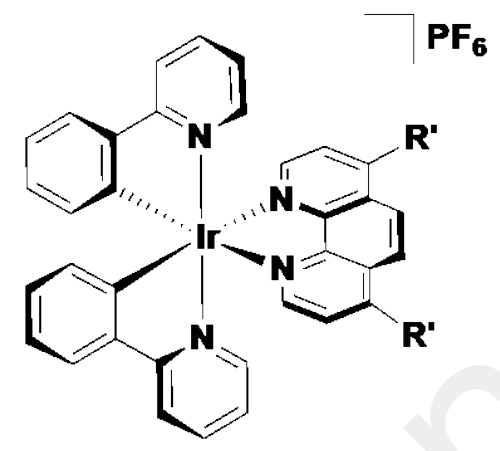

19

$\mathbf{R}^{\prime}=\mathbf{M e}, \mathbf{P h}$

Fig. 7. Bis-cyclometalated phenylpyridine iridium(III) complexes with phenanthroline ligands

These heteroleptic iridium(III) complexes are characterized by impressive $\mu \beta_{1.91}$ (EFISH) values, going from -1270 to $-2230 \times 10^{-48}$ esu (Table 6, 18a-18d, 19a-19b). The highest absolute $\mu \beta_{1.91}$ (EFISH) value is observed with the iridium compound bearing a 1,10-phenanthroline substituted with a $\mathrm{NO}_{2}$ group (18b), as expected for the increased $\pi$-acceptor character of the ancillary ligand [69]. An increase of the $\pi$-delocalization of the 1,10-phenanthroline ligand causes an enhancement of the second-order NLO activity (compare $\left[\operatorname{Ir}(\mathrm{ppy})_{2}(4-\mathrm{Ph}, 7-\mathrm{Ph}-1,10-\mathrm{phen})\right]\left[\mathrm{PF}_{6}\right]$ (19b, Table 6) and $\left[\operatorname{Ir}(\mathrm{ppy})_{2}(4-\mathrm{Me}, 7-\mathrm{Me}-1,10-\mathrm{phen})\right]\left[\mathrm{PF}_{6}\right]$ (19a). It is worth pointing out that in [Ir(ppy) $)_{2}\left(5-\mathrm{NMe}_{2}-1,10-\right.$ phen $\left.)\right]\left[\mathrm{PF}_{6}\right]$, the 1,10-phenanthroline acts as an acceptor site even though it bears the strong electron-donor group $\mathrm{NMe}_{2}$. A SOS TD-DFT investigation was carried out in order to understand the factors controlling the second order NLO properties of these iridium complexes [69]. For the complex with a $\mathrm{NO}_{2}$ substituent on the ancillary ligand, $\beta$ is the sum of negative 
contributions (due to MLCT/LLCT transitions from a $\mathrm{d} \pi_{\mathrm{ppy}}$-based HOMO orbital to $\pi^{*}$ levels of the phenanthroline with an increase of the excited state dipole moment compared to the ground state), affording an overall negative value of $\beta$. For the compound with a $\mathrm{NMe}_{2}$ substituent, there are counteracting positive (due to ILCT transitions from a $\pi$ phenanthroline orbital involving the $\mathrm{NMe}_{2}$ group to a $\pi^{*}$ antibonding of the phenanthroline ring) and negative (due to MLCT/LLCT transitions from a $\mathrm{d} \pi_{\mathrm{ppy}}$-based HOMO orbital to $\pi^{*}$ levels of the ancillary ligand) contributions, with a negative converged final value. These counteracting contributions (due to the positive or negative difference between ground and excited states dipole moments) explain why the absolute value of $\mu \beta_{1.91}(\mathrm{EFISH})$ of the compound with $\mathrm{NMe}_{2}$ is lower than that with $\mathrm{NO}_{2}$.

In summary, in these iridium(III) compounds the NLO response is mostly governed by MLCT/LLCT transitions from the $\mathrm{d} \pi_{\mathrm{ppy}}$-based HOMO donor orbital implicating the cyclometalated fragment to the LUMO $\pi$-acceptor orbitals of the 1,10-phenanthroline, regardless of the nature of the substitution on the phenanthroline ligand [69].

Later, it was observed that replacement of the cyclometalated 2-phenylpyridine by 2phenylquinoline [71], benzo(h)quinoline [72] or by 4,5-diphenyl-2-methyl-thiazole [73] affords complexes with similar $\mu \beta_{1.91}$ (EFISH) values. The latter depend on the nature of the $\mathrm{R}$ substituents on the 1,10-phenanthroline where the highest absolute value is obtained with the $\mathrm{NO}_{2}$-substituted phen ligand [74]. The related complexes with a cyclometalated 3'-(2-pyridyl)-2,2':5',2'’terthiophene have poorer second-order NLO properties due to a significant stabilization of the HOMO energy [71].

The discovery that this family of heteroleptic iridium complexes can reach an impressive second-order NLO response was particularly fascinating and led to further investigations [74]. By using both experimental (EFISH method and ${ }^{1} \mathrm{H}$ and ${ }^{19} \mathrm{~F}$ pulsed field gradient spin echo diffusion NMR techniques) and theoretical (DFT, TDDFT, SOS approach) investigations, it was found that ion pairing that is controlled by the identity of the counterion and by the concentration when 
working in $\mathrm{CH}_{2} \mathrm{Cl}_{2}$ may tune the $\mu \beta_{1.91}(\mathrm{EFISH})$ values of these compounds. For example, in the case of $\left[\operatorname{Ir}(\mathrm{ppy})_{2}\left(5-\mathrm{NO}_{2}-1,10-\mathrm{phen}\right)\right][\mathrm{Y}]$, if $\mathrm{Y}$ is $\mathrm{PF}_{6}^{-}$, a weakly interacting anion, there is an increase of the absolute value of $\mu \beta_{1.91}(\mathrm{EFISH})$ as a function of dilution in $\mathrm{CH}_{2} \mathrm{Cl}_{2}$ solution (18b, Table 6) due to a reduction of the extent of ion pairing. In fact, an increase of $\beta$ was calculated by shifting from the ion-pair to the cationic species [74]. With $\mathrm{C}_{12} \mathrm{H}_{25} \mathrm{SO}_{3}{ }^{-}$, which forms tight ion-pairs, the absolute value of $\mu \beta_{1.91}$ (EFISH) is lower and less dependent on the concentration (18b') [74]. These results demonstrate that concentration must be taken into account when studying the NLO activity of ionic species in $\mathrm{CH}_{2} \mathrm{Cl}_{2}$ with the EFISH technique.

Table 6. $\mu \beta_{1.91}($ EFISH) of some bis-cyclometalated phenylpyridine $\operatorname{Ir}$ (III) complexes with phenanthroline or bipyridine ligands [69, 74, 76, 77, 86].

\begin{tabular}{|c|c|c|c|c|}
\hline & & $\mathbf{Y}$ & $\begin{array}{l}\text { Solvent, } \\
\text { Concentration }\end{array}$ & $\begin{array}{l}\mu \beta_{1.907} \\
\left(\times 10^{-48} \text { esu }\right)\end{array}$ \\
\hline 18a & {$\left[\operatorname{Ir}(\text { ppy })_{2}(5-\mathrm{R}-1,10-\mathrm{phen})\right][\mathrm{Y}](\mathrm{R}=\mathrm{Me})$} & $\mathrm{PF}_{6}^{-}$ & $\mathrm{CH}_{2} \mathrm{Cl}_{2}, 10^{-3} \mathrm{M}$ & -1565 \\
\hline 18a' & {$\left[\operatorname{Ir}(\mathrm{ppy})_{2}(5-\mathrm{R}-1,10-\mathrm{phen})\right][\mathrm{Y}](\mathrm{R}=\mathrm{Me})$} & $\mathrm{C}_{12} \mathrm{H}_{25} \mathrm{SO}_{3}{ }^{-}$ & $\mathrm{CH}_{2} \mathrm{Cl}_{2}, 10^{-3} \mathrm{M}$ & -1350 \\
\hline $18 b$ & {$\left[\operatorname{Ir}(\mathrm{ppy})_{2}\left(5-\mathrm{R}-1,10\right.\right.$-phen)][Y] $\left(\mathrm{R}=\mathrm{NO}_{2}\right)$} & $\mathrm{PF}_{6}^{-}$ & $\mathrm{CH}_{2} \mathrm{Cl}_{2}, 10^{-3} \mathrm{M}$ & -2230 \\
\hline $18 b$ & {$\left[\operatorname{Ir}(\mathrm{ppy})_{2}(5-\mathrm{R}-1,10-\mathrm{phen})\right][\mathrm{Y}]\left(\mathrm{R}=\mathrm{NO}_{2}\right)$} & $\mathrm{PF}_{6}^{-}$ & $\mathrm{CH}_{2} \mathrm{Cl}_{2}, 10^{-4} \mathrm{M}$ & -4990 \\
\hline 18b' & $\left[\operatorname{Ir}(\text { ppy })_{2}(5-\mathrm{R}-1,10-\right.$ phen $\left.\left.)\right][\mathrm{Y}] \mathrm{R}=\mathrm{NO}_{2}\right)$ & $\mathrm{C}_{12} \mathrm{H}_{25} \mathrm{SO}_{3}{ }^{-}$ & $\mathrm{CH}_{2} \mathrm{Cl}_{2}, 10^{-3} \mathrm{M}$ & -1430 \\
\hline 18b' & {$\left[\operatorname{Ir}(\mathrm{ppy})_{2}(5-\mathrm{R}-1,10\right.$-phen $\left.)\right][\mathrm{Y}]\left(\mathrm{R}=\mathrm{NO}_{2}\right)$} & $\mathrm{C}_{12} \mathrm{H}_{25} \mathrm{SO}_{3}{ }^{-}$ & $\mathrm{CH}_{2} \mathrm{Cl}_{2}, 10^{-4} \mathrm{M}$ & -1770 \\
\hline 18c & {$\left[\operatorname{Ir}(\mathrm{ppy})_{2}(5-\mathrm{R}-1,10-\mathrm{phen})\right][\mathrm{Y}](\mathrm{R}=\mathrm{H})$} & $\mathrm{PF}_{6}^{-}$ & $\mathrm{CH}_{2} \mathrm{Cl}_{2}, 10^{-3} \mathrm{M}$ & -1270 \\
\hline 18d & {$\left[\operatorname{Ir}(\mathrm{ppy})_{2}(5-\mathrm{R}-1,10\right.$-phen $\left.)\right][\mathrm{Y}]\left(\mathrm{R}=\mathrm{NMe}_{2}\right)$} & $\mathrm{PF}_{6}^{-}$ & $\mathrm{CH}_{2} \mathrm{Cl}_{2}, 10^{-3} \mathrm{M}$ & -1330 \\
\hline 19a & {$\left[\operatorname{Ir}(\mathrm{ppy})_{2}\left(4-\mathrm{R}^{\prime}, 7-\mathrm{R}^{\prime}-1,10-\mathrm{phen}\right)\right][\mathrm{Y}]\left(\mathrm{R}^{\prime}=\mathrm{Me}\right)$} & $\mathrm{PF}_{6}^{-}$ & $\mathrm{CH}_{2} \mathrm{Cl}_{2}, 10^{-3} \mathrm{M}$ & -1454 \\
\hline $19 b$ & {$\left[\operatorname{Ir}(\mathrm{ppy})_{2}\left(4-\mathrm{R}^{\prime}, 7-\mathrm{R}^{\prime}-1,10-\mathrm{phen}\right)\right][\mathrm{Y}]\left(\mathrm{R}^{\prime}=\mathrm{Ph}\right)$} & $\mathrm{PF}_{6}^{-}$ & $\mathrm{CH}_{2} \mathrm{Cl}_{2}, 10^{-3} \mathrm{M}$ & -1997 \\
\hline 20 & {$\left[\operatorname{Ir}(\mathrm{ppy})_{2}(4,5\right.$-diazafluorene $\left.)\right][\mathrm{Y}]$} & $\mathrm{PF}_{6}^{-}$ & $\mathrm{CH}_{2} \mathrm{Cl}_{2}, 10^{-3} \mathrm{M}$ & -1640 \\
\hline 20 ' & {$\left[\operatorname{Ir}(\mathrm{ppy})_{2}\right.$ (4,5-diazafluorene)][Y] } & $\mathrm{C}_{12} \mathrm{H}_{25} \mathrm{SO}_{3}^{-}$ & $\mathrm{CH}_{2} \mathrm{Cl}_{2}, 10^{-3} \mathrm{M}$ & -1035 \\
\hline 21 & {$\left[\operatorname{Ir}(\mathrm{ppy})_{2}(9\right.$-fulleriden-4,5-diazafluorene)][Y] } & $\mathrm{PF}_{6}^{-}$ & $\mathrm{CH}_{2} \mathrm{Cl}_{2}, 10^{-3} \mathrm{M}$ & -2190 \\
\hline
\end{tabular}




\begin{tabular}{|c|c|c|c|c|}
\hline 21' & {$\left[\operatorname{Ir}(\text { ppy })_{2}(9\right.$-fulleriden-4,5-diazafluorene $\left.)\right][Y]$} & $\mathrm{C}_{12} \mathrm{H}_{25} \mathrm{SO}_{3}{ }^{-}$ & $\mathrm{CH}_{2} \mathrm{Cl}_{2}, 10^{-3} \mathrm{M}$ & -1901 \\
\hline 22 & [Ir(ppy) $)_{2}$ (9-fulleriden-4-monoazafluorene)] & & $\mathrm{CH}_{2} \mathrm{Cl}_{2}, 10^{-3} \mathrm{M}$ & -601 \\
\hline 23R & {$\left[\operatorname{Ir}(\mathrm{ppy}-\mathrm{Me})_{2}\left(\mathrm{bpy}-(\mathrm{Me})_{2}\right)\right][\mathrm{Y}]$} & $\mathrm{PF}_{6}^{-}$ & $\mathrm{CH}_{2} \mathrm{Cl}_{2}, 10^{-3} \mathrm{M}$ & -1420 \\
\hline 23a & {$\left[\operatorname{Ir}(\mathrm{ppy}-\mathrm{Me})_{2}\left(\mathrm{bpy}-(\mathrm{CHCHArR})_{2}\right)\right][\mathrm{Y}]\left(\mathrm{ArR}=\mathrm{PhNEt}_{2}\right)$} & $\mathrm{PF}_{6}^{-}$ & $\mathrm{CH}_{2} \mathrm{Cl}_{2}, 10^{-3} \mathrm{M}$ & -2770 \\
\hline 23a' & {$\left[\operatorname{Ir}(\text { ppy-Me })_{2}\left(\mathrm{bpy}-(\mathrm{CHCHArR})_{2}\right)\right][\mathrm{Y}]\left(\mathrm{ArR}=\mathrm{PhNEt}_{2}\right)$} & $\mathrm{C}_{12} \mathrm{H}_{25} \mathrm{SO}_{3}^{-}$ & $\mathrm{CH}_{2} \mathrm{Cl}_{2}, 10^{-3} \mathrm{M}$ & -1015 \\
\hline $23 b$ & {$\left[\mathrm{Ir}(\mathrm{ppy}-\mathrm{Me})_{2}\left(\mathrm{bpy}-(\mathrm{CHCHArR})_{2}\right)\right][\mathrm{Y}]\left(\mathrm{ArR}=\mathrm{PhNO}_{2}\right)$} & $\mathrm{PF}_{6}^{-}$ & $\mathrm{CH}_{2} \mathrm{Cl}_{2}, 10^{-3} \mathrm{M}$ & -2770 \\
\hline 23b’ & {$\left[\operatorname{Ir}(\text { ppy-Me })_{2}\left(\right.\right.$ bpy- $\left.\left.(\mathrm{CHCHArR})_{2}\right)\right][\mathrm{Y}]\left(\mathrm{ArR}=\mathrm{PhNO}_{2}\right)$} & $\mathrm{C}_{12} \mathrm{H}_{25} \mathrm{SO}_{3}{ }^{-}$ & $\mathrm{CH}_{2} \mathrm{Cl}_{2}, 10^{-3} \mathrm{M}$ & -1250 \\
\hline 23c & {$\left[\mathrm{Ir}(\mathrm{ppy}-\mathrm{Me})_{2}\left(\mathrm{bpy}-(\mathrm{CHCHArR})_{2}\right)\right][\mathrm{Y}](\mathrm{ArR}=$ PhOOctyl $)$} & $\mathrm{PF}_{6}^{-}$ & $\mathrm{CH}_{2} \mathrm{Cl}_{2}, 10^{-3} \mathrm{M}$ & -2430 \\
\hline 23d & $\begin{array}{l}{\left[\mathrm{Ir}(\mathrm{ppy}-\mathrm{Me})_{2}\left(\mathrm{bpy}-(\mathrm{CHCHArR})_{2}\right)\right][\mathrm{Y}] \quad(\mathrm{ArR} \quad=} \\
\text { ThienylMe })\end{array}$ & $\mathrm{PF}_{6}^{-}$ & $\mathrm{CH}_{2} \mathrm{Cl}_{2}, 10^{-3} \mathrm{M}$ & -2386 \\
\hline 23e, open & $\begin{array}{l}{\left[\mathrm{Ir}(\mathrm{ppy}-\mathrm{Me})_{2}\left(\mathrm{bpy}-(\mathrm{CHCHArR})_{2}\right)\right][\mathrm{Y}] \quad(\mathrm{ArR}=\text { DTE- }} \\
\left.\mathrm{PhNMe}_{2}\right) \text { with opened DTE }\end{array}$ & $\mathrm{PF}_{6}^{-}$ & $\mathrm{CH}_{2} \mathrm{Cl}_{2}, 10^{-3} \mathrm{M}$ & -2190 \\
\hline 23e, closed & $\begin{array}{l}{\left[\mathrm{Ir}(\mathrm{ppy}-\mathrm{Me})_{2}\left(\mathrm{bpy}-(\mathrm{CHCHArR})_{2}\right)\right][\mathrm{Y}] \quad(\mathrm{ArR}=\text { DTE- }} \\
\left.\mathrm{PhNMe}_{2}\right) \text { with closed DTE }\end{array}$ & $\mathrm{PF}_{6}^{-}$ & $\mathrm{CH}_{2} \mathrm{Cl}_{2}, 10^{-3} \mathrm{M}$ & -2000 \\
\hline 24 & $\left.\left[\mathrm{Ir}(\mathrm{ppy}-4-\mathrm{CHCHPhNEt})_{2}\right)_{2}\left(\mathrm{bpy}-\left(\mathrm{CHCHPhNEt}_{2}\right)_{2}\right)\right][\mathrm{Y}]$ & $\mathrm{PF}_{6}^{-}$ & $\mathrm{CH}_{2} \mathrm{Cl}_{2}, 10^{-3} \mathrm{M}$ & -960 \\
\hline
\end{tabular}

The observation that this family of heteroleptic iridium compounds has large $\mu \beta_{1.91}$ (EFISH) values [69, 71-74] along with the reported positive effect of fullerene on the quadratic hyperpolarizability of metal complexes [75], was at the origin of an EFISH investigation of a new class of iridium compounds bearing a diazafluorene ancillary ligand, functionalized or not with a fullerene (20, 21, Fig. 8), and of the related $\left[\operatorname{Ir}(\mathrm{ppy})_{2}(9\right.$-fulleriden-4-monoazafluorene)] complex (22) [76].

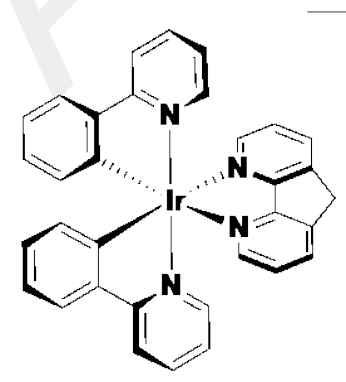

20
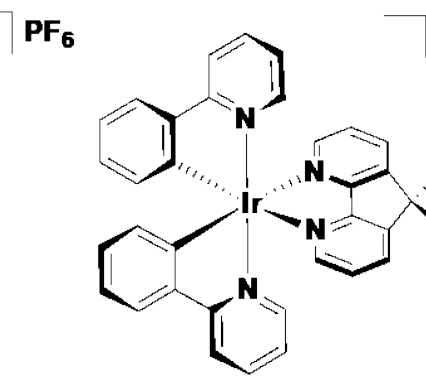

21

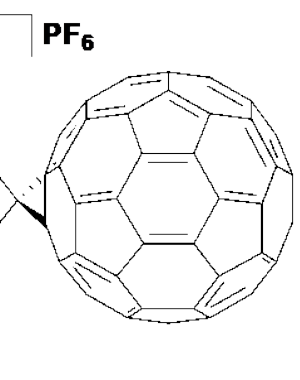

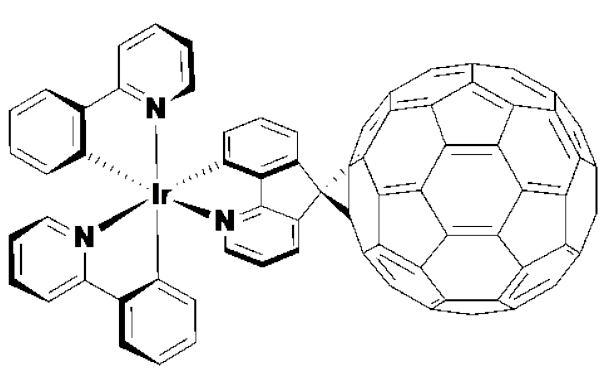

22 
Fig. 8. Bis-cyclometalated phenylpyridine iridium(III) complexes with diazafluorene ligands and related complex with monoazafluorene.

All compounds have a huge negative value of $\mu \beta_{1.91}$ (EFISH) $\left(-601\right.$ to $-2190 \times 10^{-48}$ esu; Table 6, 20-22), at $1.907 \mu \mathrm{m}$ in $10^{-3} \mathrm{M} \mathrm{CH}_{2} \mathrm{Cl}_{2}$ solution [76]. Complex [ $\operatorname{Ir}(\mathrm{ppy})_{2}(4,5-$ diazafluorene)][$\left[\mathrm{PF}_{6}\right]$ (20) shows a much higher absolute value compared to the analogous complex with $\mathrm{C}_{12} \mathrm{H}_{25} \mathrm{SO}_{3}{ }^{-}$(20', Table 6), as expected for a looser ion-pair and in agreement with a much higher percentage of free ions (57\% compared to less than $5 \%$, as determined by ${ }^{1} \mathrm{H}$ and ${ }^{19} \mathrm{~F}$ pulsed field gradient spin echo diffusion NMR techniques). The NLO activity is enhanced in the presence of fullerene (21 and 21'), an effect that can be attributed to a reduction of the electrostatic forces between the anion and cation of the ion pair that leads to an increase of free ions. Remarkably, the presence of fullerene weakens the ion pair even when $\mathrm{C}_{12} \mathrm{H}_{25} \mathrm{SO}_{3}{ }^{-}$is the counterion. The $\mu \beta_{1.91}$ (EFISH) value of [Ir(ppy) 2 (9-fulleriden-4-monoazafluorene)] (22) is lower than that of other heteroleptic cationic iridium(III) compounds, but similar to the values of bis-cyclometalated phenylpyridine iridium(III) compounds with $\beta$-diketonate ligands (see Section 4) [76].

Le Bozec et al. designed and prepared various $\pi$-delocalized 4,4'-disubstituted-[2,2']bipyridines and related dipolar and octupolar metal complexes with large second-order NLO properties [15]. Therefore, it was particularly appealing to investigate related complexes bearing a substituted bipyridine (bpy) as the ancillary ligand.

A family of $\operatorname{Ir}(\mathrm{III})$ complexes, $\left[\mathrm{Ir}(\mathrm{ppy}-\mathrm{Me})_{2}\left(\mathrm{bpy}-(\mathrm{CHCHArR})_{2}\right)\right][\mathrm{Y}]\left(\mathrm{Y}^{-}=\mathrm{PF}_{6}{ }^{-}\right.$or $\mathrm{C}_{12} \mathrm{H}_{25} \mathrm{SO}_{3}{ }^{-}$ ; 23, Fig. 9), incorporating a methylated cyclometalating phenylpyridine and an arvinyl $\pi$ system on each pyridine ring of the bipyridine (Ar = benzene or thienyl ring functionalized with acceptor or donor substituents) was investigated for their NLO activity [77]. The complex with the simple 4,4'-

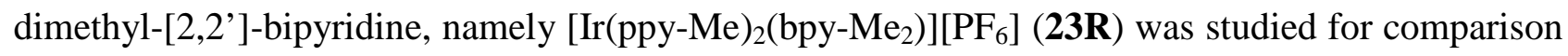
whereas a bipyridine incorporating a photochromic dimethylaminophenyl-dithienylethene (DTE) group was also used to investigate the photoregulation of the luminescence and nonlinear optical 
properties of the resulting iridium complex [77]. In fact, when irradiated with a suitable wavelength, DTE compounds undergo reversible interconversion between a non-conjugated open form and a $\pi$-conjugated closed form, which can tune the photonic properties [78-85].
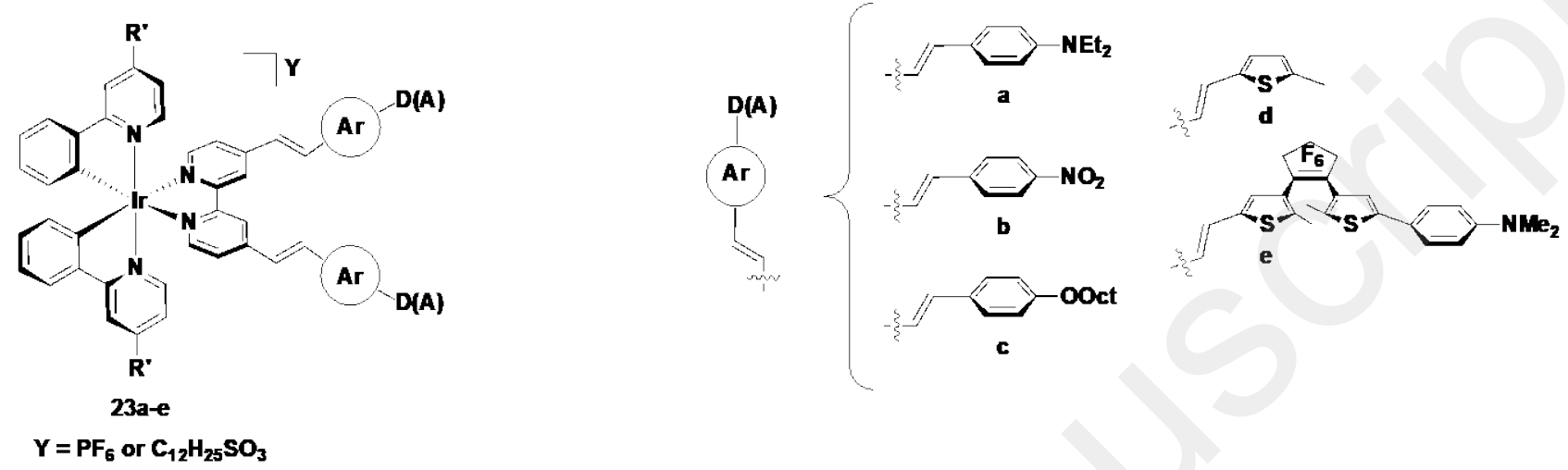

Fig. 9. Iridium(III) complexes containing $\pi$-delocalized 4,4'-disubstituted-2,2'-bipyridine ligands.

The second-order NLO activity of these iridium(III) compounds were studied by the EFISH method (Table 6, 23R, 23a-23e) [77]. The $\mu \beta_{1.91}(\mathrm{EFISH})$ value of $\left[\operatorname{Ir}(\mathrm{ppy}-\mathrm{Me})_{2}\left(\mathrm{bpy}-\mathrm{Me}_{2}\right)\right]\left[\mathrm{PF}_{6}\right]$ (23R) is similar to that of the related complex with a 4,7-dimethyl-1,10-phenanthroline (19a) demonstrating that substitution of phenanthrolines by bipyridines does not influence the secondorder NLO activity of these Ir(III) complexes nor does the presence of a methyl substituent on the cyclometalating ligand. Keeping $\mathrm{PF}_{6}^{-}$as the counterion, the absolute value of $\mu \beta_{1.91}(\mathrm{EFISH})$ is increased upon an augmentation of the $\pi$ delocalization of the 2,2'-bipyridine, with values larger than that found for $\left[\operatorname{Ir}(\mathrm{ppy})_{2}\left(5-\mathrm{NO}_{2}-1,10-\right.\right.$ phenant $\left.)\right]\left[\mathrm{PF}_{6}\right]$ (18b). The absolute values of $\mu \beta_{1.91}$ (EFISH) become larger upon dilution from $10^{-3} \mathrm{M}$ to $10^{-4} \mathrm{M}$, a behaviour that can be attributed to an increase in the numnber of free ions as shown by ${ }^{1} \mathrm{H}$ and ${ }^{19} \mathrm{~F}$ PGSE NMR spectroscopy. Also, the absolute value, measured at $10^{-3} \mathrm{M}$ in $\mathrm{CH}_{2} \mathrm{Cl}_{2}$, is lowered with $\mathrm{C}_{12} \mathrm{H}_{25} \mathrm{SO}_{3}{ }^{-}$ than with $\mathrm{PF}_{6}{ }^{-}$, attributed to an enhancement of the ion-pair strength for $\mathrm{C}_{12} \mathrm{H}_{25} \mathrm{SO}_{3}{ }^{-}$with respect to $\mathrm{PF}_{6}{ }^{-}$(compare 23a with 23a' and 23b with 23b' in Table 6) [77]. 
The dipole moment of $\left[\operatorname{Ir}(\mathrm{ppy})_{2}\left(5-\mathrm{NO}_{2}-1,10\right.\right.$-phen $\left.)\right]\left[\mathrm{C}_{12} \mathrm{H}_{25} \mathrm{SO}_{3}\right]\left(18 \times 10^{-18}\right.$ esu $)$ and [ $\operatorname{Ir}(\mathrm{ppy}-$ $\mathrm{Me})_{2}\left(\right.$ bpy- $\left.\left.\left(\mathrm{CH}=\mathrm{CH}-\mathrm{PhNO}_{2}\right)_{2}\right)\right]\left[\mathrm{C}_{12} \mathrm{H}_{25} \mathrm{SO}_{3}\right]\left(12 \times 10^{-18}\right.$ esu) were measured by the Guggenheim technique [34] using $\mathrm{CHCl}_{3}$ as solvent because it has a low dielectric constant that ensures a tight ion pairing. The absolute value of $\beta_{1.91}(\mathrm{EFISH})$ is larger for the complex with the bipyridine having two electron-acceptor $\mathrm{NO}_{2}$ substituents $\left(-104\right.$ and $-79 \times 10^{-30}$ esu, for the bipyridine and phenanthroline complex, respectively), as expected for a second-order NLO response mostly governed by MLCT/LLCT transitions [77]. Although the introduction of a DTE moiety onto the bipyridine permits the luminescence to be switched on or off, no substantial modulation of the quadratic hyperpolarizability is observed upon photocyclization (23e, open and 23e, closed), confirming that the second-order NLO activity is not governed by intraligand excited states localised on the bipyridine [77].

The Harmonic Light Scattering (HLS) method revealed that all these heteroleptic iridium(III) complexes have a huge $\left\langle\beta_{\mathrm{HLS}, 1.907}>\right.$ value $\left(375-550 \times 10^{-30} \mathrm{esu}\right.$, in $\left.\mathrm{CH}_{2} \mathrm{Cl}_{2}\right)$, which does not depend on the identity of the anion $\left(\mathrm{PF}_{6}{ }^{-}\right.$or $\left.\mathrm{C}_{12} \mathrm{H}_{25} \mathrm{SO}_{3}{ }^{-}\right)$because the HLS response of these compounds is not influenced by the strength of the ion-pairs [77]. A combination of HLS and EFISH methods showed that in these systems the quadratic hyperpolarizability is controlled more by the octupolar component than by the dipolar one [77].

As reported in Section 4, [ $\operatorname{Ir}\left(\mathrm{ppy}-4-\mathrm{CHCHPhNEt}_{2}\right)_{2}$ (acac)] shows a strong $\mu \beta_{1.907}$ (EFISH) ($550 \times 10^{-48}$ esu; 9a, Table 3) and is a convenient compound for the development of polymeric films characterized by a good second harmonic generation [41]. This observation was at the origin of an investigation on the influence of the replacement of the acetylacetonate ligand by a charge-neutral bipyridine substituted with an electron-donor group on the second-order NLO properties [86]. The complex [Ir(ppy-4-CHCHPhNEt $)_{2}\left(\right.$ bpy- $\left.\left.\left(\mathrm{CHCHPhNEt}_{2}\right)_{2}\right)\right]\left[\mathrm{PF}_{6}\right] 24$ (Fig. 10) has a negative value of $\mu \beta_{1.907}$ EFISH) $\left(-960 \times 10^{-48}\right.$ esu, Table 6), about two-fold that of [Ir(ppy-4$\left.\mathrm{CHCHPhNEt}_{2}\right)_{2}$ (acetylacetonate)] [86]. This complex has also significant two-photon absorption properties, as will be discussed in Section 7. 


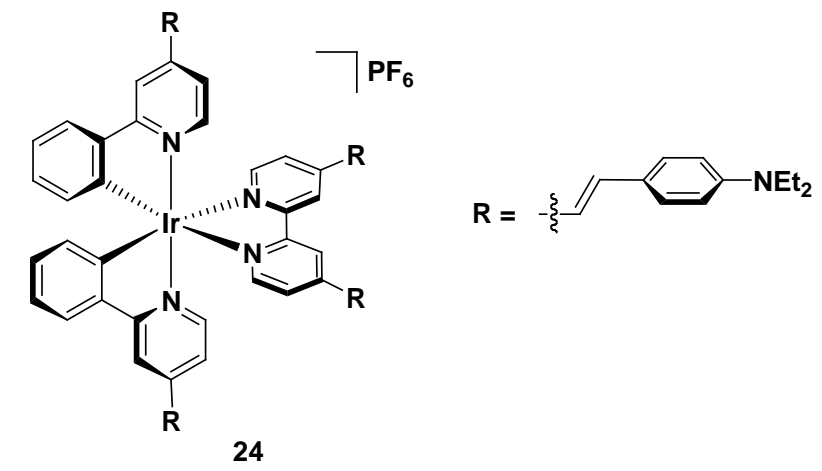

Fig. 10. Bis-cyclometalated iridium(III) complex with two substituted 2-phenylpyridines and a substituted bipyridine

Recently, an investigation was carried out on the second-order NLO activity of a new class of heteroleptic cationic iridium(III) complexes bearing cyclometalated 2-phenylpyridines with a triphenylamino substituent either in position 3 or 4 of the phenyl ring (2-(3-triphenylaminophenyl)pyridine and 2-(4-triphenylamino-phenyl)pyridine, called 3-TPAppy and 4-TPAppy, respectively) or in postion 4 of the pyridine (4-triphenylamino-2-phenylpyridine, called ppy-4TPA), where $\pi$-delocalisation could enhance the NLO response [87]. 4,4'-ditertbutyl-2,2'-bipyridine (bpy$\left.(t \mathrm{Bu})_{2}\right)$ and 5- $\mathrm{NO}_{2}-1,10$-phenanthroline (5- $\mathrm{NO}_{2}-1,10$-phen) were chosen as the ancillary ligands to give six complexes: [Ir(4-TPAppy $)_{2}\left(\right.$ bpy- $\left.\left.t \mathrm{Bu}_{2}\right)\right]\left[\mathrm{PF}_{6}\right]$ and $\left[\operatorname{Ir}(4-\mathrm{TPAppy})_{2}\left(5-\mathrm{NO}_{2}-1,10-\mathrm{phen}\right)\right]\left[\mathrm{PF}_{6}\right]$ (25, Fig. 11), $\left[\operatorname{Ir}(3-\mathrm{TPAppy})_{2}\left(\mathrm{bpy}-t \mathrm{Bu}_{2}\right)\right]\left[\mathrm{PF}_{6}\right]$ and $\left[\operatorname{Ir}(3-\mathrm{TPAppy})_{2}\left(5-\mathrm{NO}_{2}-1,10-\right.\right.$ phen$\left.)\right]\left[\mathrm{PF}_{6}\right]$ (26), $\left[\operatorname{Ir}(\text { ppy-4TPA })_{2}\left(\right.\right.$ bpy- $\left.\left.t \mathrm{Bu}_{2}\right)\right]\left[\mathrm{PF}_{6}\right]$ and $\left[\operatorname{Ir}(\mathrm{ppy}-4 \mathrm{TPA})_{2}\left(5-\mathrm{NO}_{2}-1,10-\mathrm{phen}\right)\right]\left[\mathrm{PF}_{6}\right]$ (27). 

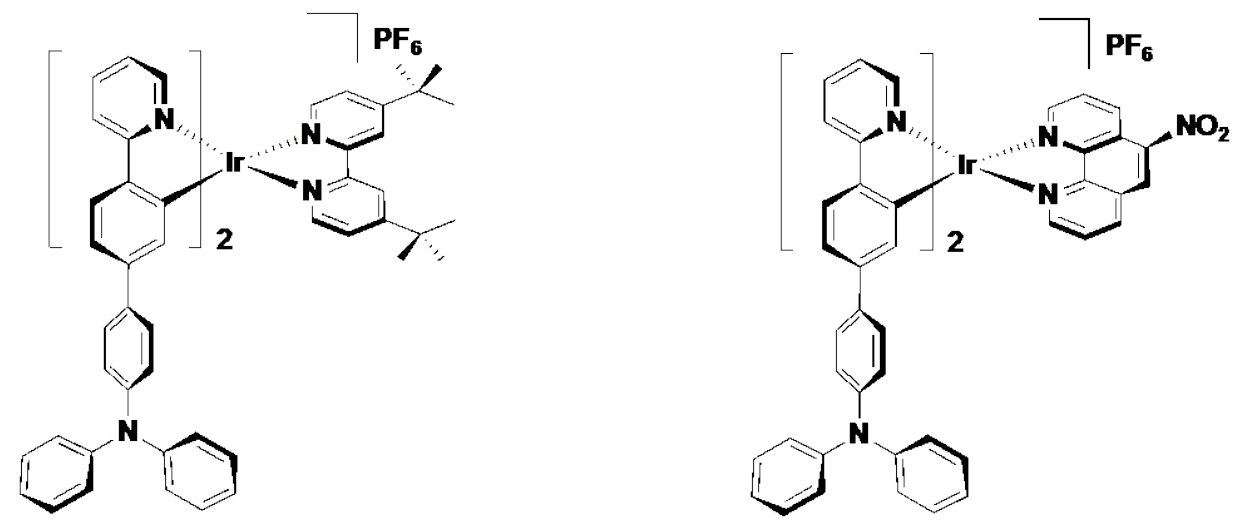

25

TPA meta to Ir-C $\mathrm{C}_{\mathrm{C} N \mathrm{~N}}$ bond
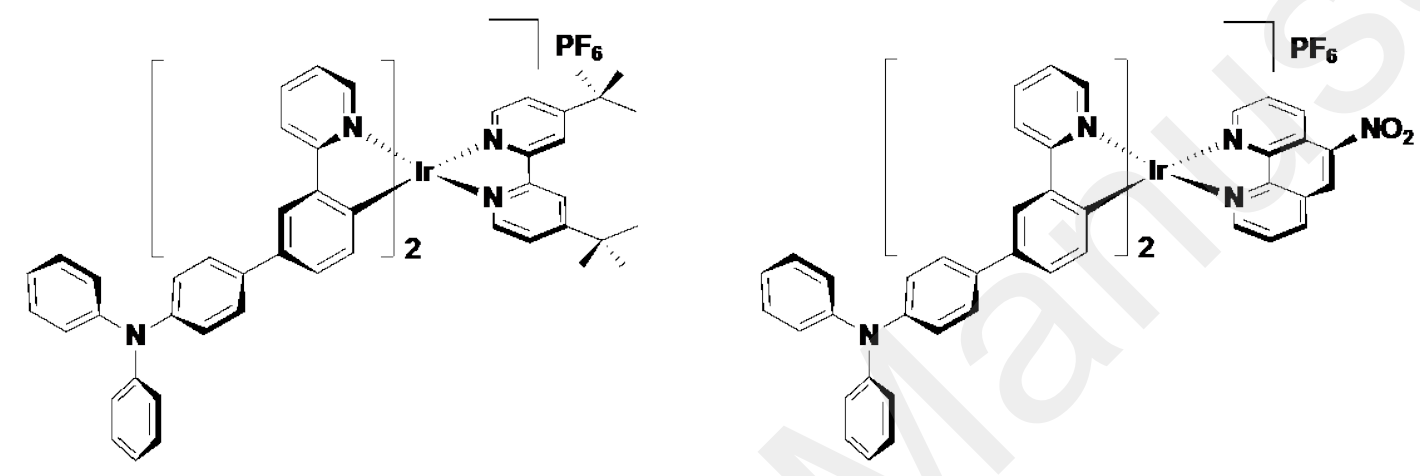

26

TPA para to Ir-C $\mathrm{C}_{\mathrm{C}^{\wedge} \mathrm{N}}$ bond
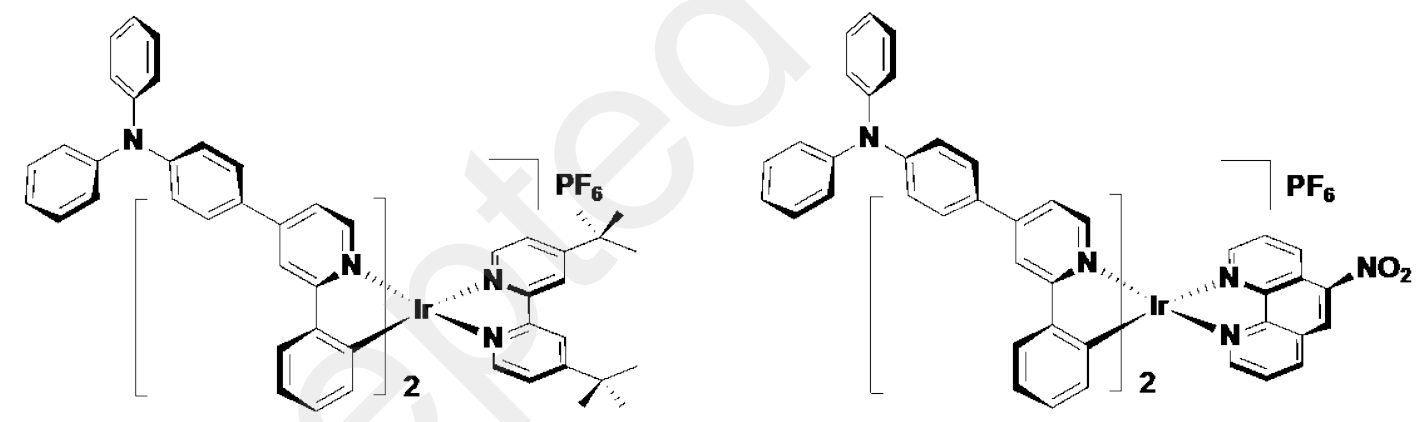

27

TPA para to Ir- $\mathbf{N}_{\text {CAN }^{\wedge}}$ bond

Fig. 11. Heteroleptic cationic iridium(III) complexes bearing cyclometalated 2-phenylpyridines substituted with a triphenylamino group

Remarkably, and contrary to the previously studied heteroleptic cationic complexes with $\mathrm{PF}_{6}{ }^{-}$as counterion, these complexes are very soluble in $\mathrm{CHCl}_{3}$. This is of particular interest for the determination of $\mu \beta$ values by the EFISH technique. As mentioned above, when using $\mathrm{CH}_{2} \mathrm{Cl}_{2}$ as 
the solvent, the counterion and the concentration must be suitably chosen in order to have a tight ion-pair. By contrast, the use of $\mathrm{CHCl}_{3}$ ensures tight ion-pairing, due to its lower dielectric constant [88].

The $\mu \beta$ values of these six complexes were determined by the EFISH method working in $\mathrm{CHCl}_{3}$; the dipole moments of the complexes were calculated with the Polarizable Continuum Model-Density Functional Theory (PCM-DFT), allowing determination of the quadratic hyperpolarizability (Table 7) [87].

Table 7 Dipole moments and quadratic hyperpolarizability of diimine cyclometalated iridium(III) complexes decorated with a triphenylamino substituent [87]

\begin{tabular}{|c|c|c|c|c|}
\hline & & $\begin{array}{l}\mu \beta_{1.907^{\mathrm{a}}} \\
\left(\times 10^{-48} \mathrm{esu}\right)\end{array}$ & $\begin{array}{l}\mu^{\mathrm{b}} \\
\left(\times 10^{-18} \mathrm{esu}\right)\end{array}$ & $\begin{array}{l}\beta_{1.907} \\
\left(\times 10^{-30} \mathrm{esu}\right)\end{array}$ \\
\hline $25 a$ & {$\left[\operatorname{Ir}(4-\mathrm{TPAppy})_{2}\left(\mathrm{bpy}-t \mathrm{Bu}_{2}\right)\right]\left[\mathrm{PF}_{6}\right]$} & -1260 & 19.8 & -64 \\
\hline $25 b$ & {$\left[\operatorname{Ir}(4-\mathrm{TPAppy})_{2}\left(5-\mathrm{NO}_{2}-1,10-\right.\right.$ phen $\left.)\right]\left[\mathrm{PF}_{6}\right]$} & -1370 & 14.2 & -96 \\
\hline 26a & {$\left[\operatorname{Ir}(3-\mathrm{TPAppy})_{2}\left(\mathrm{bpy}-t \mathrm{Bu}_{2}\right)\right]\left[\mathrm{PF}_{6}\right]$} & -1560 & 23.6 & -66 \\
\hline $26 b$ & {$\left[\operatorname{Ir}(3-\mathrm{TPAppy})_{2}\left(5-\mathrm{NO}_{2}-1,10-\right.\right.$ phen $\left.)\right]\left[\mathrm{PF}_{6}\right]$} & -1730 & 19.6 & -88 \\
\hline 27a & {$\left[\operatorname{Ir}(\mathrm{ppy}-4 \mathrm{TPA})_{2}\left(\mathrm{bpy}-t \mathrm{Bu}_{2}\right)\right]\left[\mathrm{PF}_{6}\right]$} & -1880 & 12.0 & -157 \\
\hline 27b & {$\left[\operatorname{Ir}(\mathrm{ppy}-4 \mathrm{TPA})_{2}\left(5-\mathrm{NO}_{2}-1,10-\mathrm{phen}\right)\right]\left[\mathrm{PF}_{6}\right]$} & -1890 & 6.4 & -295 \\
\hline
\end{tabular}

${ }^{\mathrm{a}} \mathrm{EFISH}$ values measured in $\mathrm{CHCl}_{3}$ at $1.907 \mu \mathrm{m}$. ${ }^{\mathrm{b}} \mathrm{Computed}$ dipole moments of the cationic iridium complex by means of PCM-DFT calculations.

All compounds show a negative $\mu \beta_{1.907}$ (EFISH) (Table 7), as expected for $\Delta \mu_{\mathrm{eg}}<0$ [87]. Complex [Ir(4-TPAppy) $\left.)_{2}\left(\mathrm{bpy}-(t \mathrm{Bu})_{2}\right)\right]\left[\mathrm{PF}_{6}\right]$ shows a large absolute value of $\mu \beta_{1.907}(\mathrm{EFISH})$ (25a, Table 7); a slightly higher value is observed for [ $\left.\operatorname{Ir}(3-\mathrm{TPAppy})_{2}\left(\mathrm{bpy}-\mathrm{B} \mathrm{Bu}_{2}\right)\right]\left[\mathrm{PF}_{6}\right](\mathbf{2 6 a})$, due to an increase of the dipole moment. An impressive NLO response is obtained for $\left[\operatorname{Ir}(\text { ppy-4TPA })_{2}\left(\right.\right.$ bpy- $\left.\left.t \mathrm{Bu}_{2}\right)\right]\left[\mathrm{PF}_{6}\right]$ (27a), due to a much higher $\beta_{1.907}(\mathrm{EFISH})$, which 
overcomes the reduction of $\mu$ that is due to the more symmetric arrangement of the donor groups around the iridium(III) centre [87]. The compounds with 5- $\mathrm{NO}_{2}-1,10$-phenanthroline (25b, 26b, 27b) have a smaller dipole moment than the related complexes with 4,4'ditertbutyl-2,2'-bipyridine but they have a higher $\mu \beta_{1.907}$ (EFISH) value due to an increase of $\beta_{1.907}$ (EFISH) caused by the electron-withdrawing strength of this phenanthroline (Table 7). The second-harmonic generation (SHG) of [Ir(3-TPAppy) $)_{2}\left(5-\mathrm{NO}_{2}-1,10-\right.$ phen $\left.)\right]\left[\mathrm{PF}_{6}\right]$ dispersed in a PMMA or polystyrene (PS) matrix, and oriented by corona poling, were also studied [87]. The SHG signal of films in PMMA decreased rapidly because of the loss of orientation of the chromophores when the electric field was switched off, whereas a good stability was obtained with PS. The $\chi^{(2)}$ value for the PS poled film based on this ionic complex was $1.70 \mathrm{pmV}^{-1}$, which is modestly lower than that observed for the neutral

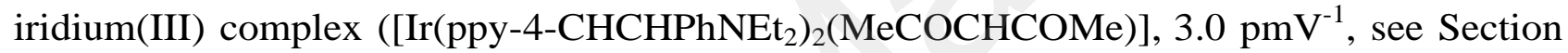
4). This result is of particular importance since it is the first example of an NLO-active polymeric film based on an ionic organometallic complex.

Recently, Qiu et al. [89] investigated computationally iridium(III) complexes bearing two cyclometalating ligands (2,4-difluorophenylpyridine, 2-benzothienylpyridine or 2phenylbenzothiazole) and two monodentate aryl isocyanide ancillary ligands [CNAr(OMe $)_{2}$, CNAr $\left(\mathrm{CF}_{3}\right)_{2}$ or $\left.\mathrm{CNArNO}_{2}\right]$. Using a combination of DFT and TD-DFT calculations, the authors found that the HOMO - LUMO energy gap decreases by increasing the electron-withdrawing properties of the substituent on the aryl isocyanide ligand. As expected, the calculated total first hyperpolarizabilities ( $\beta$ tot) and the projection of $\beta$ on the dipole moment follows the same trend. The complex bearing a combination of two cyclometalating 2-benzothienylpyridines and two 4nitrophenylisocyanide ligands (28, Figure 12) is characterized by the highest second-order NLO response, which is dominated by an LLCT transition from the cyclometalating ligands (where the HOMO is localized) to the isocyanide (where the LUMO is localized). This theoretical study 
beautifully shows how strong NLO response can be achieved using strongly $\pi$-accepting isocyanide ligands.

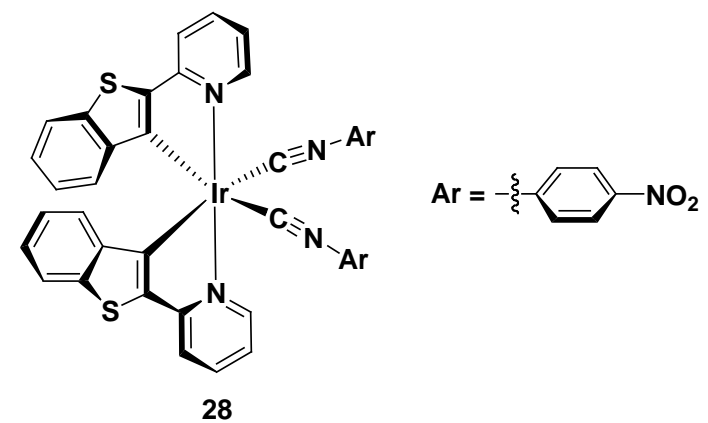

Fig. 12. Iridium(III) complex bearing isocyanide ancillary ligands identified by DFT calculations as having the highest NLO response.

\section{Bis-cyclometalated iridium(III) complexes with redox-switchable second-order NLO activity}

Among NLO active molecular species those with switchable NLO properties are of particular interest since the addition of switchable NLO behaviour increases the applications scope in emerging optoelectronic and photonic technologies [90]. Thus, over the last two decades a lot of work has been devoted to developing materials where the second-order NLO response can be modulated by external stimulus. The quadratic hyperpolarizability may be modified by reversibly manipulating the properties of specific fragments of NLOactive molecules [80, 91-98]. For example, the donor strength of the electron-rich fragment (D) of a typical push-pull, D-linker-A, can be reduced by either oxidation or protonation of this moiety. Conversely, the acceptor strength of the A moiety can be reduced by either reduction or deprotonation. Modulation of the NLO activity can occur by modification of 
the structure of the linker fragment that can result in interference with the electronic communication between D and A fragments. Second-order nonlinear optical switches have been achieved by $\mathrm{pH}$ variations, by redox processes or by interaction with electromagnetic radiations [91-98].

Whereas efficient second-order NLO switches have been reported in the case of ruthenium [17,18,99], zinc [40,55,100], platinum [82,83,101-103], nickel [102], and palladium [102] complexes, to the best of our knowledge no example has been reported involving iridium complexes. Nevertheless, iridium complexes, which have abundant valence states and rich electrochemical properties, could be excellent second-order NLO redox-switch molecular materials, as suggested by recent theoretical investigations [104-106].

The redox-switchable second-order NLO responses of various heteroleptic iridium(III) complexes bearing acetylacetonate (29) or 1,10-phenanthroline (30) as the ancillary ligand and two cyclometalated 2-phenylpyridines (29a, 30a) or substituted analogs bearing ortho (29b, 30b) meta (29c, 30c) or para (29d, 30d) carborane groups (Fig. 13) were studied using DFT methods [104]. 
<smiles></smiles>

29a-d

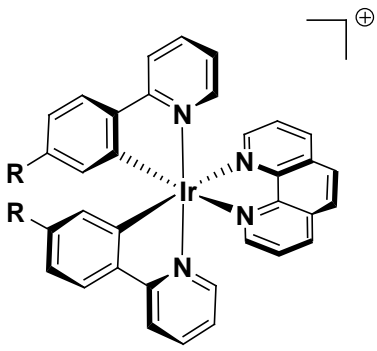

30a-d
Oxidation

Reduction

Oxidation

Reduction

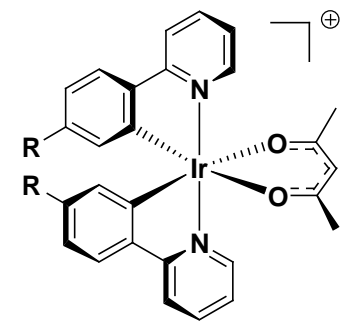

$29^{\circ \times}$ a-d

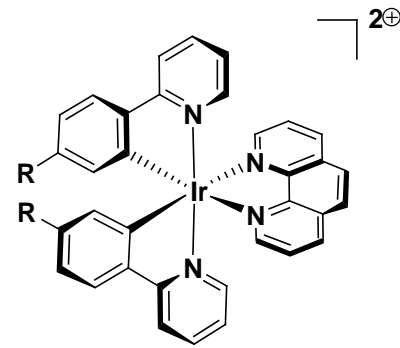

$30^{\mathrm{ox}} \mathrm{a}-\mathrm{d}$ a: $\mathbf{R}=\mathrm{H}$

b: $\mathbf{R}=$ o-carborane
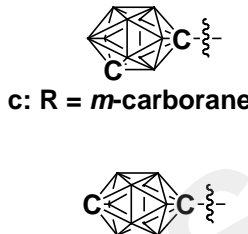

$\mathrm{d}: \mathrm{R}=\boldsymbol{p}$-carborane

Fig. 13. Putative Iridium(III) complexes studied by DFT methods predicted to show redoxswitchable second-order NLO responses.

As expected for the family of 1,10-phenanthroline-containing complexes (see Tables 3 and 6), a higher quadratic hyperpolarizability was calculated for the family of complexes $\mathbf{3 0}$ than for the family of complexes 29. The introduction of the carborane group slightly enhanced the NLO response (by a factor of 1.2-1.6), due to a new MLCT transition between the Ir center and carborane group; this effect is insensitive to the type of carborane. Oxidation of $\mathbf{2 9}$ and $\mathbf{3 0}$ caused a large enhancement of the second-order NLO activity (by a factor of 9 and 5, respectively), suggesting that it is possible to reach a large NLO contrast by redox processes [104].

Qiu et al [105] used a combination of DFT and TD-DFT calculations to predict the effect of the substituent on the ancillary ligand on the multi-state redox switchable NLO response of a series of bis-cyclometalated iridium(III) bearing a diaminocarbene (Fig. 14). 
They choose 2-(2,4-difluorophenyl)pyridine (for 31) and 2-phenylbenzothiazole (for 32) as cyclometalated ligands. One-electron-oxidized complexes and one-electron-reduced complexes were investigated along with the neutral derivatives.

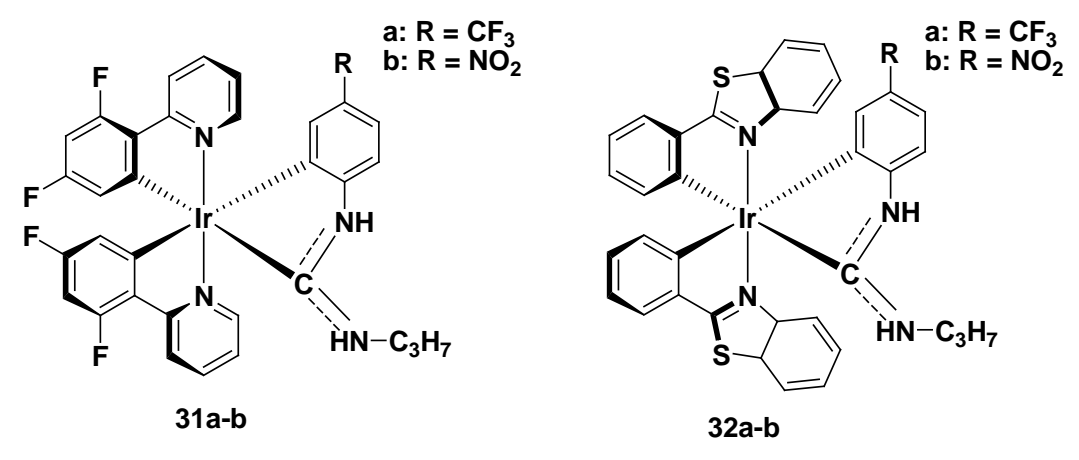

Fig. 14. Bis-cyclometalated iridium(III) complexes predicted to show multi-state redox switchable NLO response.

For the neutral complexes, the HOMO is localized on the cyclometalating aryl ring and the iridium centre while the LUMO is localized on the diaminocarbene fragment. For the oxidized complexes, the Ir/diaminocarbene now act as the electron donor (HOMO) and the cyclometalated ligands act as the acceptors (LUMO) whereas for the reduced complexes it is the opposite. A larger second-order NLO response is reached with the neutral complexes bearing the $\mathrm{NO}_{2}$ group on the diaminocarbene (31a and 32a) compared to the complexes with the $\mathrm{CF}_{3}$ group (31b and $\mathbf{3 2 b}$ ), suggesting that the introduction of strong electron-withdrawing groups on the diaminocarbenes significantly enhances the NLO activity. Complexes 31a and $\mathbf{3 1 b}$ have a larger quadratic hyperpolarizability than 32a and 32b, showing that 2-(2,4-difluorophenyl)pyridine is more suitable than 2-phenylbenzothiazole as the cyclometalated ligand. Remarkably, an improvement of the NLO response occurs on going from the neutral species to the oxidized or reduced ones, leading to a multi-state NLO switch. For example, the $\beta$ values of the one-electron-oxidized complex $\mathbf{3 1 a ^ { + }}$ and 
the one-electron-reduced complex 31a ${ }^{-}$are 5.4 and 12.7 times larger, respectively, than that of the corresponding neutral complex 31a, affording a three-state on/off/on redox-switch. These larger $\beta$ values were attributed to the lower transition energy and to the bathochromic shift of the lowest energy absorption band [105]. Similarly, neutral bis-cyclometalated iridium(III) complexes with 2(2,4-difluorophenyl)pyridines in combination with a chelating dicarbene ancillary ligands are characterized by large $\beta$ values that can be easily modulated by redox processes [106]. The NLO response of the one-electron-reduced complexes are larger compared to that of the oxidized complexes, which themselves are usually larger than that of the neutral parent complex. These theoretical studies suggest that bis-cyclometalated iridium complexes have a great potential as versatile second-order NLO redox-switching materials.

\section{Iridium complexes with two-photon absorption properties}

The rich photophysical properties of iridium complexes have resulted in their use as bioimaging reagents [107-111]. Concerning this application, two-photon absorption (TPA) is of great interest for non-invasive imaging of live cells since this nonlinear process involves the simultaneous absorption of two photons allowing excitation of the iridium complex in the red or near-infra-red region $(600-1100 \mathrm{~nm})$ where tissues are highly transparent $[112,113]$. The efficiency of TPA depends on the energy density at the excitation point. For this reason, compounds with high TPA are suitable for high image resolution [114]. Many TPA-active molecules have been prepared with various symmetries including dipoles (D- $\pi$-A, where $\pi$ stands for a $\pi$-conjugated bridge), quadrupoles (D- $\pi-A-\pi-D$ or $A-\pi-D-\pi-A)$ and octupoles. Among them, metal complexes are fascinating due to their large Stokes' shift, facile colour modulation, and long emission lifetimes, the latter of which is an important property in bioimaging that is exploited to bypass autofluorescence. Therefore, there is an increasing interest in metal complexes, and in particular in iridium complexes, with TPA properties [114]. 
The molecular TPA property is described by the TPA cross-section $\left(\sigma_{\mathrm{TPA}}\right)$, which depends on the imaginary part of the cubic hyperpolarizability of a compound [115]. The unit of measurement of $\sigma_{\text {TPA }}$ is the Göppert-Mayer $\left(1 \mathrm{GM}=1 \times 10^{-50} \mathrm{~cm}^{4} \mathrm{~s}_{\text {photon }}{ }^{-1}\right.$ molecule $\left.{ }^{-1}\right)$. The value of $\sigma_{\mathrm{TPA}}$ can be determined by the two-photon induced fluorescence method, which measures the fluorescence intensity given by two-photon excitation [116], and by the Z-scan technique, which allows to measure both the nonlinear refractive index and nonlinear absorption coefficient $[117,118]$.

The TPA efficiency of second-order NLO-active iridium complexes cis-[ $\operatorname{Ir}(\mathrm{CO})_{2} \mathrm{Cl}(4-$ (para-di-n-butylaminostyryl)pyridine)] (33, Fig. 15) and $\left[\operatorname{Ir}(\mathrm{ppy})_{2}(5-\mathrm{Me}-\mathrm{phen})\right] \mathrm{PF}_{6}$, (18 with $\mathrm{R}=\mathrm{CH}_{3}$, Fig. 7) was investigated by means of the two-photon induced fluorescence technique [119]. The $\sigma_{\text {TPA }}$ value, at $910 \mathrm{~nm}$, for complex 33 is $779 \pm 61 \mathrm{GM}$, a value fourfold larger than that of 4-(para-di-n-butylaminostyryl)pyridine) (190 \pm 34 GM) [120]. This result demonstrates that coordination to an iridium(I) metal center enhances TPA properties to a greater extent than coordination to a $\mathrm{Zn}(\mathrm{II})$ metal centre $[121,122]$. The TPA efficiency for the iridium(III) complex with 5-Me-phen $\left(\sigma_{\mathrm{TPA}}=2.9 \pm 0.5 \mathrm{GM}\right.$ at $\left.910 \mathrm{~nm}\right)$ is much lower than that for complex 33.

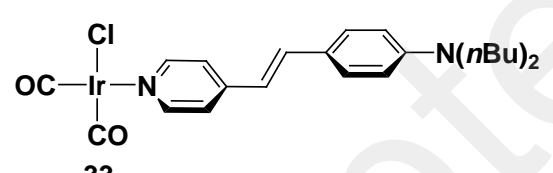

33

Fig. 15. Molecular structure of cis-[Ir(CO) $2 \mathrm{Cl}(4-($ para-di-n-butylaminostyryl)pyridine)]

Remarkably, coordination to “ $\operatorname{Ir}(\mathrm{CO})_{2} \mathrm{Cl}$ ” translates to a 4-fold enhancement of $\sigma_{\mathrm{TPA}}$, reaching a value an order of magnitude higher than that obtained for platinum(II) complexes (between 4 and 20 GM) [123, 124]. This observation acts as a springboard for the use of square planar $\operatorname{Ir}(\mathrm{I})$ complexes in bio-imaging [119].

The two-photon absorption activity of the cationic cyclometalated iridium(III) complex [Ir(ppy-4-CHCHPhNEt $\left.\left.)_{2}\right)_{2}\left(\mathrm{bpy}-\left(\mathrm{CHCHPhNEt}_{2}\right)_{2}\right)\right]\left[\mathrm{PF}_{6}\right]$, (24, Fig. 10), described in section 6, was 
investigated [86]. Its $\sigma_{\text {TPA }}$ values are quite high (100-250 GM at 600-1000 nm) [86]. By contrast to iridium(III) compounds bearing two cyclometalated 2-phenylpyridines and one Ar-vinyl $\pi$ delocalized-substituted bipyridine ancillary ligand, that are characterized by low $\sigma_{\text {TPA }}$ values (45186 GM) [125], complex 24 has less extended $\pi$-delocalized substituents on the bipyridine but it bears them also on the 2-phenylpyridine ligands. The match of the TPA spectrum of the latter complex, carried out in DMSO by means of the z-scan technique on the femtosecond time scale, with the wavelength-doubled one-photon absorption peaks shows that the TPA peaks mostly originate from a dipolar contribution [126]. In complex 24, the asymmetric charge transfer nature of the excited state and the extended $\pi$-conjugation over the whole compound leads to particularly good TPA properties.

Chao et al. studied the TPA response of a series of diimine cyclometalated iridium(III) compounds for applications as biological probes, especially for specific mitochondria [127-129]. The complexes bearing a substituted 2-phenylimidazo[4,5-f][1,10]phenanthroline (Fig. 16) displayed moderate $\sigma_{\mathrm{TPA}}$ values (48.8-65.5 $\mathrm{GM}$ at $750 \mathrm{~nm}$ ) and could therefore be used for mitochondrial imaging and tracking in living cells under two-photon (750 nm) [127].

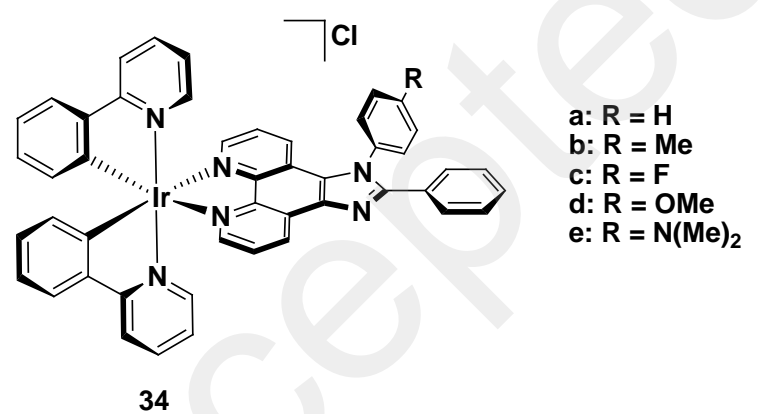

Fig. 16. Cyclometalated $\operatorname{Ir}(\mathrm{III})$ complexes bearing a substituted 2-phenylimidazo[4,5f][1,10]phenanthroline

In a similar manner, heteroleptic cationic iridium compounds bearing substituted bipyridine ligands can enter cells, localize in the mitochondria and signal the excessive presence of $\mathrm{ClO}^{-}$or 
track mitochondrial morphological changes during cell apoptosis even under hypoxia, highlighting the potential of such complexes as sensors of biomedically relevant analytes (Fig. 17) [128].

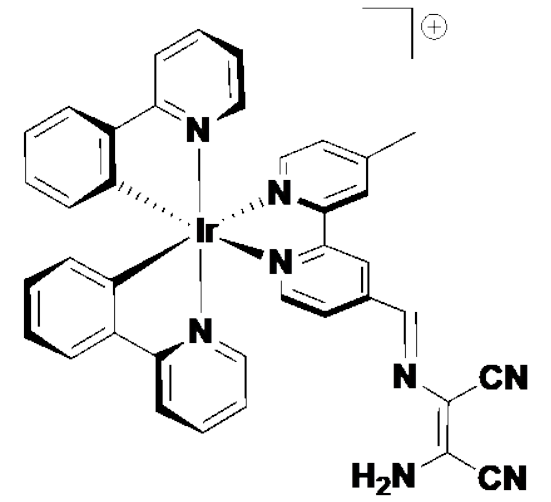

not emissive

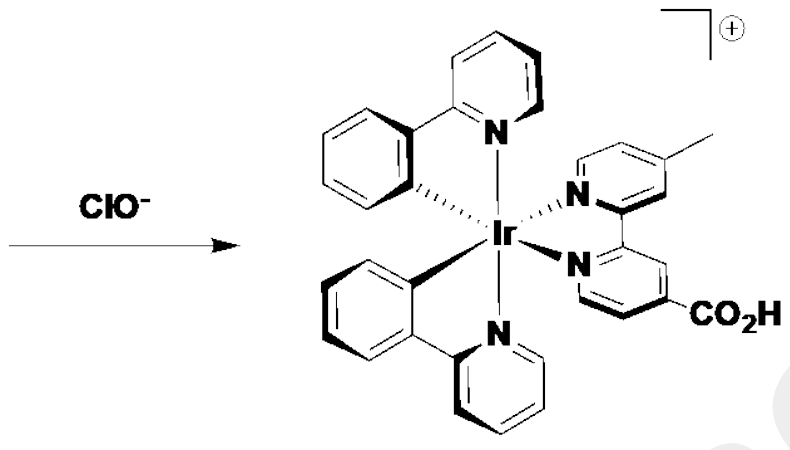

emissive even with two-photon exctiation

Fig. 17. Molecular structures of the iridium(III) probe and its oxidized product

The TPA activity of a number of other iridium(III) complexes has been reported and selected examples are described below. The near-infrared TPA spectra of a family of homoleptic and heteroleptic cyclometalated iridium compounds (Fig. 18) were reported [130]. 


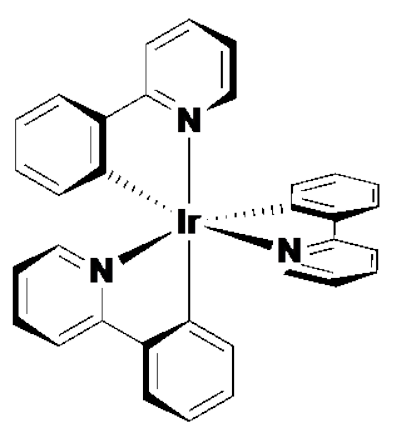

$\operatorname{Ir}(\mathbf{p p y})_{3}$

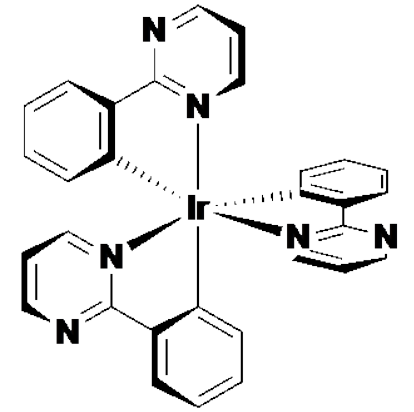

$\operatorname{Ir}(\mathbf{p p m})_{3}$

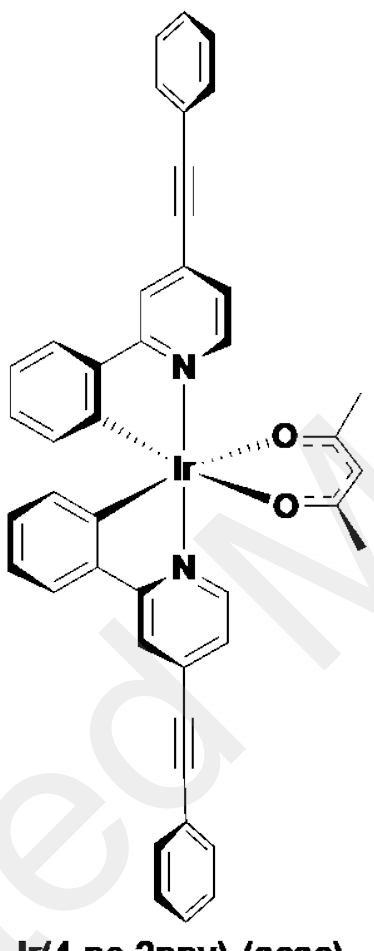

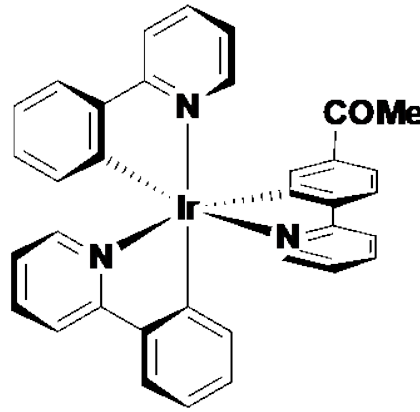

Ir(ppy)z(fppy)

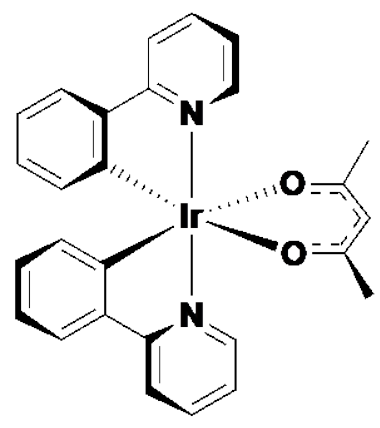

$\operatorname{Ir}(\mathbf{p p y})_{2}(\mathbf{a c a c})$

\section{Ir(4-pe-2ppy) 2 (acac)}

Fig. 18. Molecular structures of some iridium(III) complexes studied by Beeby et al.

These compounds are characterized by $\sigma_{\mathrm{TPA}}$ values of $20 \mathrm{GM}$ at $800 \mathrm{~nm}$. The complex $\operatorname{Ir}(4-$ pe-2-ppy) 2 (acac), where (4-pe-2-ppyH is 4-phenylethynyl-2-phenylpyridinato, was found to display a cross-section more than twice that of $\operatorname{Ir}(\mathrm{ppy})_{2}(\mathrm{acac})$ at $800 \mathrm{~nm}$; the extent of charge separation upon excitation enhances the ability of these molecules to undergo TPA.

Near-infrared excitation (via TPA) of the heteroleptic iridium complex 35, characterized by a low cytotoxicity, was reported for in vitro Golgi imaging in HeLa and A549 cell lines (Fig. 19; $\sigma_{\text {TPA }}$ of $350 \mathrm{GM}$ at $750 \mathrm{~nm}$ in DMSO) [131]. 


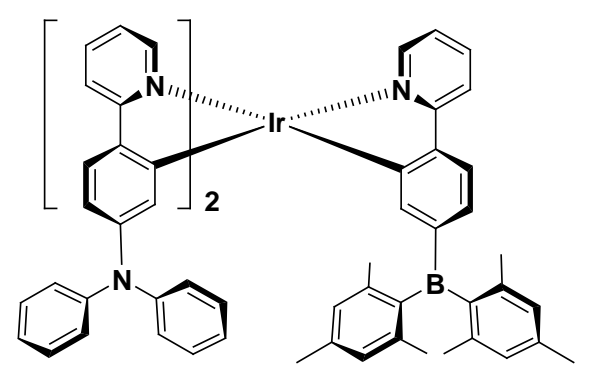

35

Fig. 19. Molecular structure of the tris-cyclometalated Ir(III) complex 35

More recently, a series of symmetrically and unsymmetrically, para- or ortho- substituted phenylpyridine-containing complexes with oligofluorene groups were reported to exhibit prominent two- and three-photon absorption properties [132]. The oligofluorene was incorporated to extend the $\pi$-conjugation length of the ligands and thus promote the NLO properties of the compounds. The TPA response was found to be proportional to the length of the conjugated ligand. With three fluorene units present the $\sigma_{\text {TPA }}$ values are enhanced fourfold compared to the complex with only a single fluorene. Furthermore, if a donor carbazole group were added at the periphery of the ligand, TPA is further improved, reaching values slightly lower than 1200 GM. These oligofluorene-based iridium complexes are among those with the largest TPA cross-sections reported in the literature.

In summary, both $\operatorname{Ir}(\mathrm{I})$ and $\operatorname{Ir}(\mathrm{III})$ complexes can present large $\sigma_{\mathrm{TPA}}$ values and thus large TPA cross-section materials are accessible with tunable emission properties for applications in photonics and biomedicine [133,134].

\section{Concluding remarks}


This trip surveying the nonlinear optical properties of iridium complexes illustrates the molecular structure-NLO activity relationship and also puts into evidence the great potential of these coordination compounds as NLO chromophores.

Various iridium(I) complexes with monodentate $\pi$-delocalized nitrogen donor ligands along with many homoleptic and heteroleptic iridium(III) complexes have been investigated as NLOactive compounds. Several of these reported complexes are characterized by large $\mu \beta_{\lambda}(\mathrm{EFISH})$ values, higher than $2000 \times 10^{-48}$ esu, that are favourably compared to that of the organic compound Disperse Red One ((trans-4,4' $-\mathrm{O}_{2} \mathrm{NC}_{6} \mathrm{H}_{4} \mathrm{~N}=\mathrm{NC}_{6} \mathrm{H}_{4} \mathrm{NEt}\left(\mathrm{CH}_{2} \mathrm{CH}_{2} \mathrm{OH}\right), \mu \beta($ EFISH $)=c a 500 \times 10^{-48}$ esu).

In the case of iridium(I) complexes with pyridine-like ligands, the highest second-order NLO response is obtained when the pyridine bears a strong donor group such as an amino substituent and there is an extended $\pi$-delocalized bridge between the pyridine ring and the donor group. Thus, cis[Ir(CO) $)_{2} \mathrm{Cl}\left(4,4^{\prime}\right.$-trans,trans- $\left.\left.\mathrm{NC}_{5} \mathrm{H}_{4}(\mathrm{CH}=\mathrm{CH})_{2} \mathrm{C}_{6} \mathrm{H}_{4} \mathrm{NMe}_{2}\right)\right]$ stands out with a five-fold enhanced NLO activity with respect to both the ligand itself and Disperse Red One. This is due to two factors: an increase of the dipole moment $\mu$ upon coordination and in parallel an increase of the quadratic hyperpolarizability due to a bathochromic shift of the ILCT transition. In this kind of complex, the iridium(I) center plays the role of an acceptor group and for this reason the role of the $\pi$-acid carbonyl co-ligands is important; in fact substitution of the carbonyls by cyclooctenes leads to a significant reduction of the quadratic hyperpolarizability although it causes a slight increase of the dipole moment.

Iridium(III) complexes with terpyridines can also show excellent NLO responses. In these complexes the iridium center acts as a donor and the emissive state is MLCT in nature. For this reason, a much higher response is obtained with a nitro than with an amino group on the terpyridine; the most NLO-active complex reported is $\left[\mathrm{Ir}\left(4-\mathrm{EtPhCO}_{2}\right)_{3}\left(4^{\prime}-\left(\mathrm{C}_{6} \mathrm{H}_{4}-p-\mathrm{NO}_{2}\right) 2,2^{\prime}: 6^{\prime}, 2^{\prime \prime}-\right.\right.$ terpyridine)]. 
Heteroleptic neutral bis-cyclometalated $\operatorname{Ir}(\mathrm{III})$ complexes containing a $\pi$-delocalized $\beta$ diketonate ancillary ligand show a good NLO response that is governed by $\pi-\pi^{*}$ ILCT transitions involving mainly the cyclometalated ligands. Iridium(III) complexes with three cyclometalated phenylpyridine substituted with $\pi$-delocalized donor groups on the phenyl or the pyridine ring can also reach good quadratic hyperpolarizabilities, mainly controlled by the octupolar part as evidenced by a combination of EFISH and HLS data. The highest second-order NLO responses occur in heteroleptic iridium complexes containing a strongly $\pi$-accepting phenanthroline or bipyridine ancillary ligand. Incorporation of a triphenylamino group para to the pyridine ring of the cyclometallating ligand is a productive strategy to further increase the NLO response. Theoretical studies suggest that bis-cyclometalated iridium(III) complexes bearing strongly $\pi$-accepting aryl isocyanide ancillary ligands will also show high NLO activity; the presence of electronwithdrawing substituents on the aryl isocyanide are predicted to provide the highest NLO response. DFT and TD-DFT calculations also suggest that the use of acetylacetonate, 1,10-phenanthroline, diaminocarbene, or chelating dicarbene as ancillary ligands in heteroleptic iridium complexes are also avenues to produce materials with versatile second-order NLO redox-switching properties.

Clearly, the interaction with an iridium center is an elegant way to tune the second order NLO response of organic chromophores. Through the modulation of the oxidation state of this metal and the choice of ligands such a response can be not only increased, sometimes quite significantly, but also its sign can be changed. The use of SOS and TD-DFT theoretical approaches have provided a means to understand the origin of the second order NLO properties of iridium complexes.

Excellent second-order NLO responses have been reached. Thermal and chemical stability should now be considered. Nanoorganization of NLO-active iridium compounds, for example in Langmuir-Blodgett films or polymeric films, has been achieved but much work remains in order to reach large and stable SHG. Looking forward, experimental efforts will surely be dedicated to achieving an efficient photo- or redox-switchability of the second order NLO activity. Iridium 
complexes are fascinating for their second-order NLO properties and for their potential as multifunctional materials, for example, combining second-order NLO, two-photon absorption and luminescence properties. At the end of our trip, we saw that both $\operatorname{Ir}(\mathrm{I})$ and $\operatorname{Ir}(\mathrm{III})$ complexes can present large TPA cross-sections and thus large TPA cross-section materials are accessible with tunable emission properties for applications in photonics and biomedicine.

\section{Acknowledgment}

We thank MIUR and the National Interuniversity Consortium of Materials Science and Technology (Project INSTMMI012) for support.

\section{References}

[1] N.P. Prasad, D.J. Williams, Introduction to Nonlinear Optical Effects in molecules and Polymers, Wiley 1991

[2] J. Zyss, Molecular Nonlinear Optics: Materials, Physics and Devices, Academic Press, Boston, 1994.

[3] Optoelectronic Properties of Inorganic Compounds; D.M. Roundhill, J.P. Fackler Jr Ed.; Plenum Press: New York, 1999.

[4] M.L.H. Green, S.R. Marder, M.E. Thompson, J.A. Bandy, D. Bloor, P.V. Kolinsky, R.J. Jones, Synthesis and structure of (cis)-[1-ferrocenyl-2-(4-nitrophenyl) ethylene], an organotransition metal compound with a large second-order optical nonlinearity, Nature 330 (1987) 360-362.

[5] H.S. Nalwa, Organometallic materials for nonlinear optics, Appl. Organomet. Chem. 5 (1991) 349-377.

[6] S.R. Marder, in Inorganic Materials, eds. D.W. Bruce and D. O’Hare D, Wiley, New York, (1992) 115-164.

[7] N.J. Long, Organometallic Compounds for Nonlinear Optics-The Search for En-light-enment!, Angew. Chem. Int. Ed. Engl. 34 (1995) 21-38.

[8] I.R. Whittall, A.M. McDonagh, M.G. Humphrey, S. Samoc, Organometallic Complexes in Nonlinear Optics I: Second-Order Nonlinearities, Adv. Organomet Chem. 42 (1998) 291-362

[9] J. Heck S. Dabek, T. Meyer-Friedrichsen, H. Wong, Mono-and dinuclear sesquifulvalene complexes, organometallic materials with large nonlinear optical properties, Coord. Chem. Rev. 190-192 (1999) 1217-1254. 
[10] H. Le Bozec, T. Renouard, Dipolar and Non-Dipolar Pyridine and Bipyridine Metal Complexes for Nonlinear Optics, Eur. J. Inorg. Chem. (2000) 229-239.

[11] C.E. Powel, M. G. Humphrey, Nonlinear otical properties of transition metal acetylides and their derivatives, Coord. Chem. Rev. 248 (2004) 725-756.

[12] S. Di Bella, Second-order nonlinear optical properties of transition metal complexes, Chem. Soc. Rev. 30 (2001) 35 5-366.

[13] B.J. Coe, in Comprehensive Coordination Chemistry II; J.A. McCleverty, T.J. Meyer TJ Eds.; Elsevier Pergamon Oxford, U.K., Nonlinear Optical Properties of Metal Complexes, 9 (2004) 621-687.

[14] B.J. Coe, N.R.M. Curati, Metal complexes for molecular electronics and photonics, Comments on Inorg. Chem. 25 (2004) 147-184.

[15] O. Maury, H. Le Bozec, Molecular Engineering of Octupolar NLO Molecules and Materials Based on Bipyridyl Metal Complexes, Acc. Chem. Res. 38 (2005) 691-704.

[16] E. Cariati, M. Pizzotti, D. Roberto, F. Tessore, R. Ugo, Coordination and organometallic compounds and inorganic-organic hybrid crystalline materials for second-order non-linear optics, Coord Chem Rev. 250 (2006) 1210-1233.

[17] B.J. Coe, Switchable nonlinear optical metallochromophores with pyridinium electron acceptor groups, Acc. Chem. Res. 39 (2006) 383-393.

[18] B.J. Coe in Non-Linear Optical Properties of Matter (G. Papadopoulos, Manthos, Sadlej, Andrzej J., J. Leszczynski, Jerzy eds), Ruthenium Complexes as Versatile Chromophores with Large, Switchable Hyperpolarizabilities, (2006) 571-608.

[19] J.P. Morrall, G.T. Dalton, M.G. Humphrey, M. Samoc, Organotransition metal complexes for nonlinear optics, Adv. Organomet. Chem. 55 (2007) 61-136.

[20] S. Di Bella, C. Dragonetti, M. Pizzotti, D. Roberto, F. Tessore, R. Ugo, in Topics in Organometallic Chemistry 28. Molecular Organometallic Materials for Optics, H. Le Bozec, V. and Guerchais (eds.), Springer Verlag Berlin Heidelberg 28 (2010), 1.

[21] O. Maury, H. Le Bozec, In Molecular Materials; Eds: D.W. Bruce, D. O’Hare, R.I. Walton, Wiley: Chichester, Metal-based quadratic molecular materials, (2010), chap 1.

[22] M.G. Humphrey, T. Schwich, P.J. West, M.P. Cifuentes, M. Samoc, In Comprehensive Inorganic Chemistry II (Second Edition): From Elements to Applications, Elsevier: Oxford, U.K., Vol 8 (2013).

[23] M. Pizzotti, R. Ugo, D. Roberto, S. Bruni, P. Fantucci, C. Rovizzi, Organometallic Counterparts of Push-Pull Aromatic Chromophores for Nonlinear Optics: Push-Pull 
Heteronuclear Bimetallic Complexes with Pyrazine and trans-1,2-bis(4-pyridyl)ethylene as Linkers, Organometallics 21 (2002) 5830-5840.

[24] J.L. Oudar, D.S. Chemla, Hyperpolarizabilities of the nitroanilines and their relations to the excited state dipole moment, J. Chem. Phys. 66 (1977) 2664-2668.

[25] J.L. Oudar, Optical nonlinearities of conjugated molecules. Stilbene derivatives and highly polar aromatic compounds, J. Chem. Phys. 67 (1977) 446-457.

[26] D.R. Kanis, M.A. Ratner, T.J. Marks, Optical nonlinearities of conjugated molecules. Stilbene derivatives and highly polar aromatic compounds, Chem. Rev. 67 (1994) 195-242.

[27] L.T. Cheng, W. Tam, S.H. Stevenson, G.R. Meredith, G. Rikken, S.R. Marder, Experimental investigations of organic molecular nonlinear optical polarizabilities. 1. Methods and results on benzene and stilbene derivatives, J Phys Chem 95 (1991) 10631-10643.

[28] L.T. Cheng, W. Tam, S.R. Marder, A.E. Stiegman, G. Rikken, C.W. Spangler, Stronger acceptors can diminish nonlinear optical response in simple donor-acceptor polyenes, J. Phys. Chem. 95 (1991) 10643-10652.

[29] L. Beverina, R. Ruffo, G. Patriarca, F. De Angelis, D. Roberto, S. Righetto, R. Ugo, G.A. Pagani, Second harmonic generation in nonsymmetrical squaraines: tuning of the directional charge transfer character in highly delocalized dyes, J. Mater. Chem. 19 (2009) 8190-8197 and references therein.

[30] L.R. Dalton, P.A. Sullivan, D.H. Bale, Electric Field Poled Organic Electro-optic Materials: State of the Art and Future Prospects, Chem. Rev. 110 (2010) 25-55.

[31] K.D. Singer, E. Sohn, L .A.King, K.M. Gordon, H.E. Katz, P.W. Dirk, Second-order nonlinear-optical properties of donor-and acceptor-substituted aromatic compounds, J. Opt. Soc. Am. B 6 (1989) 1339.

[32] M.A.L. Marques MAL, E.K.U. Gross EKU, Time-dependent density functional theory, Annual Rev. Phys. Chem. 55 (2004) 427-455.

[33] I. Ledoux, J. Zyss, Influence of the molecular environment in solution measurements of the second-order optical susceptibility for urea and derivatives, Chem. Phys. 73 (1982) 203-213.

[34] E.A. Guggenheim, A proposed simplification in the procedure for computing electric dipole moments, Trans. Faraday Soc. 45 (1949) 714-720.

[35] P.D. Maker, Spectral broadening of elastic second-harmonic light scattering in liquids, Phys. Rev. A 1 (1970) 923-951.

[36] K. Clays, K.; Persoons, A. Hyper-Rayleigh scattering in solution, Phys. Rev. Lett. 66 (1991) 2980-2983. 
[37] J. Zyss, Molecular engineering implications of rotational invariance in quadratic nonlinear optics: From dipolar to octupolar molecules and materials, J. Chem. Phys. 98 (1993) 65836600.

[38] J. Zyss, I. Ledoux, Nonlinear optics in multipolar media: theory and experiments, Chem. Rev. 94 (1994) 77-105.

[39] B.J. Coe, Developing iron and ruthenium complexes for potential nonlinear optical applications, Coord. Chem. Rev. 257 (2013) 1438-1458.

[40] S. Di Bella, A. Colombo, C. Dragonetti, S. Righetto, D. Roberto, Zinc(II) as a versatile template for the preparation of fascinating dipolar and octupolar second-order nonlinear optical molecular materials, Inorganics 6 (2018) 133.

[41] C. Dragonetti, A. Colombo, D. Marinotto, S. Righetto, D. Roberto, A. Valore, M. Escadeillas, V. Guerchais, H. Le Bozec, A. Boucekkine, C. Latouche, Functionalized styryl Iridium(III) complexes as active second-order NLO chromophores and building blocks for SHG polymeric films, J. Organomet. Chem. 751 (2014) 568-572.

[42] E. Zysman-Colman, Iridium(III) in Optoelectronic and Photonics Applications 2017 John Wiley \& Sons Ltd.

[43] D.W. Bruce, A. Thornton, Electronic Hyperpolarisabilities of Some Mesogenic Stilbazole Complexes of Rh (I) and Ir (I), Mol. Cryst. Liq. Cryst. 231 (1993) 253-256.

[44] D. Roberto, R. Ugo, S. Bruni, E. Cariati, F. Cariati, P.C. Fantucci, I. Invernizzi, S. Quici, I. Ledoux, J. Zyss, Quadratic Hyperpolarizability Enhancement of para-Substituted Pyridines Upon Coordination to Organometallic Moieties: the Ambivalent Donor or Acceptor Role of the Metal, Organometallics 19 (2000) 1775-1788.

[45] D. Locatelli, S. Quici, D. Roberto, F. De Angelis, The Unexpected Similar Second Order NLO Response for Nearly Planar and Largely Twisted Push-Pull Stilbazole Chromophores: an EFISH and Theoretical TD-DFT Evidence, Chem. Commun. (2005) 5405-5407.

[46] V. Calabrese, S. Quici, E. Rossi, E. Cariati, C. Dragonetti, D. Roberto, E. Tordin, F. De Angelis, S. Fantacci, Highly stable 7-N,N-dibutylamino-2-azaphenanthrene and 8-N,Ndibutylamino-2-azachrysene as a new class of second order NLO-active chromophores Chem. Commun. 4(2010) 8374-8376.

[47] L.-T. Cheng, W. Tam, D. F. Eaton, Quadratic hyperpolarizabilities of Group 6A metal carbonyl complexes, Organometallics 9 (1990) 2856-2857.

[48] D.R. Kanis, P.G. Lacroix, M.A. Ratner, T.J. Marks, Electronic Structure and Quadratic Hyperpolarizabilities in Organotransition Metal Chromophores Having Weakly Coupled $\pi$ - 
Networks. Unusual Mechanisms for Second-Order Response, J. Am. Chem. Soc. 116 (1994) 10089-10102.

[49] M. Pizzotti, R. Ugo, C. Dragonetti, E. Annoni, F. Demartin, P. Mussini, Unexpected Formation of a Week Metal-Metal Bond: Synthesis, Electronic Properties and Second-Order NLO Responses of Push-Pull Late-Early Heteronuclear Bimetallic Complexes with [W(CO)3(1,10-phenantroline)] Acting as a Donor Ligand.Organometallics 22 (2003) 40014011.

[50] D. Roberto, F. Tessore, R. Ugo, S. Bruni, A. Manfredi, S. Quici, Terpyridine Zn(II), Ru(III) and $\operatorname{Ir}(\mathrm{III})$ complexes as new asymmetric chromophores for nonlinear optics: first evidence for a shift from positive to negative value of the quadratic hyperpolarizability of a ligand carrying an electron donor substituent upon coordination to different metal centres. Chem. Commun. (2002) 846-847.

[51] F. Tessore, D. Roberto, R. Ugo, M. Pizzotti, S Quici, M. Cavazzini, S. Bruni, F. De Angelis, Terpyridine Zn(II), Ru(III), and Ir(III) Complexes: The Relevant Role of the Nature of the Metal Ion and of the Ancillary Ligands on the Second-Order Nonlinear Response of Terpyridines Carrying Electron Donor or Electron Acceptor Groups. Inorg. Chem. 44 (2005) 8967-8978.

[52] D. Locatelli, S. Quici, S. Righetto, D. Roberto, F. Tessore, G.J. Ashwell, M. Amiri, Secondharmonic generation from monolayer Langmuir-Blodgett films of various push-pull pyridine and terpyridine metal complexes. Progress in Solid State Chemistry 33 (2005) 223-232.

[53] M. Bourgault, K. Baum, H. Le Bozec, G. Pucetti, I. Ledoux, J. Zyss, Synthesis and molecular hyperpolarisabilities of donor-acceptor bipyridyl metal complexes (M= Re, Zn, Hg), New J. of Chem. (1998) 517-522.

[54] F. Tessore, D. Roberto, R. Ugo, P. Mussini, S. Quici, I. Ledoux-Rak, J. Zyss, Large, Concentration-Dependent Enhancement of the Quadratic Hyperpolarizability of $\left[\mathrm{Zn}\left(\mathrm{CH}_{3} \mathrm{CO}_{2}\right)_{2}(\mathrm{~L})_{2}\right]$ in $\mathrm{CHCl}_{3}$ on Substitution of Acetate by Triflate, Angew. Chem. Int. Ed. 42 (2003) 456-459.

[55] V. Aubert, V. Guerchais, E. Ishow, K. Hoang-Thy, I. Ledoux, K. Nakatani, H. Le Bozec, Efficient Photoswitching of the Nonlinear Optical Properties of Dipolar Photochromic Zinc(II) Complexes. Angew. Chem. Int. Ed. 47 (2008) 577-580.

[56] A. Colombo, C. Dragonetti, S. Righetto, D. Roberto, A. Valore, T. Benincori, F. Colombo, F. Sannicolò, Novel highly conjugated push-pull 4,5-diazafluoren-9-ylidene based efficient NLO chromophores as a springboard for coordination complexes with large second-order NLO properties. J. Mater. Chem. 22 (2012) 19761-19766. 
[57] A. Valore, A. Colombo, C. Dragonetti, S. Righetto, D. Roberto, R. Ugo, F. De Angelis, S. Fantacci, Luminescent cyclometalated $\operatorname{Ir}(\mathrm{III})$ and $\mathrm{Pt}(\mathrm{II})$ complexes with $\beta$-diketonate ligands as highly active second-order NLO chromophores. Chem. Commun. 46 (2010) 2414-2416.

[58] R. Macchi, E. Cariati, D. Marinotto, D. Roberto, E. Tordin, R. Ugo, R. Bozio, M. Cozzuol, D. Pedron, G. Mattei, Stable SHG from in situ grown oriented nanocrystals of [(E)-N,Ndimethylamino- $N$ '-methylstilbazolium][p-toluenesulfonate] in a PMMA film J. Mater. Chem. 20 (2010) 1885-1890.

[59] M. Zaarour,V. Guerchais, H. Le Bozec, C. Dragonetti, S. Righetto, D. Roberto, F. De Angelis, S. Fantacci, M. Grazia Lobello; An investigation on the second order nonlinear optical of tris-cyclometallated Ir(III) complexes with variously substituted 2-phenylpyridines. Dalton. Trans. 42 (2013) 155-159.

[60] M. Zaarour, A. Singh, C. Latouche, J. A. G. Williams, I. Ledoux-Rak, J. Zyss, A. Boucekkine, H. Le Bozec, V. Guerchais, C. Dragonetti, A. Colombo, D. Roberto, A Valore, Linear and Nonlinear Optical Properties of Tris-cyclometalated Phenylpyridine Ir(III) Complexes Incorporating $\pi$-Conjugated Substituents, Inorg. Chem. 52 (2013) 7987-7994.

[61] Breu, J.; Stössel, P.; Schrader, S.; Starukhin, A; Finkenzeller, W. J.; Yersin, H. J., Crystal structure of fac- $\operatorname{Ir}(\mathrm{ppy})_{3}$ and emission properties under ambient conditions and at high pressure, Chem. Mater. 17 (2005) 1745-1752.

[62] T. Le Bouder, L. Viau, J.-P. Guégan, O. Maury, H. Le Bozec, Hydroxy-Functionalized Bipyridine and Tris(bipyridine) metal Chromophores: Synthesis and Optical Properties, Eur. J. Org. Chem. (2002) 3024-3033.

[63] C.G. Claessens, D. Gonzalez-Rodriguez, T. Torres. G. Martin, F. Agullo-Lopez; I. Ledoux, J. Zyss, V.R. Ferro, J. Garcia de la Vega, Structural Modulation of the Dipolar- Octupolar Contributions to the NLO Response in Subphthalocyanines, J. Phys. Chem. B 109 (2005) 3800-3809.

[64] M.S. Lowry, S. Bernhard, Synthetically tailored excited states: phosphorescent, cyclometalated iridium (III) complexes and their applications, Chem. Eur. J. 12 (2006) 7970-7977.

[65] F. De Angelis S. Fantacci, N. Evans, C. Klein, S.M. Zakeeruddin, J.E. Moser, K. Kalyanasundaram, H.J. Bolink, M. Graetzel, M.K. Nazeeruddin, Controlling phosphorescence color and quantum yields in cationic iridium complexes: a combined experimental and theoretical study, Inorg. Chem. 46 (2007) 5989-6001.

[66] Q. Zhao, S. Liu, M. Shi, C. Wang, M. Yu, L. Li, F. Li, T. Yi, C. Huang, Series of New Cationic Iridium(III) Complexes with Tunable Emission Wavelength and Excited State 
Properties: Structures, Theoretical Calculations, and Photophysical and Electrochemical Properties, Inorg. Chem. 45 (2006) 6152-6160.

[67] H.J. Bolink, E. Cappelli, E. Coronado, M. Graetzel, E. Orti, R.D. Costa, P. M. Viruela Md. K. Nazeeruddin, Stable single-layer light-emitting electrochemical cell using 4, 7-diphenyl-1, 10phenanthroline-bis (2-phenylpyridine) iridium (III) hexafluorophosphate J. Am. Chem. Soc. 128 (2006) 14786-14787.

[68] C. Dragonetti, L. Falciola, P. Mussini, S. Righetto, D. Roberto, R. Ugo, A. Valore, F. De Angelis, S. Fantacci, A. Sgamellotti, M. Ramon, M. Muccini, The Role of Substituents on Functionalized 1,10-Phenanthroline in Controlling the Emission Properties of Cationic Iridium(III) Complexes of Interest for Electroluminescent Devices, Inorg. Chem. 46 (2007) 8533-8547.

[69] C. Dragonetti, S. Righetto, D. Roberto, R. Ugo, A. Valore, S. Fantacci, A. Sgamellotti, F. De Angelis, Cyclometallated Iridium(III) complexes with substituted 1,10-phenanthrolines: a new class of highly active organometallic second order NLO-phores with excellent transparency with respect to second harmonic emission, Chem. Commun. 40 (2007) 41164118.

[70] V. Alain, M. Blanchard-Desce, I. Ledoux-Rak, J. Zyss, Amphiphilic polyenic push-pull chromophores for nonlinear optical applications, Chem. Commun. (2000) 353-354.

[71] C. Dragonetti, S. Righetto, D. Roberto, A. Valore, T. Benincori, F. Sannicolò, F. De Angelis, S. Fantacci, Cationic cyclometallated iridium(III) complexes with substituted 1,10phenanthrolines: the role of the cyclometallated moiety on this new class of complexes with interesting luminescent and second order non linear optical properties, J Mater Sci: Mater. Electron (2009) 20:S460-S464.

[72] C. Dragonetti, S. Righetto, D. Roberto, A. Valore, The role of the cyclometalated moiety on the second order nonlinear optical properties of cationic Ir(III) organometallic NLOphores. Phys. Status Solid C 6 (2009) S50-S53.

[73] C. Dragonetti, S. Righetto, D. Roberto, R. Ugo, A. Valore, F. Demartin, F. De Angelis, A. Sgamellotti, S. Fantacci, The role of 5-R-1,10-phenanthroline $\left(\mathrm{R}=\mathrm{CH}_{3}, \mathrm{NO}_{2}\right)$ on the emission properties and second order NLO response of cationic Ir(III) organometallic chromophores. Inorg. Chim. Acta 61 (2008) 4070-4076.

[74] A. Valore, E. Cariati, C. Dragonetti, S. Righetto, D. Roberto, R. Ugo, F. De Angelis, S.

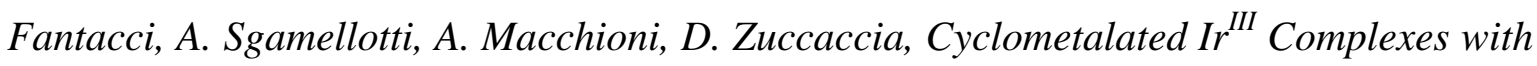
Substituted 1,10-Phenanthrolines: A New Class of Efficient Cationic Organometallic Second-Order NLO Chromophores. Chem. Eur. J. 16 (2010) 4814-4825. 
[75] A. Valore, M. Balordi, A. Colombo, C. Dragonetti, S. Righetto, D. Roberto, R. Ugo, T. Benincori, G. Rampinini, F. Sannicolò, F. Demartin, Novel ruthenium(II) complexes with substituted 1,10-phenanthroline or 4,5-diazafluorene linked to a fullerene as highly active second order NLO chromophores, Dalton. Trans. 39 (2010) 10314-10318.

[76] C. Dragonetti, A. Valore, A. Colombo, S. Righetto, G. Rampinini, F. Colombo, L. Rocchigiani, A. Macchioni, An investigation on the second-order NLO properties of novel cationic cyclometallated $\operatorname{Ir}(\mathrm{III})$ complexes of the type [Ir(2-phenylpyridine) $2(9-\mathrm{R}-4,5-$ diazafluorene $]^{+}(\mathrm{R}=\mathrm{H}$, fulleridene) and the related neutral complex with the new 9fulleriden-4-monoazafluorene ligand, Inorg. Chim. Acta 382 (2012) 72-78.

[77] V. Aubert, L. Ordronneau, M. Escadeillas, J.A.G. Williams, A. Boucekkine, E. Coulaud, C. Dragonetti, S. Righetto, D. Roberto, R. Ugo, A. Valore, A. Singh, J. Zyss, I. Ledoux-Rak, H. Le Bozec, V. Guerchais, Linear and nonlinear optical properties of cationic bipyridyl iridium(III) complexes: tunable and photoswitchable? Inorg. Chem. 50 (2011) 5027-5038.

[78] M. Irie, Diarylethenes for memories and switches, Chem. Rev. 100 (2000) 1685-1716.

[79] H. Le Bozec, V. Guerchais, Photochromic bipyridyl metal complexes: Photoregulation of the nonlinear optical and/or luminescent properties, Comptes Rendus Chimie 16 (2013), 11721182.

[80] V. Guerchais, L. Ordronneau, H. Le Bozec, Recent developments in the field of metalcomplexes containing photochromic ligands: Modulation of linear and nonlinear optical properties, Coord. Chem. Rev. 254 (2010) 2533-2545.

[81] D. Marinotto, R. Castagna, S. Righetto, C. Dragonetti, A. Colombo, C. Bertarelli, M. Garbugli, G. Lanzani, Photoswitching of the Second Harmonic Generation from Poled PhenylSubstituted Dithienylethenes Thin Film and EFISH Measurements. J. Phys. Chem. C. 115 (2011) 20425-20432.

[82] J. Boixel, V. Guerchais, H. Le Bozec, D. Jacquemin, A. Amar, A. Boucekkine, A. Colombo, C. Dragonetti, D. Marinotto, D. Roberto, S. Righetto, R. De Angelis, Second-order NLO switches from molecules to polymer films based on photochromic cyclometalated platinum(II) complexes, J. Am. Chem. Soc. 136 (2014) 5367-5375.

[83] J. Boixel, V. Guerchais, H. Le Bozec, A. Chantzis, D. Jacquemin, A. Colombo, C. Dragonetti, D. Marinotto, D. Roberto, Sequential double second-order nonlinear optical switch by an acido-triggered photochromic cyclometallated platinum(II) complex, Chem. Comm., 71 (2015) 7805-7808. 
[84] V. Aubert, V. Guerchais, E. Ishow, K. Hoang-Thi, I. Ledoux, K. Nakatani, H. Le Bozec, Efficient photoswitching of the nonlinear optical properties of dipolar photochromic zinc (II) complexes, Angew. Chem. Int. Ed. 47 (2008) 577-580.

[85] V. Aubert, E. Ishow, V. Guerchais, H. Le Bozec, F. Ibersiene, A. Boucekkine, L. Toupet, R. Métivier, J.A.G. Williams, A "reverse interrupter": the novel molecular design of a fluorescent photochromic DTE-based bipyridine, New. J. Chem. 33 (2009), 1320-1323.

[86] A. Colombo, E. Garoni, C. Dragonetti, S. Righetto, D. Roberto, N; Baggi, M. Escadeillas, V. Guerchais, K. Kamada, A novel multifunctional cyclometallated iridium(III) complex with interesting second-order nonlinear optical properties and two-photon absorption activity, Polyhedron 140 (2018) 116-121.

[87] C. Hierlinger, D.B. Cordes, A.M.Z. Slawin, A. Colombo, C. Dragonetti, S. Righetto, D. Roberto, D. Jacquemin, E. Zysman-Colman, V. Guerchais, An investigation on the secondorder nonlinear optical response of cationic bipyridine or phenanthroline iridium(III) complexes bearing cyclometallated 2-phenylpyridines with a triphenylamine substituent, Dalton Trans. 47 (2018) 8292-8300.

[88] F. Tessore, E. Cariati, F. Cariati, D. Roberto, R. Ugo, P. Mussini, C. Zuccaccia, A. Macchioni, The role of ion pairs in the second order NLO response of 4-X-1-Methylpyridinium salts, ChemPhysChem 11 (2010) 495-507.

[89] H.-Y. Wang, L.-X. Jing, H.-Q. Wang, J.-T. Ye, Y.-Q. Qiu, Improving the NLO response of bis-cyclometalated iridium(III) complexes by modifying ligands: A DFT study, J. Organomet. Chem. 869 (2018) 18-25.

[90] Y. Wang, D. Astruc, A.S. Abd-El-Aziz, Metallopolymers for advanced sustainable applications, Chem. Soc. Rev. 48 (2019) 558-636.

[91] B.J. Coe, Molecular Materials Possessing Switchable Quadratic Nonlinear Optical Properties, Chem. Eur. J. 5 (1999) 2464-2471.

[92] J.A. Delaire, K. Nakatani, Linear and Nonlinear Optical Properties of Photochromic Molecules and Materials, Chem. Rev. 100 (2000) 1817-1846.

[93] I. Asselberghs, K. Clays, A. Persoons, M.D. Ward, J. McCleverty, Switching of molecular second-order polarisability in solution, J. Mater. Chem. 14 (2004) 2831-2839.

[94] K.A. Green, M.P. Cifuentes, M. Samoc, M.G. Humphrey, Metal alkynyl complexes as switchable NLO systems, Coord. Chem. Rev. 255 (2011) 2530-2541.

[95] F. Castet, V. Rodriguez, J.-L. Pozzo, L. Ducasse, A. Plaquet, B. Champagne, Design and Characterization of Molecular Nonlinear Optical Switches, Acc. Chem. Res. 46 (2013) 26562665. 
[96] E. Cariati, C. Dragonetti, E. Lucenti, F. Nisic, S. Righetto, D. Roberto, E. Tordin, An acidotriggered reversible luminescent and nonlinear optical switch based on a substituted styrylpyridine: EFISH measurements as an unusual method to reveal a protonationdeprotonation NLO contrast, Chem. Commun. 50 (2014) 1608-1610 and references therein.

[97] F. Nisic, A. Colombo, C. Dragonetti, M. Fontani, D. Marinotto, S. Righetto, D. Roberto, J.A.G. Williams, Highly efficient acido-triggered reversible luminescent and nonlinear optical switch based on 5- $\pi$-delocalized-donor-1,3-di(2-pyridyl)benzenes, J. Mater. Chem. C 3 (2015) 7421-7427 and references therein.

[98] V. Guerchais, J. Boixel, H. Le Bozec, Linear and Nonlinear Optical Molecular Switches Based on Photochromic Metal Complexes. In Photon-Working Switches; Yokoyama Y., Nakatani K. Eds.; Springer: Tokyo, 2017; pp. 363-384.

[99] B.J. Coe, A. Avramopoulos, M.G. Papadopoulos, K. Pierloot, S. Vancoillie, H. Reis, Theoretical Modelling of Photoswitching of Hyperpolarisabilities in Ruthenium Complexes, Chemistry 19 (2013) 15955-15963.

[100] S. Di Bella, I.P. Oliveri, I.P. A. Colombo, C. Dragonetti, S. Righetto, D. Roberto, An unprecedented switching of the second-order nonlinear optical response in aggregate bis(salicylaldiminato)zinc(II) Schiff-base complexes, Dalton Trans. 41 (2012) 7013-7016 and references therein.

[101] S. Attar, D. Espa, F. Artizzu, L. Pilia, A. Serpe, M. Pizzotti, G. Di Carlo, L. Marchiò, P. Deplano, Optically Multiresponsive Heteroleptic Platinum Dithiolene Complex with Proton-Switchable Properties, Inorg. Chem. 56 (2017) 6763-6767.

[102] D. Espa, L. Pilia, L. Marchiò, M.L. Mercuri, A. Serpe, A. Barsella, A. Fort, S.J. Dalgleish, N. Robertson, P. Deplano, Redox-Switchable Chromophores Based on Metal (Ni, Pd, Pt) Mixed-Ligand Dithiolene Complexes Showing Molecular SecondOrder Nonlinear-Optical Activity, Inorg. Chem. 50 (2011) 2058-2060.

[103] H. Zhao, E. Garoni, T. Roisnel, A. Colombo, C. Dragonetti, D. Marinotto, S. Righetto, D. Roberto, D. Jacquemin, J. Boixel, V. Guerchais, Photochromic DTE-Substituted1,3-di(2-pyridyl)benzene Platinum(II) Complexes: Photomodulation of Luminescence and Second-Order Nonlinear Optical Properties, Inorg. Chem. 57 (2018) 7051-7063.

[104] J. Wang, W.-Y. Wang, X.-Y. Fang, Y.-Q. Qiu, Carborane tuning on iridium complexes: redox-switchable second-order NLO responses, J. Mol. Model 21 (2015) 95. 
[105] X. Li, H.-Q. Wang, J.-T. Ye, Y. Zhang, Y.-Q. Qiu, Second-order NLO properties of bis-cyclometalated iridium(III) complexes: Substituent effect and redox switch, J. Molec. Graph. Model. 89 (2019) 131-138.

[106] Y. Shen, X. Li, J. Ye, Y.-Q. Qiu, A DFT study on second-order NLO properties of bis-cyclometalated Iridium (III) complexes with chelating dicarbene auxiliary ligands, Computational and Theoretical Chem. 1163 (2019) 112535.

[107] E. Baggaley, J. A. Weinstein, J.A.G. Williams, Lighting the way to see inside the live cell with luminescent transition metal complexes, Coord. Chem. Rev. 256 (2012)17621785 and references therein.

[108] E. Baggaley, J.A. Weinstein, J.A.G. Williams, Time-resolved emission imaging microscopy using phosphorescent metal complexes: Taking FLIM and PLIM to new lengths, Struct. Bond. 165 (2015) 205-256.

[109] L. Murphy, A. Congreve, L.-O. Palsson, J.A.G. Williams, The time domain in co-stained cell imaging: time-resolved emission imaging microscopy using a protonatable luminescent iridium complex, Chem Commun. 46 (2010) 8743-8745.

[110] P. Steunenberg, A. Ruggi, N.S. van den Berg, T. Buckle, T.; J. Kuil, F.W.B. van Leeuwen, A.H. Velders,. Phosphorescence Imaging of Living Cells with Amino Acid-Functionalized Tris(2-phenylpyridine)iridium(III) Complexes, Inorg. Chem. 51 (2012) 2105-2114 and references therein.

[111] A. Colombo, M. Fontani, C. Dragonetti, D. Roberto, J. A. G. Williams, R. Scotto di Perrotolo, F. Casagrande, S. Barozzi, S. Polo, A highly luminescent tetrahydrocurcumin Ir(III) complex with remarkable photoactivated anticancer activity, Chem. Eur. J. 25 (2019) 7948-7952 and references therein.

[112] W.R. Zipfel, R.M. Williams, R.M.; W.W. Webb, Nonlinear magic: multiphoton microscopy in the biosciences. Nonlinear magic: multiphoton microscopy in the biosciences, Nat. Biotechnol. 21 (2003) 1368-1376.

[113] W. Denk, J.H. Strickler, W.W. Webb, Two-photon laser scanning fluorescence microscopy. Two-photon laser scanning fluorescence microscopy, Science 248 (1990) 73-76.

[114] M. Pawlicki, H.A. Collins, R. G. Denning, H.L. Anderson, Two-photon absorption and the design of two-photon dyes, Angew. Chem. Int. Ed. 48 (2009) 3244-3266.

[115] R.L. Sutherland, Handbook of nonlinear optics, $2^{\text {nd }}$ edn. 2003, Marcel Dekker, New York.

[116] S. Mazzucato, I. Fortunati, S. Scolaro, M. Zerbetto, C. Ferrante, R. Signorini, D. Pedron, R. Bozio, D. Locatelli, S. Righetto, D. Roberto, R. Ugo, A. Abbotto, G. Archetti, L. Beverina S. 
Ghezzi, Two-photon absorption of Zn (II) octupolar molecules, Phys. Chem. Chem. Phys. 9 (2007) 2999-3005.

[117] M. Sheik-Bahae, A.A. Said, T.-H. Wei, D.G. Hagan, E.W. van Stryland, Sensitive measurement of optical nonlinearities using a single beam, IEEE J. Quant. Electr. 26 (1990) 760-769.

[118] K. Kamada, K. Matsunaga, A. Yoshino, K. Ohta, Two-photon-absorption-induced accumulated thermal effect on femtosecond Z-scan experiments studied with time-resolved thermal-lens spectrometry and its simulation, J. Opt. Soc. Am. B 20 (2003) 529-537.

[119] A. Colombo, C. Dragonetti, D. Roberto, A. Valore, C. Ferrante, I. Fortunati, A. L. Picone, F. Todescato, J. A. G. Williams, Two-photon absorption properties and ${ }^{1} \mathrm{O}_{2}$ generation ability of Ir complexes: unexpected large cross section of $\left[\operatorname{Ir}(\mathrm{CO})_{2} \mathrm{Cl}(4\right.$-(para-di-nbutylaminostyryl)pyridine)], Dalton Trans. 44 (2015) 15712-15720.

[120] F. Todescato, I. Fortunati, S. Carlotto, C. Ferrante, L. Grisanti, C. Sissa, A. Painelli, A. Colombo, C. Dragonetti, D. Roberto, Dimers of polar chromophores in solution: role of excitonic interactions in one- and two-photon absorption properties, Phys. Chem. Chem. Phys. 13 (2011) 11099-11109.

[121] C. Dragonetti, M. Balordi, A. Colombo, D. Roberto, R. Ugo, I. Fortunati, E. Garbin, C. Ferrante, R. Bozio, A. Abbotto, H. Le Bozec, Two-photon absorption properties of Zn(II) complexes: Unexpected large TPA cross section of dipolar [ $\mathrm{ZnY}_{2}(4,4$ '-bis(para-di-nbutylaminostyryl)-2,2'-bipyridine)] (Y = Cl, $\mathrm{CF}_{3} \mathrm{CO}_{2}$ ), Chem. Phys. Lett. 475 (2009) 245-249.

[122] L. Grisanti, C. Sissa, F. Terenziani, A. Painelli, D. Roberto, F. Tessore, R. Ugo, S. Quici, I. Fortunati, E. Garbin, C. Ferrante, R. Bozio, Enhancing the efficiency of two-photon absorption by metal coordination, Phys. Chem. Chem. Phys. 11 (2009) 9450-9457.

[123] R.M. Edkins, S.L. Bettington, A.E. Goeta, A. Beeby, Two-photon spectroscopy of cyclometalated iridium complexes, Dalton Trans. 40 (2011) 40, 12765- 12770 and references therein.

[124] S.W. Botchway, M. Charnley, J.W. Haycock, A.W. Parker, D.L. Rochester, J.A. Weinstein, J.A.G. Williams, Time-resolved and two-photon emission imaging microscopy of live cells with inert platinum complexes, Proc. Natl. Acad. Sci. U. S. A. 105 (2008) 16071-16076.

[125] M. Sarma, T. Chatterjee, R. Bodapati, K. N. Krishnakanth, S. Hamad, S. V. Rao, S. K. Das,. Cyclometalated Iridium(III) Complexes Containing 4,4' $-\pi$-Conjugated 2,2' -Bipyridine Derivatives as the Ancillary Ligands: Synthesis, Photophysics, and Computational Studies, Inorg. Chem. 55 (2016) 3530-3540. 
[126] K. Kamada, Two-Photon Absorption Spectrum of Non-Centrosymmetric Molecules, Disp. Imag. 1 (2014) 107-130.

[127] C. Jin, J. Liu, Y. Chen, L. Zeng, R. Guan, C. Ouyang, L. Ji, H. Chao, Cyclometalated Iridium (III) Complexes as Two-Photon Phosphorescent Probes for Specific Mitochondrial Dynamics Tracking in Living Cells, Chem. Eur. J. 21 (2015) 12000-12010.

[128] G. Li, Q. Lin, L. Sun, C. Feng, P. Zhang, B. Yu, Y. Chen, Y. Wen, H. Wang, L. Ji, H. Chao, A mitochondrial targeted two-photon iridium (III) phosphorescent probe for selective detection of hypochlorite in live cells and in vivo, Biomaterials 53 (2015) 285-295.

[129] L. Sun, Y. Chen, S. Kuang, G. Li, R. Guan, J. Liu, L. Ji, H. Chao, Iridium (III) anthraquinone complexes as two-photon phosphorescence probes for mitochondria imaging and tracking under hypoxia, Chem. Eur. J. 22 (2016) 8955-8965.

[130] R.M. Edkins, S.L. Bettington, A.E. Goeta, A. Beeby, Two-photon spectroscopy of cyclometalated iridium complexes, Dalton Trans. 40 (2011), 12765-12770.

[131] C.-L. Ho, K.-L. Wong, H.-K. Kong, Y.-M. Ho, C. T.-L. Chan, W.-M. Kwok, K. S.-Y. Leung, H.-L. Tam, M. H.-W. Lam, X.-F. Ren, A.-M. Ren, J.-K. Fengf, W.-Y. Wong, A strong twophoton induced phosphorescent Golgi-specific in vitro marker based on a heteroleptic iridium complex, Chem. Commun. 48 (2012) 2525-2527.

[132] Y. Fan, D. Ding, D. Zhao, Two- and three-photon absorption and excitation phosphorescence of oligofluorene-substituted $\operatorname{Ir}(\mathrm{ppy})_{3}$, Chem. Commun. 51 (2015) 3446-3449.

[133] L.S. Natrajan, A. Toulmin, A. Chewa, S.W. Magennis, Two-photon luminescence from polar bis-terpyridyl-stilbene derivatives of Ir(III) and Ru(II), Dalton Trans. 39 (2010) 10837-10846.

[134] M. Lepeltier, F. Appaix, Y. Y. Liao, F. Dumur, J. Marrot, T. Le Bahers, C. Andraud, C. Monnereau, Carbazole-Substituted Iridium Complex as a Solid State Emitter for Two-Photon Intravital Imaging, Inorg. Chem. 55 (2016) 9586-9595. 